\title{
The Recovery of Irradiation Damage for Zircaloy-2 and Zircaloy-4 following low dose
}

\section{$\underline{\text { neutron irradiation at nominally } 358^{\circ} \mathrm{C}}$}

\author{
B.V. Cockeram ${ }^{*(1)}$, K.J. Leonard ${ }^{(2)}$, T.S. Byun ${ }^{(2)}$, L.L. Snead ${ }^{(2)}$, and J.L. Hollenbeck ${ }^{(1)}$, \\ (1) Bettis Laboratory, Bechtel Marine Propulsion Corporation, West Mifflin, PA 15122-0079, USA \\ ${ }^{(2)}$ Oak Ridge National Laboratory, P.O. Box 2008, Oak Ridge, TN 37831-6138, USA \\ *Corresponding author. Tel.: +1 412476 5647; fax: +1 412476 5779. bcockeram@verizon.net
}

\begin{abstract}
The recovery of irradiation damage in wrought Zircaloy-2 and Zircaloy-4 was determined following a series of post-irradiation anneals at temperatures ranging from $343^{\circ} \mathrm{C}$ to $510^{\circ} \mathrm{C}$ and for time periods ranging from 1 -hour to 500 hours. The materials had been irradiated at nominally $358^{\circ} \mathrm{C}$ in the High Flux Isotope Reactor (HFIR) at neutron fluences of nominally $3 \times 10^{25} \mathrm{n} / \mathrm{m}^{2}(\mathrm{E}>1 \mathrm{MeV})$. Irradiation at nominally $358^{\circ} \mathrm{C}$ resulted in a coarser distribution of $<\mathrm{a}>$ loops that result in a $25 \%-45 \%$ lower irradiation hardening than reported in the literature for irradiations at $260-326^{\circ} \mathrm{C}$. The irradiation hardening and recovery were determined using tensile testing at room-temperature. Post-irradiation annealing at $343-427^{\circ} \mathrm{C}$ was shown to result in an increase in irradiation hardening to values even higher than for the as-irradiated material in the first 1-10 hours of annealing. This Radiation Anneal Hardening (RAH) was followed by a relatively slow recovery of the irradiation damage. Much faster recovery with no $\mathrm{RAH}$ was observed for post-irradiation annealing at temperatures of $454-510^{\circ} \mathrm{C}$. Irradiation at $358^{\circ} \mathrm{C}$ was shown to result in different recovery kinetics than observed in the literature for irradiation at $260-326^{\circ} \mathrm{C}$. While the general trend described above is true for the four materials tested (alpha-annealed and beta-treated Zircaloy-2 and Zircaloy-4), notable and yet unexplained differences in $\mathrm{RAH}$ and in recovery are observed between the materials that might be a result of differing solute effects. Examinations of microstructure using Transmission Electron Microscopy were used to investigate the $\mathrm{RAH}$ and recovery mechanisms. Agreement between the measured and calculated irradiation hardening using a generalized Orowan hardening model to
\end{abstract}


account for the observed loop structure was not as close for the post irradiation annealed condition as for the as-irradiated condition, which can likely be attributed to unaccounted for changes in the configuration of the $<$ a $>$ loops to dislocation lines, segregation of solutes to dislocation loops, and the potential for the formation of fine clusters of point defects or solutes during annealing.

\section{Introduction}

Two zirconium-base alloys used in nuclear applications are Zircaloy-2 and Zircaloy-4 [115]. Both alloys contain nominally $1.5 \% \mathrm{Sn}$ in solid-solution and consist primarily of a hexagonal alpha $\mathrm{Zr}$-phase. Zircaloy-2 contains low alloying levels of $\mathrm{Ni}, \mathrm{Fe}$, and $\mathrm{Cr}$ additions that are tied up as Laves phase precipitates $\left(\mathrm{Zr}(\mathrm{Fe}, \mathrm{Cr})_{2}\right)$ or as Zintl phase precipitates $\left(\mathrm{Zr}_{2}(\mathrm{Fe}, \mathrm{Ni})\right)$ [1-16]. Zircaloy-4 contains only low alloying levels of $\mathrm{Fe}$ and $\mathrm{Cr}$ and contains only Laves phase precipitates [1-16]. The neutron irradiation of Zircaloy results in the formation of dislocation loops that are barriers to dislocation motion that result in irradiation hardening [1-37].

The hexagonal structure of Zircaloy produces an anisotropic distribution of point defects resulting from irradiation that leads to the production of two different types of dislocation loops. Irradiation hardening is primarily the result of the high number density of small <a> loops (4-30 $\mathrm{nm}$ diameter) that are formed on the prism planes $(\{10 \overline{1} 0\})$ with a Burgers vector $\mathrm{b}_{<\mathrm{a}>}=$ $\frac{1}{3}<11 \overline{2} 0>[1-3,6-10,13-16,24-33]$. These $<$ a $>$ loops are nucleated after a neutron fluence of 0.3 to $1.1 \times 10^{24} \mathrm{n} / \mathrm{m}^{2}(\mathrm{E}>1 \mathrm{MeV})$ and then rapidly saturate to a relatively constant size / number density at a fluence of about $1-5 \times 10^{25} \mathrm{n} / \mathrm{m}^{2}$, depending on the irradiation temperature $[1-4,14-16]$. The <a> loops are both interstitial or vacancy in nature, and the fraction of loop type is a strong function of irradiation temperature, with the majority being an interstitial type for irradiations at a temperature of $300^{\circ} \mathrm{C}$ or lower, about $50 \%$ interstitial for irradiation at $350^{\circ} \mathrm{C}$, and about $30 \%$ interstitial for irradiation at $400^{\circ} \mathrm{C}[6,14,30,32]$. The irradiation temperature is also shown to have a strong effect on the $<$ a $>$ loop distribution with the smallest $<$ a $>$ loop size 
and highest $<a>$ loop number density (ND) observed at the lower temperature of $300^{\circ} \mathrm{C}$, while $<$ a loop sizes of 7-22 nm and ND of $5 \times 10^{20}$ to $5 \times 10^{22} \mathrm{n} / \mathrm{m}^{2}$ were observed at temperatures of about $350^{\circ} \mathrm{C}$ and fluences of greater than $1 \times 10^{25} \mathrm{n} / \mathrm{m}^{2}[1-5,14,32]$. At temperatures of about $400^{\circ} \mathrm{C}$ the $<$ a $>$ loop sizes are still larger $(16-23 \mathrm{~nm})$ with a lower ND $\left(2 \times 10^{21}\right.$ to $\left.2 \times 10^{22} \mathrm{n} / \mathrm{m}^{2}\right)$ $[1-2,26]$. Since plasticity in Zircaloy mainly occurs by slip on the prism planes, the irradiation hardening can be related to the <a> loop size and ND using an Orowan hardening relationship with less hardening observed at higher irradiation temperatures. The increase in flow stress due to $<$ a $>$ loop formation by irradiation generally results in the activation of slip on the basal ( $\{0001\})$ and pyramidal $(\{10 \overline{1} 1\}$ or $\{10 \overline{1} 2\})$ planes [1-3,13-15]. The other type of loop formed from irradiation damage of zirconium alloys is a vacancy $<c>$ loop with a Burgers vector $b_{<c>}=$ $\frac{1}{2}<0001>$ that are formed on the basal planes $(\{0001\})[1-2,6,9-13,34-40]$.

Since the processes of loop nucleation and change in precipitate structure are believed to be interrelated and are primarily driven by solid-state diffusion, there is a strong dependence of irradiation temperature and flux on these processes that strongly influence the irradiation hardening of Zircaloy [1-6, 34-45]. Irradiation of Zircaloy at higher temperatures $\left(326-450^{\circ} \mathrm{C}\right)$ have generally been reported to result in nominally $10-60 \%$ less irradiation hardening $(\Delta \sigma)$ than for irradiation at lower temperatures of $260-326^{\circ} \mathrm{C}[5-6,44,45]$. A strong effect of flux was observed for recent irradiations in the ATR [5] at relatively high temperatures $\left(377-410^{\circ} \mathrm{C}\right)$, where the lower flux resulted in a greater extent of amorphization of Laves phase precipitates that produced a finer <a> loop distribution and irradiation hardening only slightly less than reported in the literature for irradiations at nominally $260-326^{\circ} \mathrm{C}[1,5-6,32,44,46]$. This amorphization may also provide iron that strengthens the $<$ a> loop barriers. In a different set of samples irradiated in the High Flux Isotope Reactor (HFIR) at a higher flux at $358^{\circ} \mathrm{C}$ [5], the $\mathrm{Zr}(\mathrm{Fe}, \mathrm{Cr})_{2}$ precipitates were crystalline and exhibited less dissolution, and the lower fraction of 
iron solute may explain the greater $<$ a $>$ loop coarsening and lower irradiation hardening observed in these specimens. The lower hardening observed for the $358^{\circ} \mathrm{C}$ irradiations of Zircaloy-2 and Zircaloy-4 in HFIR has been shown to be the result of a coarser distribution of $<$ a loops than reported for Zircaloy-4 and Zircaloy-2 irradiations at $260-326^{\circ} \mathrm{C}[1-6,14-16,24-$ 26,45-53]. For irradiations at 260-326C, a higher flux is observed to increase the extent of amorphization of Laves phase precipitates. The opposite effect of flux is observed for irradiations at $358-450^{\circ} \mathrm{C}$ where the higher flux obtainable in HFIR resulted in less extent of precipitate dissolution and change in structure that likely contributes to greater coarsening of the loop structure and less irradiation hardening. The greater degree of amorphization and dissolution of $\mathrm{Zr}(\mathrm{Fe}, \mathrm{Cr})_{2}$ precipitates observed for irradiations at lower flux for the irradiation at $377-410^{\circ} \mathrm{C}[5]$ suggests that irradiation at a lower flux at higher temperatures of $358-410^{\circ} \mathrm{C}$ may actually increase the amorphization of $\mathrm{Zr}(\mathrm{Fe}, \mathrm{Cr})_{2}$ precipitates, which is opposite to the trend generally seen under lower temperature irradiation conditions. Furthermore, these results suggest a strong interplay between the amorphization of $\mathrm{Zr}(\mathrm{Fe}, \mathrm{Cr})_{2}$ precipitates and the $<\mathrm{a}>$ loop distribution and strength of the loop barriers that affects the irradiation hardening.

Post-irradiation heat treatment at temperatures between $260-450^{\circ} \mathrm{C}$ results in the recovery of irradiation damage that is characterized by a decrease in irradiation hardening resulting from a coarsening of the loop structure [1-3,17-23]. Several mechanisms have been used to explain the coarsening of the $<a>$ loop distribution during recovery, but the consensus is that loop coarsening occurs by bulk diffusion of vacancies to loops so that larger loops are formed by vacancy emission from smaller vacancy loops. Since interstitial loops always absorb vacancies, the interstitial loops are expected to rapidly disappear during recovery. As a result, the relative proportion of the type of <a> loop changes to a greater fraction of vacancy loops during recovery $[1,2,17,21]$. The purpose of this work is to understand and quantify some of the effects of recovery that are observed following irradiation at higher temperatures where the irradiation hardening is lower. Starting material for the annealing studies discussed herein were 
the alpha-annealed and late beta-treated Zircaloy-2 and Zircaloy- 4 specimens (discussed above) irradiated in $\mathrm{HFIR}$ at $358^{\circ} \mathrm{C}$ where the flux is high, little amorphization of the laves precipitates is produced, and a coarser distribution of $<$ a $>$ loops is observed [4]. Irradiation hardening following high temperature annealing was determined by tensile testing and characterized as the change in yield strength $(\Delta \sigma)$. Detailed TEM examinations of microstructure are performed to determine the $<a>$ and $<c>$ loop distributions and the evolution of precipitate structure.

\section{Materials and Experimental procedure}

Compositions for the Zircaloy-4 and Zircaloy-2 starting materials are given in Table 1. The late beta-treated material is given a heat treatment late in the process that produces a basketweave Widmanstätten microstructure consisting of colonies of lath shaped alpha grains within prior beta grains with a random texture [4]. This late beta-treated material is referred to as beta-treated in this paper. The alpha-annealed material has an equiaxed grain structure with a rolled plate texture. Tensile specimens (SSJ type) were machined in the transverse orientation (16 mm long, $0.25 \mathrm{~mm}$ thick, and $4 \mathrm{~mm}$ wide with a gauge section nominally $5 \mathrm{~mm}$ long and $1.2 \mathrm{~mm}$ width) and then pickled at room temperature in a solution of nitric acid (30-39 volume\%), hydrofluoric (HF) acid (0.5-3 volume \%) and water to remove about $25 \mu \mathrm{m}$ to $100 \mu \mathrm{m}$ total thickness [4]. The SSJ specimen was used in previous testing of as-irradiated material [4]. The non-irradiated tensile properties obtained using a SSJ tensile specimen have been shown to be comparable to those obtained using a SSJ specimen [5] and larger sized specimens, suggesting a reasonable measure of irradiation hardening and recovery is obtained.

The irradiations were performed at $312-358^{\circ} \mathrm{C}$ to fluences between 0.058 to $29.6 \times 10^{24}$ $\mathrm{n} / \mathrm{m}^{2}(\mathrm{E}>1 \mathrm{MeV})$ in the High Flux Isotope Reactor (HFIR) using the conditions given in Table 2 [4]. The majority of specimens used for the recovery studies were irradiated at $312^{\circ} \mathrm{C}$ to a nominal fluence of $29.6 \times 10^{24} \mathrm{n} / \mathrm{m}^{2}$. The slightly different mass in the capsule resulted in the 
slightly lower irradiation temperature of $312^{\circ} \mathrm{C}$ compared to the nominal temperature of $358^{\circ} \mathrm{C}$ for most of the previous testing [4]. Passive SiC temperature monitors were used to determine the specimen temperatures. The zirconium dpa levels were determined using a reported conversion $[4,54]$. The irradiation hardening following annealing was determined by tensile testing performed at room-temperature at an actuator displacement rate of $0.508 \mathrm{~mm} / \mathrm{min}$ (strain rate $=0.1 \mathrm{~min}^{-1}$ ) in accordance with ASTM E8 procedures [55]. Engineering stress/strain values were determined from the load and crosshead displacement record with no correction made for the compliance of the load train [4]. Discs nominally $3 \mathrm{~mm}$ in diameter were punched from the grip of the tested tensile specimens for Transmission Electron Microscopy (TEM). The TEM discs were prepared by mechanically thinning and then electropolished using a 10 vol\% $\mathrm{HClO}_{4}$ in ethanol solution at $5^{\circ} \mathrm{C}$ at a current of less than $100 \mathrm{~mA}$. A CM200-FEG instrument was used for TEM analysis of the loop structures using two-beam imaging conditions at a range of magnifications. The thickness of each location was determined using the Kossel-Möllenstedt fringe spacing technique in the zero order Laue zone convergent beam electron diffraction pattern for a given g-vector under 2-beam conditions.

Recovery measurements were made following post-irradiation annealing using a series of cumulative isochronal anneals in 5-hour increments at temperatures between $343^{\circ} \mathrm{C}$ and $510^{\circ} \mathrm{C} \pm 5^{\circ} \mathrm{C}$ in accordance with the schedule given in Table 3. For example, a $399^{\circ} \mathrm{C}$ isochronal anneal consisted of a $343^{\circ} \mathrm{C} / 5 \mathrm{~h}+371^{\circ} \mathrm{C} / 5 \mathrm{~h}+399^{\circ} \mathrm{C} / 5 \mathrm{~h}$ anneal. The annealing at temperatures of $427^{\circ} \mathrm{C}$ and lower was performed in air in stainless-steel capsules that were mechanically sealed with the specimens wrapped in tantalum foil with tantalum foil at the ends as an oxygen getter. Testing of non-irradiated control specimens annealed under the same condition showed this method resulted in negligible oxidation effects and the tensile results were comparable to the starting materials. The post-irradiation isochronal annealing at $454^{\circ} \mathrm{C}$, $482^{\circ} \mathrm{C}$, and $510^{\circ} \mathrm{C}$ was performed in a vacuum furnace. The isothermal annealing at $427^{\circ} \mathrm{C}( \pm$ $5^{\circ} \mathrm{C}$ ) was also performed in air using the same methods for times between 1 -hour to 500 -hours 
(Table 3). Non-irradiated control specimens were included in each series of isochronal and isothermal anneals.

\section{Results and Discussion: Post-irradiation Tensile Testing Following Annealing}

The yield strength, the change in yield strength $(\Delta \sigma$, that is also known as irradiation hardening), total elongation, and the uniform elongation values determined from post-irradiated tensile testing following isochronal annealing are given in Fig. 1, while those for the $427^{\circ} \mathrm{C}$ isothermal annealing are given in Fig. 3. The engineering stress-strain curves for the isochronal and isothermal annealing conditions are given in Figs. 2 and 4, respectively. Fractography following isochronal annealing is given in Fig. 5. Single tensile tests were performed for each post-irradiation annealed condition, but previous tensile testing of as-irradiated materials performed in duplicate and triplicate generally exhibited little scatter with differences in yield strength ranging from 4.1 to $43.4 \mathrm{MPa}$ within a dataset that generally amount to less than $10 \%$ variation $[4,5]$.

\subsection{Isochronal Annealing Results}

The tensile results following isochronal annealing for alpha-annealed and beta-treated Zircaloy-2 and Zircaloy-4 for periods of 5-hours are compared in Fig. 1 with literature data [45,56-58] for post-irradiation annealing performed at the appropriate temperatures for shorter time periods of 1-2 hours. The shorter annealing time of 1-2 hours for the literature data $[45,56-$ 58] would be expected to result in less recovery than observed in this work. However, higher yield strength values and $\Delta \sigma$ values were generally observed in this work for the isochronal annealing at temperatures of $427^{\circ} \mathrm{C}$ and lower than for the literature data. The higher irradiation temperature in this work generally results in lower initial irradiation hardening compared to literature data reported for irradiation at lower temperatures of $260-326^{\circ} \mathrm{C}$ [4], but the literature data shown in Fig. 1 are for irradiations at temperatures greater than $326^{\circ} \mathrm{C}$. This results in comparable values of as-irradiated yield strength and initial irradiation hardening. Higher 
values for yield strength and irradiation hardening are shown in Figs. 1a and 1b, respectively, between the annealing temperatures of $343^{\circ} \mathrm{C}$ to $454^{\circ} \mathrm{C}$ in comparison to the initial as-irradiated condition and the literature data [45,56-58]. The exception is the yield strength results for betatreated Zircaloy-2 were less than for the literature data, but the irradiation hardening values are shown in Fig. $1 \mathrm{~b}$ to be higher than for literature results. This increase in strength during postirradiation annealing is known as Radiation Anneal Hardening (RAH). RAH has been observed in the literature for Zircaloy [45,57-58], and is thought to result either from the movement of interstitial impurities or alloying elements to dislocation loops to produce additional hardening or to the coalescence of point defects or point defect clusters to produce additional barriers that lead to additional hardening. The RAH for the isochronal annealing was the largest for alphaannealed Zircaloy-2 and beta-treated Zircaloy-4 at annealing temperatures of $343^{\circ} \mathrm{C}$ through $399^{\circ} \mathrm{C}$ in Fig. 1. Both started to exhibit recovery at the $427^{\circ} \mathrm{C}$ isochronal annealing temperatures to values lower than or comparable to the as-irradiated values at $510^{\circ} \mathrm{C}$. The increase in strength or RAH was less for beta-treated Zircaloy-2 and alpha-annealed Zircaloy-4 at annealing temperatures of $343^{\circ} \mathrm{C}$ to $427^{\circ} \mathrm{C}$. The reason for the sharp increase in yield strength observed for the alpha-annealed Zircaloy-4 specimen subjected to the $427^{\circ} \mathrm{C}$ isochronal anneal is not known, and could be attributed to bending of the specimen during handling and the associated cold work of the specimen rather than solely the result of RAH.

Recovery was observed for all materials at isochronal annealing temperatures of $427^{\circ} \mathrm{C}$ or $454^{\circ} \mathrm{C}$ and continuing to the higher isochronal annealing temperature of $510^{\circ} \mathrm{C}$ to values for yield strength and irradiation hardening that are comparable to the as-irradiated values. However, full recovery of the yield strength to values comparable to the non-irradiated materials was not observed. Recovery at the higher isochronal annealing temperatures was shown to be slightly greater for alpha-annealed and beta-treated Zircaloy-2 than for alpha-annealed and beta-treated Zircaloy-4. A closer match between the results obtained here and the literature data $[45,56-58]$ were generally observed for the $510^{\circ} \mathrm{C}$ isochronal anneal where rapid recovery 
is observed. There is scatter in the measurements of yield stress used to quantify the recovery of irradiation damage present in both this work and the literature data, but the amount of scatter was not quantified.

The stress-strain curves for the isochronal anneal tests are shown in Fig. 2 to generally exhibit results similar to that observed for the as-irradiated materials (fluence of $29.3 \times 10^{20}$ $\mathrm{n} / \mathrm{cm}^{2}$ [4]), with no yield point being observed and a flat stress-strain curve present for most of the tests. The exceptions are the results for 4 of the 6 tests for beta-treated Zircaloy- 4 at the lower isochronal annealing temperatures of $343^{\circ} \mathrm{C}$ to $454^{\circ} \mathrm{C}$ shown if Fig. $2 \mathrm{~b}$, one test for alphaannealed Zircaloy- 4 for the $427^{\circ} \mathrm{C}$ anneal in Fig. $2 \mathrm{a}$ (where the specimen was believed to be bent and cold-worked during handling), and one test for beta-treated Zircaloy-2 for the $510^{\circ} \mathrm{C}$ anneal in Fig. 2d. In these cases, RAH was present and some level of flow localization was observed with a peak in the stress-strain curves. The total elongation values for the isochronal annealed alpha-annealed Zircaloy-2 and Zircaloy-4 materials are shown in Fig. $1 \mathrm{c}$ to be generally within the range of values reported in the literature [56]. The total elongation values following isochronal annealing for beta-treated Zircaloy-2 and Zircaloy-4 are shown in Fig. 1c to generally be below the range of literature values [56]. There is a general tendency for the total elongation for beta-treated Zircaloy-2 and Zircaloy-4 to be lower than for alpha-annealed Zircaloy-2 and Zircaloy-4 for either the non-irradiated or irradiated condition [1-5]. The lower total elongation values for isochronal annealed beta-treated Zircaloy- 4 are consistent with the greater tendency for flow localization to be observed for this material in Fig. 2. Since there is little tendency for flow localization to be observed in most of the stress-strain curves for the isochronal annealed specimens in this work, the uniform elongation values for alpha-annealed Zircaloy-2, alpha-annealed Zircaloy-4, and beta-treated Zircaloy-2 are shown in Fig. 1d to range from $1.4 \%$ to $9.5 \%$ in value and are generally above or within the range of values reported in the literature. The uniform elongation values for beta-treated Zircaloy-4 (0.2\% to $6.2 \%)$ were 
generally at the low end of the range of values for literature data and values for the other materials in this work.

Examinations of the fracture surfaces show in Fig. 5 that the failures for all isochronal annealed specimens were ductile in nature with dimple-like features observed. The alphaannealed Zircaloy-4 specimens isochronal annealed at $427^{\circ} \mathrm{C}$ and $510^{\circ} \mathrm{C}$ are shown in Fig. $5 \mathrm{a}$ and $5 \mathrm{~b}$, respectively, to consist of an inhomogeneous distribution of dimples and tearing ridges on the fracture surface that separate smooth regions and give the appearance of larger dimples. Although large amounts of RAH were observed for alpha-annealed Zircaloy-4 at the isochronal annealing temperature of $427^{\circ} \mathrm{C}$ that is followed by recovery at $510^{\circ} \mathrm{C}$, the fracture surfaces appear to be similar. For beta-treated Zircaloy- 4 isochronal annealed at $427^{\circ} \mathrm{C}$ where RAH was observed and the total elongation was lower, the fracture surface is shown in Fig. $5 \mathrm{c}$ to consist of regions of flat fracture separated by bands of fine dimples or tearing ridges. For the betatreated Zircaloy-4 specimen following isochronal annealing at $510^{\circ} \mathrm{C}$ where recovery was observed, Fig $5 \mathrm{~d}$ shows a much greater fraction of the surface is covered with both fine and coarse voids and tearing ridges that separate smooth regions in the shape of laths from the original microstructure. This result indicates that high levels of RAH can lower the percentage of dimple features that are formed on the fracture surface, which correlates with the lower tensile ductility observed for beta-treated Zircaloy-4.

For alpha-annealed and beta-treated Zircaloy-2 given an isochronal anneal at $427^{\circ} \mathrm{C}$ where RAH was observed, the fracture surfaces are shown in Figs. 5e and 5f, respectively, to exhibit the same features previously described for alpha-annealed Zircaloy-4 (Figs. 5a and 5b) and beta-treated Zircaloy-4 (Fig. 5d) when a ductile failure is observed. The fracture surfaces for the isochronal annealed specimens exhibiting recovery are generally similar in appearance to the non-irradiated material with the exception of cracks observed perpendicular to the plane of the fracture surface, fine spherical voids observed, and planar steps observed at the side of the fracture surface, which is similar to that observed for the as-irradiated material $[4,5]$. The 
fine dimples observed for the recovered and as-irradiated materials are believed to result from a process of void nucleation, growth, and coalescence [4-5].

\subsection{Isothermal Annealing Results}

The $427^{\circ} \mathrm{C}$ isothermal annealing results obtained in this work are compared with literature results for annealing at $427-500^{\circ} \mathrm{C}[45,56]$ in Fig. 3. A log scale for annealing time is used in Figure 3 to show the full range of change in values from $1 \mathrm{~h}$ to $500 \mathrm{~h}$, and a magnified linear scale of $0-50 \mathrm{~h}$ is also used in Figure $3 \mathrm{a}$ to show the RAH. The yield strength and irradiation hardening observed in this work after 1-hour of annealing are higher than for the literature data, which indicates that the initial recovery observed in this work is slower than for the literature data. The higher annealing temperature $\left(427-500^{\circ} \mathrm{C}\right)$ for the literature data $[45,56]$ may partially explain the lower yield strength values. However, very significant RAH occurs for annealing times between 1 hours to 10 hours for alpha-annealed and beta-treated Zircaloy-2 and Zircaloy-4 that produces increases in yield strength and irradiation hardening to values much higher than observed for the as-irradiated condition and for literature data for the asirradiated condition following irradiation at the lower temperatures of $260-326^{\circ} \mathrm{C}[1,5-$ $6,32,44,46]$. There is some notable variation in the $\mathrm{RAH}$ among the different alloys during the $427^{\circ} \mathrm{C}$ isothermal anneal, with the largest increase in strength observed for beta-treated Zircaloy-2 after 5-hours that is preceded by a little change in strength for the 1-hour anneal. For alpha-annealed Zircaloy-2, a slight increase in strength is observed for the 1-hour anneal followed by a decrease in strength at 5-hours and then an increase in strength at the 10-hour anneal. The hardening due to RAH for alpha-annealed and beta-treated Zircaloy-2 results in a higher yield strength and irradiation hardening than observed for Zircaloy-4. An increase in strength is observed for the 1-hour and 5-hour anneals for alpha-annealed Zircaloy-4 that is followed by a significant decrease in strength. An increase in strength for the 1-hour anneal for the beta-treated Zircaloy-4 is followed by a slight decrease in strength. It is not yet known if these variations in the $\mathrm{RAH}$ behavior among the material types represents data scatter or if the 
RAH really follows very different trends among the alloy types.

Following the period of $\mathrm{RAH}$ in the first $1-10$ hours of isothermal annealing at $427^{\circ} \mathrm{C}$, consistent recovery is observed during the cumulative annealing times of $10-500 \mathrm{~h}$. The yield strength values for the $427^{\circ} \mathrm{C}$ isothermal anneal to 500 hours are similar to or slightly lower than for literature data at much shorter annealing times of 1-2 hours. However, the irradiation hardening values $(\Delta \sigma)$ following the $500 \mathrm{~h}$ anneal at $427^{\circ} \mathrm{C}$ show in Fig. $3 \mathrm{~b}$ that full recovery that eliminates all irradiation hardening has not occurred. High values for $\mathrm{RAH}$ that are followed by slower recovery, as determined from $\Delta \sigma$ values, is generally observed for the $427^{\circ} \mathrm{C}$ isothermal recovery of beta-treated Zircaloy-2 and Zircaloy-4 in this work, while faster recovery following RAH are observed for alpha-annealed Zircaloy-2 and Zircaloy-4.

The stress-strain curves for the $427^{\circ} \mathrm{C}$ isothermal anneal shown in Fig. 4 were generally similar to those observed for the as-irradiated material with little flow localization observed [4], but some notable exceptions were observed when RAH occurred within 1-10 hours of annealing. The exceptions are that either lower levels of total elongation, a less smooth stressstrain curve with slight drops in stress, or a tendency for flow localization in the stress-strain curve are generally observed when large amounts of RAH were present. The greatest degree of flow localization following $427^{\circ} \mathrm{C}$ isothermal annealing is observed for beta-treated Zircaloy-4 in Fig. $4 \mathrm{~b}$ where very low values of elongation $\left(427^{\circ} \mathrm{C} / 1-\mathrm{h}\right.$ and $10-\mathrm{h}$ anneal) or discontinuity in the stress-strain curve $\left(427^{\circ} \mathrm{C} / 5-\mathrm{h}\right.$ anneal) are observed for conditions where RAH is observed. A discontinuity in the stress-strain curves is observed for the $427^{\circ} \mathrm{C} / 100-\mathrm{h}$ isothermal anneal of beta-treated Zircaloy-2 that requires additional explanation.

The total elongation values for alpha-annealed and beta-treated Zircaloy-2 and Zircaloy4 for the $427^{\circ} \mathrm{C}$ isothermal anneal are shown in Fig. 4c to be below the range reported in the literature. Higher total elongation results were generally observed for alpha-annealed Zircaloy-2 and Zircaloy-4 than for beta-treated Zircaloy-2 and Zircaloy-4. Low elongation values of $0.2 \%$ and $0.5 \%$ were observed for beta-treated Zircaloy- 4 for the $427^{\circ} \mathrm{C}-1 \mathrm{~h}$ anneal where $\mathrm{RAH}$ was in 
effect, but also for the $427^{\circ} \mathrm{C} / 50-\mathrm{h}$ anneal where recovery had started. Very low total elongation and low uniform elongation values were also previously observed for the isochronal anneals of beta-treated Zircaloy- 4 at $399^{\circ} \mathrm{C}, 427^{\circ} \mathrm{C}$, and $454^{\circ} \mathrm{C}$. Clearly, something unusual is occurring for beta-treated Zircaloy-4 following irradiation to higher temperatures and then post-irradiation annealing that requires further investigation. The microstructure of beta-treated Zircaloy-4 consists mainly of Laves phase precipitates located at lath boundaries that are sites for void nucleation that result in fracture initiation, and then failure by void growth and coalescence $[4,5]$. The RAH during annealing could allow void nucleation to occur at the lath boundaries more easily, and is supported by the fine voids observed in the fractography from the isochronal annealed specimens in Figs. $5 c$ and 5d. Beta-treated Zircaloy-2 has a higher concentration of second phases in the regions between laths that break-up the formation of a void network that may lead to failure, allowing higher amounts of total elongation following post-irradiation annealing. The uniform elongation values for the literature data for a $427-500^{\circ} \mathrm{C}$ isothermal anneal are shown in Fig. $3 \mathrm{~d}$ to be within the range of values obtained in this work for the $427^{\circ} \mathrm{C}$ isothermal anneals. The lower uniform elongation values observed when RAH is present indicate that some flow localization has occurred, while little flow localization was generally observed after the $427^{\circ} \mathrm{C}$ isothermal anneal to longer times where $\mathrm{RAH}$ is no longer observed.

\subsection{Meechan-Brinkman Analysis of the Isothermal and Isochronal Annealing Results}

One purpose for performing the isochronal and isothermal series of post-irradiation annealing schedules followed by tensile testing at room-temperature is to provide an independent measurement of the activation energy term for recovery using the MeechanBrinkman method [60-63]. This method has successfully been used to determine the activation energy for post-irradiation recovery of steels, copper and molybdenum. The method involves the measurement of a fractional irradiation hardening term $(f)$ used to quantify the irradiation hardening in terms of the yield strength at an instance of annealing $\left(\sigma_{y-a}\right)$, the non-irradiated 
yield strength $\left(\sigma_{y-N I}\right)$, and the yield strength in the irradiation hardened condition following irradiation to high fluence at an irradiation temperature less than $326^{\circ} \mathrm{C}\left(\sigma_{y-A R}\right)$

$$
f=\frac{\sigma_{y-a}-\sigma_{y-N I}}{\sigma_{y-A R}-\sigma_{y-N I}}
$$

where the term $\left(\sigma_{y-a}-\sigma_{y-N I}\right)$ is equivalent to the irradiation hardening term $(\Delta \sigma)$ previously given in Figs. $1 \mathrm{~b}$ and $3 \mathrm{~b}$. The recovery rate has the general form [61]

$$
-d f / d t=K(T) F(f)
$$

where $K(T)$ is an Arrhenius function for a single recovery process given by the following rate constant

$$
K(T)=v_{o} \exp \left(-E_{a} / k T\right)
$$

where $E_{a}$ is the activation energy for the recovery process, $v_{o}$ is the frequency factor, and $k$ is the Boltzmann's constant. Substitution of Eq. (3) into (2) with integration gives the form of the equation used for the Meechan-Brinkmann analysis [61]

$$
\left(1 / V_{o}\right) g(f)=\left(\frac{1}{v_{o}}\right) \int d f / F(f)=t \exp \left(-E_{a} / K T\right)
$$

A second order poly-nominal empirical fit to $f$ versus the isochronal annealing temperature shown in Fig. 6 is used to determine the temperature dependence for the $f$ versus isochronal annealing temperature. The RAH effects for the lower isochronal annealing temperatures $\left(427^{\circ} \mathrm{C}\right.$ or less) are shown. The determination of activation energy is obtained from the plot of $427^{\circ} \mathrm{C}$ isothermal annealing time versus the inverse temperature, where temperature is the temperature from isochronal annealing where the fractional irradiation hardening $(f)$ is equivalent to the $427^{\circ} \mathrm{C}$ isothermal annealing time. A semi-log Arrhenius plot of isothermal annealing time versus the inverse of the isochronal annealing temperature is then used to determine the activation energy for recovery in Fig. 7. 
Since there was a significant contribution of $\mathrm{RAH}$ in the first $1-\mathrm{h}$ to $10-\mathrm{h}$ of annealing for most of the results for the $427^{\circ} \mathrm{C}$ isothermal annealing, these points could not be used for the determination of the recovery kinetics. The result is that only 3 or 4 points could be used for the determination of the activation energy for recovery using the Meechan-Brinkman method in Fig. 7. The low numbers of data points, and scatter, results in relatively large standard deviation values [64] (and therefore high uncertainty) for the activation energy measurement values given in Table 4. The activation energy values and recovery kinetics were also shown to be different for most of the material types. Higher activation energy values of $84,900 \pm 39,200 \mathrm{~J} / \mathrm{mol}$ and $102,200 \pm 48,500 \mathrm{~J} / \mathrm{mol}$, where the \pm value is 1 -standard deviation [64], were observed for alpha-annealed Zircaloy-4 and beta-treated Zircaloy-2, respectively, but the overall recovery kinetics for these two materials were different with slower recovery shown for beta-treated Zircaloy-2 in Figs. 1 and 3. The recovery kinetics for alpha-annealed Zircaloy-2 and betatreated Zircaloy- 4 in terms of fractional recovery are shown in Figs. 1 and 3 to be similar, but the activation energy values are much lower with values of $40,200 \pm 10,000 \mathrm{~J} / \mathrm{mol}$ and $41,600 \pm$ $17,200 \mathrm{~J} / \mathrm{mol}$, respectively. The wider spread of data due to the difference in the fractional recovery values likely results in the lower activation energy values. These results indicate there are subtle but important differences in the recovery kinetics among Zircaloy-2 and Zircaloy-4, and for the alpha-annealed and beta-treated heat treatment condition.

Higher activation energy values are reported for the creep of Zircaloy by a dislocation climb-controlled process (270,000 J/mol [65]), dislocation glide (174,000 J/mol [65]), and selfdiffusion in $\operatorname{Zr}(270,000 \mathrm{~J} / \mathrm{mol})$ [66]. Activation energy values of $247,000 \mathrm{~J} / \mathrm{mol}$ [56] and 209,000 $\mathrm{J} / \mathrm{mol}$ [45] have been reported for the recovery of irradiated Zircaloy. The effects of RAH have been reported in the literature for the recovery of Zircaloy $[45,57,58]$, but the specific activation energy for the recovery mechanisms that is consistent with the lower activation energy results observed herein have not been discussed in the literature. The recovery process is believed to be the coarsening and eventual disappearance of the dislocation loops that produce irradiation 
hardening by the diffusion of point defects to sinks that remove these defects from the microstructure. The fundamental kinetic process that controls this step may be different than that for self-diffusion or creep. The lower activation energy values reported in this work are more consistent with the activation energy of $96,500 \mathrm{~J} / \mathrm{mol}$ reported [67] for the binding of a point defect to defect clusters or "depletion zones" produced by irradiation [66], and used to explain the recovery of irradiation growth. The binding of point defects to point defect clusters or even clusters of solute atoms, or solute atom interactions with point defects or point defect clusters, could be the process that controls the recovery process observed in our data. The higher irradiation temperatures of $312-358^{\circ} \mathrm{C}$ in this work, which are followed by RAH effects, may have resulted in a fundamental change to the controlling mechanisms in the recovery kinetics to produce the lower values for the activation energy observed in our data.

\section{TEM Examinations of the Post-Irradiated Annealed Microstructure}

TEM examinations were performed on a selected number of post-irradiated annealed specimens that had been isochronal annealed at $399^{\circ} \mathrm{C} / 5$-hours where RAH was observed and at $510^{\circ} \mathrm{C} / 5$-hours where the greatest extent of recovery was observed. For alpha-annealed Zircaloy-4, and alpha-annealed and beta-treated Zircaloy-2, TEM examination results were also obtained for the tensile specimens that had been isothermal annealed at $427^{\circ} \mathrm{C}$ for 500 hours. Representative images from these TEM examinations are given in Figs. 8 through 11. The changes in the size and number density of the $<\mathrm{a}>$ and $<\mathrm{c}>$ loops were also determined by comparison to the measurements made from the as-irradiated microstructure [4] in Tables 5 through 8. The $<$ a $>$ loop distributions are shown in Fig. 12. Images of the as-irradiated materials that can be used for comparison are available [4]. All precipitates in the annealed materials were observed to be crystalline, which is consistent with the observations previously made on the as-irradiated materials $[4,67]$.

One important change observed when large levels of recovery are present following the post-irradiation anneal is that many of the <a> loops in Figs. 8 through 11 became more like 
dislocation lines. The greatest number of dislocation line segments was observed for the $510^{\circ} \mathrm{C}$ isochronal and $427^{\circ} \mathrm{C} / 500 \mathrm{~h}$ isothermal anneals where the recovery was the most significant. These dislocation line segments are different in appearance than observed for the as-irradiated material [4]. The dislocation segments were curved in appearance, had kinks, and are present in greater number density than the segments present in as-irradiated material [4]. These observations indicate the segments are formed from the loops during recovery. This change in the $<$ a $>$ dislocations from loops to segments is likely a mechanism for the recovery of irradiation damage by the annihilation of point defects at the respective loops, e.g. vacancy annihilation at interstitial loops and vacancy emission from loops that is followed by annihilation at vacancy loops to produce coarsening. There was also a much greater tendency for the $<a>$ loops to be aligned in the $g=10-10$ orientation with annealing than observed for the as-irradiated condition. Stacking faults were faintly visible in some cases under $\mathrm{g}=10-10$ imaging conditions for the isochronal anneals, with the stacking faults parallel to the $g=10-10$ orientation, see Fig $8 f$ for example. These stacking faults were observed for alpha-annealed and beta-treated Zircaloy-4 for the $510^{\circ} \mathrm{C}$ isochronal annealed condition but not for materials following the $427^{\circ} \mathrm{C} / 500$ hour anneal. Stacking faults were not visible for the as-irradiated material $[4,67]$. The formation of these stacking faults may be part of the recovery process and could be the result of the formation of $<\mathrm{a}+\mathrm{c}>$ type dislocations. Detailed analysis of the faults was not performed.

\subsection{Examinations for the $399^{\circ} \mathrm{C}$ Isochronal Anneal}

For the $399^{\circ} \mathrm{C}$ isochronal anneal condition, both alpha-annealed Zircaloy-4 and betatreated Zircaloy-2 exhibited a lesser degree of $\mathrm{RAH}$, and an increase in the average size of the $<$ a $>$ loops with a decrease in the $<$ a $>$ loop number density compared to the as-irradiated condition that is characterized by an overall coarsening of the <a> loop distribution. In the case of alpha-annealed Zircaloy-2 and beta-treated Zircaloy-4 where the RAH was very significant, a decrease in the average size of the <a> loops and increase in the <a> loop number density was observed that was shown by a refinement of the $<a>$ loop distribution in Fig. 12. The results for 
beta- treated Zircaloy- 4 for the $399^{\circ} \mathrm{C}$ isochronal anneal condition were notably different than all other materials, with the average $<$ a $>$ loop diameters being smaller than observed for the asirradiated Zircaloy materials, and no $<c>$ loops were observed. The increase in the $<a>$ loop number density with the corresponding decrease in <a> loop size and refinement of the <a> loop distribution during the $399^{\circ} \mathrm{C}$ isochronal anneal could result from additional <a> loop nucleation from available point defects or point defect clusters within the matrix of the irradiated material during annealing, or the coarsening of fine point defect clusters during annealing that were below the size detection limit for TEM $(<0.4 \mathrm{~nm})$ in the as-irradiated condition. The formation of these additional <a> loops may also result from the movement of impurity atoms, such as oxygen [45,57-58], to defect clusters or dislocation loops that may enable the nucleation of additional $<$ a $>$ loops. The nucleation of additional $<$ a $>$ loops would be expected to produce the RAH during the isochronal annealing that is observed for alpha-annealed Zircaloy-2 and beta- treated Zircaloy-4. The movement of interstitial or substitutional solute impurities to dislocation loops to further harden these barriers is another possible mechanism for RAH that cannot be shown by these investigations, but may produce the lesser degree of RAH observed for alpha-annealed Zircaloy-4 and beta- treated Zircaloy-2 for the $399^{\circ} \mathrm{C}$ isochronal anneal condition where an increase in <a> loop size and decrease in <a> loop number density was observed. There is a microstructure/alloy effect on the kinetics for <a loop coarsening that requires further study to better understand the results.

Although very low number densities of voids were observed in the as-irradiated condition for beta- treated Zircaloy-2, no voids were observed for the $399^{\circ} \mathrm{C}$ isochronal anneal condition where RAH was observed. This could result from the fact that the voids were present in a very low number density and are very inhomogeneously distributed. A few voids were observed for alpha-annealed Zircaloy-4 for the $399^{\circ} \mathrm{C}$ isochronal anneal condition that are shown in Figs. $8 \mathrm{~b}$ and $8 \mathrm{c}$, but these voids were again very inhomogeneously distributed and too few in number for reliable statistics on the void number density to be obtained. 
An increase in the $<\mathrm{c}>$ loop number density was observed for the $399^{\circ} \mathrm{C}$ isochronal anneal conditions for alpha-annealed Zircaloy-4 and Zircaloy-2, but a decrease in $<\mathrm{c}>$ loop number density was observed for beta-treated Zircaloy-2. A slight decrease in the average $<\mathrm{c}>$ loop sizes were observed for alpha-annealed and beta- treated Zircaloy-2 for the $399^{\circ} \mathrm{C}$ isochronal anneal condition, but an increase in the $<c>$ loop sizes was observed for alphaannealed Zircaloy-4. As observed for the as-irradiated materials [4], the number densities of $<\mathrm{c}>$ loops are so low, and the $<\mathrm{c}>$ loops are relatively inhomogeneously distributed, such that additional examinations are needed to obtain a more certain measurement of the $<\mathrm{c}>$ dislocation loop distributions. These changes in $<\mathrm{c}>$ loop sizes and distributions with annealing could have an effect on the RAH observed for the $399^{\circ} \mathrm{C}$ isochronal anneal condition, but further investigations are needed. Some of the $<\mathrm{c}>$ loops for the $399^{\circ} \mathrm{C}$ isochronal anneal condition shown in Figs. 10b and 11b, are no longer straight, but are kinked in appearance, which is evidence that dislocation climb or dissociation of the $<\mathrm{c}>$ dislocation into $<\mathrm{a}+\mathrm{c}>$ components has occurred.

\subsection{Examinations for the $510^{\circ} \mathrm{C}$ Isochronal Anneal}

For the $510^{\circ} \mathrm{C}$ isochronal anneal condition, the increase in <a> loop diameter and decrease in <a> loop number density and coarsening of the <a> loop distribution observed for alpha-annealed and beta-treated Zircaloy-2 and Zircaloy-4 were generally consistent with the recovery observed for these materials. An increase in <a> loop size and decrease in <a> loop number density was also observed for alpha-annealed Zircaloy-2 for the $510^{\circ} \mathrm{C}$ isochronal anneal condition in comparison to the $399^{\circ} \mathrm{C}$ isochronal anneal condition, but the <a> loop size and number density for the $510^{\circ} \mathrm{C}$ isochronal anneal condition are only slightly coarser than the as-irradiated condition. However, recovery was still observed for the $510^{\circ} \mathrm{C}$ isochronal anneal condition for alpha-annealed Zircaloy-2 in comparison to the as-irradiated and RAH condition for the $399^{\circ} \mathrm{C}$ isochronal anneal, indicating that this recovery cannot be explained by the <a> loop size and <a> loop number density alone. Part of the reason for such lack of correlation may be 
related to the fact that many of the $<$ a loops are changed from dislocation loops to dislocation line segments for the $510^{\circ} \mathrm{C}$ isochronal anneal, so the effective hardening of the dislocation loops is reduced. There may also be measurement difficulties with quantifying dislocation loops compared to <a> line segments. The line segments were also not specifically measured or quantified as appropriate ways of doing such do not effectively consider dislocation tangles. A change in the strength of the hardening barriers must be occurring by the diffusion of interstitial or substitutional solute atoms away from the $<$ a $>$ loops during the annealing, so the effective strength of the barriers is reduced and recovery is produced. The same type of effect is also observed for beta-treated Zircaloy- 2 for the $510^{\circ} \mathrm{C}$ isochronal anneal condition, where the <a> loop sizes are comparable to the as-irradiated condition, but a slight decrease in the $<$ a loop number density may explain some of the recovery observed in relation to the RAH observed for the $399^{\circ} \mathrm{C}$ isochronal annealed condition. Again, there may be solute atom interaction effects for Zircaloy-2 that appear to stabilize the $<$ a loop distributions but alter the strength of these barriers. Solute interactions with the $<a>$ loops could explain the unusual observation of little change in the $<$ a loop distributions for the $510^{\circ} \mathrm{C}$ isochronal anneal condition in comparison to the as-irradiated condition. More investigation is needed to better understand the development of the microstructure during annealing.

Most of the $<\mathrm{c}>$ loops observed for alpha-annealed and beta- treated Zircaloy-2 and Zircaloy- 4 for the $510^{\circ} \mathrm{C}$ isochronal anneal condition showed evidence of dislocation climb and dissociation of the dislocations into $<\mathrm{a}+\mathrm{c}>$ segments that was shown by a kinked appearance. The degree of climb and dissociation of the $<\mathrm{c}>$ loops observed for the $510^{\circ} \mathrm{C}$ isochronal anneal condition appeared much greater than observed for the $399^{\circ} \mathrm{C}$ isochronal anneal condition. This indicates that more point defect annihilation to produce climb or dissociation had occurred at the higher annealing temperature, as expected. The change in the $<\mathrm{c}>$ loop size and number density for the $510^{\circ} \mathrm{C}$ isochronal anneal condition in comparison to the as-irradiated condition was generally small for alpha-annealed and beta- treated Zircaloy-2 and Zircaloy-4. Given the 
low number density of the $<\mathrm{c}>$ loops, the impact of these defects on hardening and recovery would be expected to be small.

\subsection{Examinations of Precipitates following the Isochronal Anneals}

Examinations of precipitates following recovery was pursued to determine if a change in composition or structure occurred that could influence the evolution of the defect structure. Based on limited examination of precipitates following the isochronal anneals, little change in the overall structure of the precipitates was observed in comparison to the as-irradiated condition, which show changes on the order of $2-4 \% \mathrm{Fe}$ and $\mathrm{Cr}$ in comparison to the asirradiated condition $[4,67]$. One $\mathrm{Zr}(\mathrm{Fe}, \mathrm{Cr})_{2}$ precipitate was analyzed for alpha-annealed Zircaloy-4 following the $399^{\circ} \mathrm{C}$ isochronal anneal condition, and the slight gradient in $\mathrm{Fe}$ and $\mathrm{Cr}$ measured through the precipitate (decrease in Fe and $\mathrm{Cr}$ to the precipitate/matrix interface) was similar to that observed for the as-irradiated material $[4,67]$. The composition of the $\mathrm{Zr}(\mathrm{Fe}, \mathrm{Cr})_{2}$ precipitate in alpha-annealed Zircaloy-4 was measured to be $\mathrm{Zr}-42.2 \% \mathrm{Fe}-24.6 \% \mathrm{Cr}$ and $\mathrm{Zr}-$ $36.24 \% \mathrm{Fe}-22.5 \% \mathrm{Cr}$ (atom\%) for the $399^{\circ} \mathrm{C}$ isochronal anneal condition, which is similar to the compositions measured for the $\mathrm{Zr}(\mathrm{Fe}, \mathrm{Cr})_{2}$ precipitates in the as-irradiated material [67]. For alpha-annealed Zircaloy-2, an EDS trace was made across two $\mathrm{Zr}(\mathrm{Fe}, \mathrm{Cr})_{2}$ precipitates following the $510^{\circ} \mathrm{C}$ isochronal anneal condition, see Fig. 10e. A slight decrease in Fe was again observed to the precipitate/matrix interface with a nominal composition of $\mathrm{Zr}-25.8 \% \mathrm{Fe}-$ $40.1 \% \mathrm{Cr}-0.9 \% \mathrm{Ni}$ measured for one precipitate and compositions of $\mathrm{Zr}-29.1 \% \mathrm{Fe}-34.4 \% \mathrm{Cr}$, $\mathrm{Zr}-24.0 \% \mathrm{Fe}-40.8 \% \mathrm{Cr}$, and $\mathrm{Zr}-21.2 \% \mathrm{Fe}-41.9 \% \mathrm{Cr}$ observed for the other precipitate. The $\mathrm{Zr}_{2}(\mathrm{Fe}, \mathrm{Ni})$ precipitate exhibited no variation in composition and the nominal composition was $\mathrm{Zr}$ $-12.9 \% \mathrm{Fe}-19.6 \% \mathrm{Ni}$. These results and precipitate compositions are consistent with those observed in the as-irradiated material [67].

\subsection{Examinations for the $427^{\circ} \mathrm{C} / 500 \mathrm{~h}$ Isothermal Anneal}

For alpha-annealed Zircaloy-4, the $427^{\circ} \mathrm{C} / 500$ hour isothermal anneal resulted in a factor of 1.4 increase in the <a> loop size and factor of 3.1 decrease in <a> loop number density 
compared to the as-irradiated condition, but the <a> loop sizes and <a> loop number density were smaller than for the $399^{\circ} \mathrm{C}$ and $510^{\circ} \mathrm{C}$ isochronal anneal conditions. Although the <a> loop sizes and number densities for alpha-annealed Zircaloy-4 for the as-irradiated condition at the fluence of $2.93 \times 10^{25} \mathrm{n} / \mathrm{m}^{2}$ are shown in Tables 5 to 8 to be different than for alphaannealed and beta- treated Zircaloy-2, it is interesting to note that the $<a>$ loop sizes and number densities for alpha-annealed Zircaloy-4 and Zircaloy-2 are similar following the $427^{\circ} \mathrm{C} / 500$ hour isothermal annealed condition. A larger $<$ a $>$ loop size and lower $<$ a $>$ loop number density were observed for beta- treated Zircaloy-2 than for alpha-annealed Zircaloy-4 and Zircaloy-2 following the $427^{\circ} \mathrm{C} / 500$ hour isothermal anneal. For alpha-annealed and betatreated Zircaloy- 2 in the $427^{\circ} \mathrm{C} / 500$ hour isothermal annealed condition, the <a> loop sizes and number densities were similar to that observed for the $399^{\circ} \mathrm{C}$ isochronal annealed condition. For alpha-annealed Zircaloy-2, the <a> loop size and <a> loop distribution for the $427^{\circ} \mathrm{C} / 500$ hour isothermal annealed condition was slightly finer than the as-irradiated. For beta-treated Zircaloy-2, the <a> loop size and <a> loop distribution was only slightly larger than the asirradiated condition and the <a> loop number density was only slightly lower than the irradiated condition. Large amounts of $\mathrm{RAH}$ are observed during the $427^{\circ} \mathrm{C}$ isothermal anneal followed by recovery, and the RAH may produce the slower recovery of the <a> loop structure observed for the $427^{\circ} \mathrm{C} / 500$ hour isothermal annealed condition. The $\mathrm{RAH}$ likely results in an increase in $<\mathrm{a}>$ loop number density, that is then coarsened with further annealing at $427^{\circ} \mathrm{C}$. Additional examinations are needed at the shorter annealing time for the $427^{\circ} \mathrm{C}$ isothermal anneals where $\mathrm{RAH}$ occurs to truly understand the recovery. Although not completely understood and characterized at this point, the TEM results are consistent with a general recovery being observed for the $427^{\circ} \mathrm{C} / 500$ hour isothermal annealed condition.

The $<\mathrm{c}>$ loops are observed to increase in size and number density for alpha-annealed Zircaloy-4 in the $427^{\circ} \mathrm{C} / 500$ hour isothermal annealed condition. An increase in <c> loop size and decrease in $<\mathrm{c}>$ loop number density was observed for alpha-annealed Zircaloy-2 in the 
$427^{\circ} \mathrm{C} / 500$ hour isothermal annealed condition. A decrease in $<\mathrm{C}>$ loop size and number density was observed for beta- treated Zircaloy-2 for the $427^{\circ} \mathrm{C} / 500$ hour isothermal annealed condition. Given the low number density of $<\mathrm{c}>$ loops and inhomogeneous distribution of $\langle\mathrm{C}>$ loops, the general effect of these changes on recovery of the irradiation hardening and the overall evolution of microstructure may be of little or no consequence. In all cases for the $427^{\circ} \mathrm{C} / 500$ hour isothermal annealed condition the climb of the $<\mathrm{c}>$ loops was observed by the kinking of the dislocations.

\section{Irradiation Hardening and Microstructure}

The relationship between the measured irradiation hardening $\left(\Delta \sigma_{y}\right)$ and the $<$ a loop and $<\mathrm{c}>$ loop structure is quantified using a generalized Orowan hardening model $[1-2,4-5,68-$ 69]

$$
\Delta \sigma_{y}=\alpha M G b \sqrt{(D)(N D)}
$$

where $M$ is the Taylor factor ( assumed to be $M=2$ as a bounding value based on the assumption that local deformation occurred in grains that were optimally orientated for slip [4]), $G$ is the shear modulus, $b$ the Burgers vector $(b=0.323 \mathrm{~nm}$ for $<$ a $>$ loops and $b=0.515 \mathrm{~nm}$ for $<$ c> loops), $N D$ the loop number density and $D$ the loop diameter. The parameter $\alpha$ is the strength of the individual barriers, and previous work [4-5] showed the loops needed to be assumed to be hard barriers such as voids or precipitates with $\alpha=1$ to result in a closer match between the measured irradiation hardening and values calculated from the TEM examination results. In previous work for as-irradiated materials [4-5], it was shown that the ratio of measured versus predicted values with the assumption that $\alpha=1$ ranged from 0.33 to 2.5 higher or lower than the measured values with a mean measured versus predicted value of 1.32 and standard deviation of 0.66 in Reference [4] and a mean measured versus predicted value of 1.01 and standard deviation of 0.36 in Reference [5]. The barrier strength of dislocation loops 
has been shown to vary with the level of solute segregation, such as observed for vanadium [70]. For the as-irradiated materials [4], the differences in the calculated and measured irradiation hardening for the irradiated Zircaloy-2 and Zircaloy-4 were theorized to result from the influence of solute atoms on the barrier strength of the loops and the level of solute segregation. The variation in solute could be tied to the partial dissolution of $\mathrm{Zr}(\mathrm{Fe}, \mathrm{Cr})_{2}$ precipitates, which injects iron into the alpha-Zr matrix phase [1-2,4-8,19,33-35,38].

One other effect to considered for as-irradiated materials [4-5] is the role of the $<\mathrm{c}>-$ loops on irradiation hardening in addition to the effects of $<a>$ loop hardening. A superposition approach by a linear sum of squares value for barriers that have a similar strength gives [71],

$$
\Delta \sigma_{y}=\sqrt{\left(\alpha_{\langle a\rangle} M G b_{\langle a>} \sqrt{\left(D_{\langle a\rangle}\right)\left(N D_{\langle a\rangle}\right)}\right)^{2}+\left(\alpha_{\langle c>} M G b_{\langle c>} \sqrt{\left(D_{\langle c\rangle}\right)\left(N D_{\langle c\rangle}\right)}\right)^{2}}
$$

Direct linear addition of the $<\mathrm{a}>$ and $<\mathrm{c}>$ loop strengthening is also considered for the asirradiated materials as a bounding value for the calculated irradiation hardening contribution due to the combined effects of $<a>$ and $<c>$ loop hardening [4-5]

$$
\Delta \sigma_{y}=\alpha_{<a>} M G b_{<a>} \sqrt{\left(D_{<a>}\right)\left(N D_{<a>}\right)}+\alpha_{\langle c\rangle} M G b_{\langle c>} \sqrt{\left(D_{<c>}\right)\left(N D_{<c>}\right)}
$$

For the as-irradiated materials [4], the use of the summation approach (Eq. (7)) was shown to give values closer to the measured results than Eq. (6), which indicates that the $<\mathrm{C}>$ loops could have an effect on irradiation hardening that requires additional investigation. Basal slip that would interact with $<\mathrm{c}>$ loops has been shown to become important for irradiated Zircaloy [1$2,26,53,72]$.

For post-irradiation annealed alpha-annealed and beta-treated Zircaloy-2 and Zircaloy-4, Figs. 13a and 13c show the match between the measured irradiation hardening and the calculated <a> loop hardening using Eq. (5) is less close than observed for as-irradiated materials. One reason for this lack of match for post-irradiated annealed material can be that the $<$ a loops are changed to line segments during the annealing. In cases where RAH was 
observed during the $399^{\circ} \mathrm{C}$ isochronal anneal, conflicting results were observed. For betatreated Zircaloy-4 and alpha-annealed Zircaloy-2, the measured irradiation hardening is much greater than the calculated value for <a> loop irradiation hardening alone, but for beta-treated Zircaloy-2 and alpha-annealed Zircaloy-4, a closer match between the measured and calculated irradiation hardening was observed. The match between the measured and calculated irradiation hardening for the $510^{\circ} \mathrm{C}$ isochronal anneal and the $427^{\circ} \mathrm{C} / 500 \mathrm{~h}$ isothermal anneal exhibited no consistent trends. The greater scatter between the measured irradiation hardening and calculated $<$ a $>$ loop hardening determined for post-irradiated annealed material could possibly be explained by variation in the barrier strength term for the <a> loops $(\alpha)$ resulting from annealing, which could be attributed to diffusion of interstitial solutes (e.g., oxygen, nitrogen, and carbon) and/or substitutional solute atoms (e.g., iron, chromium, nickel, tin, and silicon) either to the loops or away from the loops. Another possible mechanism for the greater scatter between the measured and calculated irradiation hardening values for the postirradiation specimens could be the formation of a fine distribution of solute and/or point defect clusters under the irradiation/annealing that are below the size detection limit for TEM $(<0.4 \mathrm{~nm})$. The re-alignment of $<\mathrm{c}>$ loops into different configurations, and kinking of the $<\mathrm{c}>$ loops due to dislocation climb are other changes in microstructure that could potentially have an influence on irradiation hardening.

\section{Summary and Conclusions}

Post-irradiated annealing experiments were performed on alpha-annealed and betatreated Zircaloy-4 and Zircaloy-2 to investigate rates of recovery from irradiation damage. Recovery was measured by performing room-temperature tensile tests following a series of isochronal annealings for periods of 5 -hours at annealing temperatures of $343^{\circ} \mathrm{C}, 371^{\circ} \mathrm{C}, 399^{\circ} \mathrm{C}$, $427^{\circ} \mathrm{C}, 454^{\circ} \mathrm{C}, 482^{\circ} \mathrm{C}$, and $510^{\circ} \mathrm{C}$, and following a separate series of isothermal annealings at $427^{\circ} \mathrm{C}$ for 1 to 500 hours. These annealing series were used in a Meechan-Brinkman analysis to determine the activation energy for recovery. In addition to the lower irradiation hardening for 
the as-irradiated condition [4], the higher irradiation temperature of $312-358^{\circ} \mathrm{C}$ seen by the materials used in this work produced Radiation Anneal Hardening (RAH) during the isochronal annealings at $343-399^{\circ} \mathrm{C}$ and during isothermal anneals at $427^{\circ} \mathrm{C}$ for the times of $1-10 \mathrm{~h}$ that was characterized by a significant increase in the yield strength from the as-irradiated condition. Such RAH effects have been reported in the literature for irradiations at high temperatures [5658], and are believed to result from the movement of solutes to dislocation loops and/or ripening of point defect clusters into stronger barriers during annealing. The effects of RAH to increase the irradiation hardening are also observed to generally slow the overall rate of subsequent recovery in comparison to literature data derived from samples irradiated at lower temperatures $\left(260^{\circ} \mathrm{C}\right.$ to $\left.326^{\circ} \mathrm{C}\right)$. Notable and yet unexplained differences in RAH and in recovery are observed in this work among alpha-annealed and beta-treated Zircaloy-2 and Zircaloy-4 that might be explained by solute effects related to differences in the precipitate type. Although the as-irradiated hardening values observed in this work were lower than typically reported in the literature due to the high irradiation temperatures [4], the occurrence of RAH during the isochronal anneals at $343-399 \mathrm{C}^{\circ} \mathrm{F}$ results in irradiation hardening values more similar to the asirradiated literature data for irradiations at temperatures of $260-326^{\circ} \mathrm{C}$. Fast recovery was observed for all materials at isochronal annealing temperatures of $454-510^{\circ} \mathrm{C}$ to result in a similar level of irradiation hardening. For the $427^{\circ} \mathrm{C}$ isothermal anneal, the lower as-irradiated hardening values observed in this work in comparison to literature data for irradiations at 260$326^{\circ} \mathrm{C}$ is followed by significant RAH in the first $1-10 \mathrm{~h}$ that increases the irradiation hardening values to those greater than the $260-326^{\circ} \mathrm{C}$ as-irradiated literature values. Recovery effects become more dominant in the $10-500 \mathrm{~h}$ times for the $427^{\circ} \mathrm{C}$ isothermal anneal, but the overall recovery is generally slower than observed for literature data with irradiations at $260-326^{\circ} \mathrm{C}$.

The activation energy for recovery, following RAH increases, measured in this work for alpha-annealed Zircaloy-4 $(102,200 \pm 48,500 \mathrm{~J} / \mathrm{mol})$ and beta-treated Zircaloy-2 $(84,900 \pm$ $39,200 \mathrm{~J} / \mathrm{mol}$ ) are comparable to the value of $96,500 \mathrm{~J} / \mathrm{mol}$ for the binding energy of point 
defects to defect cluster [66]. However, much lower activation energy values for post RAH recovery of $40,200 \pm 10,000 \mathrm{~J} / \mathrm{mol}$ and $41,600 \pm 17,200 \mathrm{cal} / \mathrm{mol}$ are observed in this work for alpha-annealed Zircaloy-2 and beta-treated Zircaloy-4, showing the effects of RAH and higher irradiation temperature can significantly influence the recovery kinetics and likely the recovery processes. Overall, these results show that higher irradiation temperatures of $312^{\circ} \mathrm{C}$ to $358^{\circ} \mathrm{C}$ produce very different recovery kinetics and likely result in different recovery processes than occur following irradiations at $260^{\circ} \mathrm{C}$ to $326^{\circ} \mathrm{C}$.

TEM examinations were performed on alpha-annealed and beta-treated specimens that had been isochronal annealed at $399^{\circ} \mathrm{C}$ and $510^{\circ} \mathrm{C}$, and isothermal annealed at $427^{\circ} \mathrm{C}$ for 500 hours. The observed evidence in the microstructure of recovery during annealing is the coarsening of the $<$ a $>$ loop distributions, decrease in <a> loop number density, change in <a> loops to line segments, and kinking of $<\mathrm{c}>$ loops that were most prominent for the $510^{\circ} \mathrm{C}$ isochronal and $427^{\circ} \mathrm{C} / 500-\mathrm{h}$ isothermal anneal. These changes are evidence of point defect annihilation at the $<\mathrm{a}>$ and $<\mathrm{c}>$ loops during post-irradiation annealing. The observed evidence in microstructure for RAH is the increase in <a> loop number density observed for the $399^{\circ} \mathrm{C}$ isochronal anneal for alpha-annealed Zircaloy-2 and beta-treated Zircaloy-4, where the measured RAH from tensile testing was large. Little <a> loop distribution change for betatreated Zircaloy-2 and alpha-annealed Zircaloy-4 was observed where low amounts of RAH were determined from tensile testing. The degree of $<a>$ loop coarsening and decrease in $<a>$ loop number density observed for the $427^{\circ} \mathrm{C} / 500-\mathrm{h}$ isothermal anneal compared to the asirradiated condition was relatively slight. Although the short time $427^{\circ} \mathrm{C}$ annealed samples were not examined, this may indicate that an increase in <a> loop number density may occur at the shorter annealing times to result in the measured $\mathrm{RAH}$ and result in less net change in the $<\mathrm{a}>$ loop distributions at the longer annealing time in comparison to the as-irradiated microstructure. TEM characterization of additional annealed specimens is needed to understand the change in microstructure that produces $\mathrm{RAH}$ and characterize the change in defect structure during 
annealing that leads to recovery. The match between the measured and calculated irradiation hardening using a generalized Orowan hardening model was not as close for the postirradiation annealed condition as for the as-irradiated condition, which can likely be attributed to the change in the configuration of the <a> loops to dislocation lines, segregation of solutes to the dislocation loops, and the potential for the formation of fine clusters of point defects during annealing.

\section{Acknowledgments}

This work was supported by USDOE. The authors are grateful for the review and comments provided by B.F. Kammenzind. Thanks also to the following ORNL personnel for their efforts in completing the testing (A.W. Williams, L.T. Gibson, and M.J. Meyers), a Department of Energy Office of Science User Facility.

\section{References}

[1] F. Ominus \& L. Béchade, Comprehensive Nuclear Materials, Chap 4.01, "Radiation Effects in Zirconium Alloys”, Elsevier, Amsterdam, (2012).

[2] R. Adamson and B. Cox, ZIRAT-10 Special Topics Report, "Impact of Irradiation on Material Performance", ANT International, Sweden, October, 2005.

[3] P. H. Kreyns, W.F. Bourgeois, C.J. White, P.L. Carpentier, B.F. Kammenzind, and D.G. Franklin: Zirconium in the Nuclear Industry: Eleventh International Symposium, ASTM STP 1295, E.R. Baradley and G.P. Sabol, Eds., American Society for Testing and Materials, 1996, pp. 758-782.

[4] B.V. Cockeram, R.W. Smith, K.J. Leonard, T.S. Byun, and L.L. Snead, Journal of Nuclear Materials, Vol. 418 (2011) 48-61.

[5] B.V. Cockeram, J.L. Hollenbeck, K.J. Leonard, T.S. Byun, and L.L. Snead, Journal of Nuclear Materials, Vol. 449 (2014) 69-87.

[6] M. Griffiths, J. Nuclear Materials, 159 (1988), 190-218.

[7] M. Griffiths, R.W. Gilbert, V. Fidleris, R.P. Tucker, and R.B. Adamson, J. Nuclear Materials, 150 (1987), 159-168.

[8] W.J.S. Yang, R.P. Tucker, B. Cheng, and R.B. Adamson, J. Nuclear Materials, 138 (1986), 185-195.

[9] R.A. Holt, J. Nuclear Materials, 35 (1970), 322.

[10] D. Churquet, R. Haton, E. Ortlieb, J-P. Gros, and J.F. Wadier, Zirconium in the Nuclear Industry: Eighth Symposium, ASTM STP 1023, L.F.P. Van Swam and C.M. Euken, eds., ASTM Philadelphia, PA, 1988, pp. 405-422.

[11] A. T. Motta, et al, Zirconium in the Nuclear Industry: Thirteenth International Symposium, ASTM STP 1423, G. D. Moan and P. Rudling, Eds., ASTM International, West Conshohocken, PA, 2002, pp. 59-79.

[12] O.T. Woo, D.T. Seng, K. Tangri, and S.R. MacEwen, J. Nuclear Materials, 87 (1979), 135.

[13] M. Griffiths, R.A. Holt, and A. Rogerson, J. Nuclear Materials, 225 (1995), 245-258. 
[14] D.O. Northwood, et al., J. Nuclear Materials, 79 (1979), 379-394.

[15] N. Hashimoto and T.S. Byun, Mat. Sci. Forum, 561-565 (2007), 1769-1772.

[16] K. Kakiuchi, et al., J. Nucl. Tech., 43 (2006), 1031-1036.

[17] P.M. Kelly, and R.G. Blake, Philos. Mag., 28(2) (1973), 415-426.

[18] L. Howe and W.R. Thomas, J. Nuclear Materials, 2 (1960), 248-260.

[19] R.B. Adamson and W.L. Bell, "Effects of neutron irradiation and oxygen content on the microstructure and mechanical properties of zircaloy": Microstructure and Mechanical Behavior of Materials, X'ian, Republic of China, Oct 21-24, EMAS Warley, UK, 1985, Vol. I, pp. 237-246.

[20] J. Ribis, F. Onimus, and J.L. Béchade, J. ASTM Int., 5(3) (2008).

[21] G.J.C. Carpenter and J.F. Watters, Zirconium in the Nuclear Industry, ASTM STP 551, J.H. Schemel, and H.S. Rosenbaum, eds., ASTM West Conshohocken, PA, 1974, p. 400.

[22] C.D. Williams and R.W. Gilbert, Proceedings of the IAEA Symposium, Vienna, 1969, Vol. 1, p. 235.

[23] D.O. Northwood and A.R. Causey, J. Nuclear Materials, 64 (1977), 308-312.

[24] C.Regnard, et al., Proceeding of the $13^{\text {th }}$ International Symposium on Zirconium in the Nuclear Industry, ASTM STP 1423, 2002, p. 384.

[25] R.W. Gilbert, K. Farrell, and C.E. Coleman, J. Nuclear Materials, 84 (1979), 137-148.

[26] G.J.C. Carpenter and D.O. Northwood, J. Nuclear Materials, 56 (1975), 260-266.

[27] T.D. Gulden, and I.M. Bernstein, Phil. Mag., 14 (1966), 1087-1091.

[28] P.M. Kelly, and R.G. Blake, Phil. Mag., 28 (1973), 415-426.

[29] D.O. Northwood, et al., J. Nuclear Materials, 61 (1976), 123-130.

[30] A. Jostons, P.M. Kelly, and R.G. Blake, J. Nuclear Materials, 66 (1977), 236-256.

[31] G.J.C. Carpenter and J.F. Waters, J. Nuclear Materials, 96 (1981), 213-226.

[32] C. Hellio, C.H. de Novion, and L.J. Boulanger, J. Nuclear Materials, 159 (1988), 368378.

[33] M. Griffiths, Phil. Mag. B, 63 (1991), 835-847.

[34] M. Griffiths, J. Nuclear Materials, 205 (1993), 225-241.

[35] M. Griffiths, J. Nuclear Materials, 170 (1990), 294-300.

[36] J.Ribis, F. Onimus, J.L. Bechade, S. Doriot, C. Cappelaere, C. Lemaignan, A. Barbu, and O. Rabouille, Zirconium in the Nuclear Industry: Fifteenth International Symposium, ASTM STP 1505, J of ASTM International, Vol. 5, 2009, p. 674.

[37] J.Ribis, F. Onimus, J.L. Bechade, S. Doriot, A. Barbu, C. Cappelaere, and C. Lemaignan, J. Nuclear Materials, Vol 403 (2010), pp 135-146.

[38] M. Griffiths, R.W. Gilbert, and C.E. Coleman, J. Nuclear Materials, 159 (1988), 405-416.

[39] A.L. Bement, J.C. Tobin, and R.G. Hoagland, ASTM STP-380, June, 1964.

[40] A.L. Bement, "Radiation Damage in Hexagonal Close-Packed Metals and Alloys", BNWL-SA-236, June 1, 1965.

[41] M. Griffiths, and R.W. Gilbert: Zirconium in the Nuclear Industry: Eighth International Symposium, ASTM STP 1023, L.F.P. Van Swam and C.M. Eucken, Eds., American Society for Testing and Materials, 1989, pp. 658-677.

[42] D. L. Douglass: Atomic Energy Review Supplement, International Atomic Energy Agency: Vienna, 1971, pp. 311-342.

[43] H.R. Higgy, and F.H. Hammad, J. Nuclear Materials, 44 (1972), 215-227.

[44] S.B. Wisner, G.H. Henderson, R.P. Tucker, and R.B. Adamson, "Mechanical Properties of Zircaloy Irradiated in the EBR-II", GEAP-25163-10, Appendix B, 1984.

[45] T. Torimaru, T. Yasuda, and M. Nakatsuka, Journal of Nuclear Materials, Vol. 238 (1996) 169.

[46] S.T. Mahmood, D.M. Farkas, and R.B. Adamson, Zirconium in the Nuclear Industry: Twelfth International Symposium, ASTM STP 1384, American Society for Testing and 
Materials, West Conshohocken, PA, 2000, pp. 139-169.

[47] B. Lustman, M.L. Bleiberg, E.S. Byron, J.N. Chirigos, J.C. Goodwin, and G.J. Salvaggio, Nucleonics, v. 19(1) (1961) pp. 58-63.

[48] D.G. Hardy, ASTM STP-484, June 1970.

[49] H.H. Klepfer and C.N. Spalaris, Nuclear Metallurgy, Vol. VIII, AIME, New York, 1960.

[50] S.B. Wisner and R.B. Adamson, Nucl. Eng and Design, v. 185 (1998) pp. 33-49.

[51] P. Morize, J. Baicry, and J.P. Mardon, Zirconium in the Nuclear Industry: Seventh International Symposium, ASTM STP 936, R.B. Adamson and L.F.P. Van Swam, Eds., American Society for Testing and Materials, West Conshohocken, PA, 1987, pp. 101119.

[52] R S. Ishimoto, T. Kubo, and O. Kubota, "Development of New Zirconium Alloys for High Burnup Fuel”, Proceedings of TopFuel 2003, Wurzburg, Germany, 2003.

[53] F. Onimus, I. Monnet, J.L. Bechade, C. Prioul, and P. Pilvin, J. Nuclear Materials, 328 (2004), 165-179.

[54] N. Hashimoto and T.S. Byun, Mat. Sci. Forum, 561-565 (2007), 1769-1772.

[55] Standard Test Methods for Tension Testing of Metallic Materials, ASTM E8-01, American Society for Testing and Materials, Philadelphia, PA, 2001.

[56] A.A. Bauer and L.M. Lowry, Nucl. Tech., Vol. 41 (1978) 359.

[57] K.U. Snowden and K. Veevers, Radiat. Eff., Vol. 20 (1973) 169.

[58] K. Veevers, W.B. Rotsey and K.U. Snowden, ASTM STP 458 (1969) 194.

[59] E.N. Harbinson and C.J. Baroch, Journal of Materials, Vol. 3 (1968), 107-115.

[60] C.J. Meechan and J.A. Brinkman, Phys. Rev., Vol. 103 (1956) 1193.

[61] D.J. Harvey and M.S. Wechsler, in: Proceedings of $11^{\text {th }}$ Conference on Effects of Radiation on Materials, Scottsdale, AZ, ASTM, Philadelphia, PA, 1982, p. 505.

[62] D. Pachur, Nucl. Technol., Vol 59 (1982) p. 463.

[63] B.V. Cockeram, J.L. Hollenbeck, and L.L. Snead, Journal of Nuclear Materials, Vol. 336 (2005) 299-313.

[64] J. Philibert, "Atom Movements, Diffusion, and Mass Transport”, Les Editions de Physique, p 191.

[65] P. Merle, C. Vauglin, G. Fantozzi, J.L. Derep, and D. Charquet, ASM STP 939 (1987) 555.

[66] C.C. Dollins, J. Nucl. Mater., 59 (1975) 61.

[67] B.V. Cockeram, K.J. Leonard, L.L. Snead, and M.K. Miller, Journal of Nuclear Materials, Vol. 433 (2013) 460-478.

[68] G.S. Was, "Fundamentals of Radiation Materials Science“, Springer, New York, 2007, pp 581-640.

[69] D. R. Olander, Fundamental Aspects of Nuclear Reactor Fuel Elements, Technical Information Center, US-DOE, ERDA 1976.

[70] R. Bajaj and M.S. Wechsler, Met. Trans., Vol. 7A (1976) 351-358.

[71] M. Griffiths, Zirconium in the Nuclear Industry: Fifteenth International Symposium, ASTM STP 1505, J of ASTM International, Vol. 5, 2009, pp. 19-26.

[72] M.S. Wechsler, "Dislocation Channeling in irradiated and quenched metals, The inhomogeneity of Plastic Deformation“, ASM, Metals Park, OH, 1973. 
Table 1. Nominal Chemical Composition for alpha-annealed Zircaloy-4, alpha-annealed Zircaloy-2, and beta-treated Zircaloy-2 (weight\%) [4].

\begin{tabular}{|c|c|c|c|c|c|c|c|c|}
\hline Element & $\mathrm{Zr}$ & $\mathrm{Sn}$ & $\mathrm{Fe}$ & $\mathrm{Cr}$ & $\mathrm{Ni}$ & $\mathrm{Hf}$ & $\mathrm{C}$ & $\mathrm{O}$ \\
\hline $\begin{array}{c}\text { Alpha- } \\
\text { annealed } \\
\text { Zircaloy-4 }\end{array}$ & $\mathrm{Bal}$ & 1.52 & 0.22 & 0.11 & $<.0035$ & $<0.008$ & 0.012 & 0.15 \\
\hline $\begin{array}{c}\text { Alpha- } \\
\text { annealed } \\
\text { Zircaloy-2 }\end{array}$ & $\mathrm{Bal}$ & 1.50 & 0.15 & 0.11 & 0.06 & 0.0035 & 0.0087 & 0.15 \\
\hline $\begin{array}{c}\text { Beta- } \\
\text { treated } \\
\text { Zircaloy-2 }\end{array}$ & Bal & 1.56 & 0.15 & 0.11 & 0.06 & 0.0055 & 0.0074 & 0.10 \\
\hline
\end{tabular}

Table 2. Summary of the irradiation conditions for the Zircaloy HFIR irradiations [4].

\begin{tabular}{|c|c|c|c|c|c|c|}
\hline $\begin{array}{c}\text { Irradiation } \\
\text { Capsule }\end{array}$ & $\begin{array}{c}\text { Design } \\
\text { Specimen } \\
\text { Irradiation } \\
\text { Temperature } \\
{ }^{\circ} C^{[1]}\end{array}$ & $\begin{array}{c}\text { True } \\
\text { Irradiation } \\
\text { Temperature } \\
\text { for } \\
\text { Temperature } \\
\text { Monitor } \\
\text { Analysis } \\
{ }^{\circ} \mathbf{C}^{[3]}\end{array}$ & $\begin{array}{l}\text { HFIR Cycle } \\
\text { Number }^{[2]}\end{array}$ & $\begin{array}{c}\text { Neutron } \\
\text { Flux } \\
{\left[\mathrm{X} 10^{18}\right.} \\
\mathrm{n} / \mathrm{m}^{2}-\mathrm{sec} \\
\mathrm{E}>1 \mathrm{MeV}]\end{array}$ & $\begin{array}{c}\text { Neutron } \\
\text { Fluence } \\
{\left[X 10^{24} \mathrm{n} / \mathrm{m}^{2}\right.} \\
\mathrm{E}>1 \mathrm{MeV}]\end{array}$ & $\begin{array}{c}\text { zirconium } \\
\text { dpa }\end{array}$ \\
\hline $\mathrm{SCl}-1$ & \multirow{5}{*}{$343^{\circ} \mathrm{C}$} & \multirow{5}{*}{$358^{\circ} \mathrm{C} \pm 20^{\circ} \mathrm{C}$} & 415 & 3.2 & 0.058 & 0.013 \\
\hline $\mathrm{SCl}-2$ & & & 415 & 3.2 & 1.10 & 0.25 \\
\hline $\mathrm{SCl}-3$ & & & 415 and 416 & 3.2 & 5.5 & 1.27 \\
\hline $\mathrm{SCl}-4$ & & & $415,416,417$ & 2.9 to 3.2 & 10.6 & 2.45 \\
\hline SCl-5 & & & $\begin{array}{c}414,415,416 \\
417,418\end{array}$ & 2.9 to 3.2 & 29.3 & 6.76 \\
\hline SCl-6,7 & $343^{\circ} \mathrm{C}$ & $312^{\circ} \mathrm{C} \pm 20^{\circ} \mathrm{C}$ & $\begin{array}{c}414,415,416 \\
417,418\end{array}$ & 2.9 to 3.2 & 29.6 & 6.83 \\
\hline
\end{tabular}

Notes:

1. The design irradiation temperature was the tensile specimen temperature objective for the irradiation test. The irradiation temperatures were generally within $\pm 20^{\circ} \mathrm{C}$ of the design temperature.

2. More details on the irradiation conditions are given in [4].

3. Actual specimen irradiation temperatures were determined from analysis of the $\mathrm{SiC}$ temperature monitors. 
Table 3. Summary of annealing conditions used for the recovery studies of alpha-annealed and beta-treated Zircaloy-4 and Zircaloy-2 following HFIR irradiations at $312^{\circ} \mathrm{C}$ to a nominal fluence of $29.6 \times 10^{24} \mathrm{n} / \mathrm{m}^{2}$.

\begin{tabular}{|c|c|c|c|c|c|c|c|c|}
\hline \multicolumn{9}{|c|}{ Temperature } \\
\hline & & $343^{\circ} \mathrm{C}$ & $371^{\circ} \mathrm{C}$ & $399^{\circ} \mathrm{C}$ & $427^{\circ} \mathrm{C}$ & $454^{\circ} \mathrm{C}$ & $482^{\circ} \mathrm{C}$ & $510^{\circ} \mathrm{C}$ \\
\hline & 1 & & & & Isothermal & & & \\
\hline & 5 & Isochrona & Isochronal & ||sochrona & Isochronal & Isochronal & Isochronal & Isochronal \\
\hline (hrs) & 10 & & & & Isothermal & & & \\
\hline & 50 & & & & Isothermal & & & \\
\hline & 100 & & & & Isothermal & & & \\
\hline & 500 & & & & Isothermal & & & \\
\hline
\end{tabular}

Notes:

1. Isochronal $=$ The conditions for the 7 specimens used for the isochronal anneal.

2. Isothermal $=$ The conditions for the 6 specimens used for the isothermal anneal. The cumulative annealing time for a particular specimen is given.

3. Non-irradiated control specimens were included in each series of Isochronal and Isothermal anneals.

Table 4. Summary of activation energy values determined from the $427^{\circ} \mathrm{C}$ isothermal annealing and isochronal annealing for the recovery of alpha-annealed and beta-treated Zircaloy-2 and Zircaloy-4 from this work.

\begin{tabular}{|c|c|c|}
\hline Alloy & $\begin{array}{c}\text { Neutron Fluence } \\
{\left[\begin{array}{cc}\mathrm{X} & 10^{25} \mathrm{n} / \mathrm{m}^{2}, \quad \\
\mathrm{MeV}]\end{array}\right.}\end{array}$ & $\begin{array}{c}\text { Activation Energy, } \mathrm{Q} \pm \\
\text { Standard Deviation } \\
{[\mathrm{J} / \mathrm{mol}]}\end{array}$ \\
\hline Alpha-annealed Zircaloy-2 & 2.96 & $40,200 \pm 10,000$ \\
\hline Beta-treated Zircaloy-2 & 2.96 & $84,900 \pm 39,200$ \\
\hline Alpha-annealed Zircaloy-4 & 2.96 & $102,200 \pm 48,500$ \\
\hline Beta-treated Zircaloy-4 & 2.96 & $41,600 \pm 17,200$ \\
\hline
\end{tabular}


Table 5. Summary of TEM characterization results from Alpha-annealed Zircaloy-4 postirradiated tensile specimens following irradiation testing at nominally $358^{\circ} \mathrm{C}$ to nominal fluences of $1.1,5.5,10.6$, and $29.3 \times 10^{24} \mathrm{n} / \mathrm{m}^{2}$ previously reported [4] compared with TEM following post-irradiation isochronal annealing to $399^{\circ} \mathrm{C} / 5$-hours and $510^{\circ} \mathrm{C} / 5$-hours, and one specimen from capsule $\mathrm{SCl}-5$ that was post-irradiated isothermal annealed at $427^{\circ} \mathrm{C}$ for 500 hours. Each line is the average for each specimen.

\begin{tabular}{|c|c|c|c|c|c|c|c|}
\hline \multirow[b]{2}{*}{ Capsule } & \multirow{2}{*}{$\begin{array}{c}\text { Neutron } \\
\text { Fluence } \\
{\left[X 10^{24} \mathrm{n} / \mathrm{m}^{2}\right.} \\
(\mathrm{E}>1 \mathrm{MeV})]\end{array}$} & \multicolumn{3}{|c|}{$<$ a loops } & \multicolumn{3}{|c|}{$<\mathrm{c}>$ loops } \\
\hline & & \begin{tabular}{|c|} 
Average \\
diameter \pm St. \\
deviation [nm]
\end{tabular} & $\begin{array}{c}\text { Max-Min } \\
\text { diameter } \\
{[\mathrm{nm}]}\end{array}$ & $\begin{array}{c}\text { Average Loop } \\
\text { number density } \\
\pm \text { St. deviation / } \\
\text { Max - Min } \\
{\left[\# / \mathrm{cm}^{3}\right]}\end{array}$ & $\begin{array}{c}\text { Average } \\
\text { diameter } \pm \\
\text { St. deviation } \\
{[\mathrm{nm}]}\end{array}$ & $\begin{array}{l}\text { Max - Min } \\
\text { diameter } \\
{[\mathrm{nm}]}\end{array}$ & $\begin{array}{c}\text { Loop number } \\
\text { density } \\
{\left[\# / \mathrm{cm}^{3}\right]}\end{array}$ \\
\hline $\mathrm{SCl}-2$ & 1.1 & $8.18 \pm 2.95$ & $\begin{array}{c}17.15- \\
1.26\end{array}$ & $\begin{array}{c}3.34 \times 10^{15} \\
\pm 1.44 \times 10^{15} \\
6.73-1.78 \\
\times 10^{15}\end{array}$ & $\mathrm{~N} / \mathrm{A}$ & $N / A$ & $\mathrm{~N} / \mathrm{A}$ \\
\hline $\mathrm{SCl}-3$ & 5.5 & $11.33 \pm 4.99$ & $\begin{array}{c}28.93- \\
3.24\end{array}$ & $\begin{array}{c}1.89 \times 10^{15} \\
\pm 1.29 \times 10^{15} \\
3.65-0.78 \\
\times 10^{15}\end{array}$ & N/A & $\mathrm{N} / \mathrm{A}$ & $\mathrm{N} / \mathrm{A}$ \\
\hline $\mathrm{SCl}-4$ & 10.6 & $5.70 \pm 2.40$ & $\begin{array}{c}16.02- \\
1.65\end{array}$ & $\begin{array}{c}12.21 \times 10^{15} \\
\pm 7.79 \times 10^{15} \\
23.40-5.69 \\
\times 10^{15}\end{array}$ & $\mathrm{~N} / \mathrm{A}$ & $\mathrm{N} / \mathrm{A}$ & N/A \\
\hline $\mathrm{SCl}-5$ & 29.3 & $9.65 \pm 5.09$ & $\begin{array}{c}34.45- \\
2.48\end{array}$ & \begin{tabular}{|c|}
$3.42 \times 10^{15}$ \\
$\pm 1.67 \times 10^{15} /$ \\
$6.02-1.95$ \\
$\times 10^{15}$
\end{tabular} & $136.7 \pm 67.2$ & $\begin{array}{c}289.0- \\
67.2\end{array}$ & $\begin{array}{c}1.37 \times 10^{13} \\
\pm 2.55 \times 10^{12} \\
/ \\
1.63-1.12 \\
\times 10^{13} \\
\end{array}$ \\
\hline \multicolumn{8}{|c|}{ This Specimen Was Post-irradiated Isochronal Annealed at $399^{\circ} \mathrm{C} / 5$-hours } \\
\hline $\mathrm{SCl}-7$ & 29.6 & $20.37 \pm 13.40$ & $\begin{array}{c}98.23- \\
5.00\end{array}$ & $\begin{array}{c}4.65 \times 10^{14} \\
\pm 2.01 \times 10^{14} \\
7.60-2.25 \\
\times 10^{14}\end{array}$ & $194.7 \pm 97.8$ & $\begin{array}{c}424.9- \\
48.7\end{array}$ & \begin{tabular}{|c|}
$4.60 \times 10^{13}$ \\
$\pm 3.62 \times 10^{13}$ \\
$/$ \\
$8.74-2.01$ \\
$\times 10^{13}$ \\
\end{tabular} \\
\hline \multicolumn{8}{|c|}{ This Specimen Was Post-irradiated Isochronal Annealed to $510^{\circ} \mathrm{C} / 5$-hours } \\
\hline $\mathrm{SCl}-7$ & 29.6 & $33.42 \pm 21.09$ & $\begin{array}{c}127.7- \\
10.29\end{array}$ & $\begin{array}{c}5.87 \times 10^{13} \\
\pm 2.10 \times 10^{13} \\
9.09-3.45 \\
\times 10^{13}\end{array}$ & $\begin{array}{c}232.6 \pm \\
147.8\end{array}$ & $\begin{array}{c}647.2- \\
101.0\end{array}$ & $5.93 \times 10^{12}$ \\
\hline \multicolumn{8}{|c|}{ This Specimen Was Post-irradiated Isothermal Annealed at $427^{\circ} \mathrm{C} / 500$-hours } \\
\hline $\mathrm{SCl}-5$ & 29.3 & $\mid 13.08 \pm 6.08$ & $\begin{array}{c}33.33- \\
3.29\end{array}$ & $\begin{array}{c}1.09 \times 10^{15} \\
\pm 0.55 \times 10^{15} / \\
1.47-0.70 \\
\times 10^{15}\end{array}$ & $\mid 175.6 \pm 76.4$ & $\begin{array}{c}361.1- \\
75.9\end{array}$ & \begin{tabular}{|c|}
$3.86 \times 10^{13}$ \\
$\pm 0.69 \times 10^{13}$ \\
$/$ \\
$4.35-3.37$ \\
$\times 10^{13}$ \\
\end{tabular} \\
\hline
\end{tabular}

Note: 1. "--" means the data were not measured.

2. N/A means the respective $<a>$ or $<c>$ loops were not observed. 
Table 6. Summary of TEM characterization results from Beta-treated Zircaloy-4 post-irradiated tensile specimens following irradiation testing at nominally $358^{\circ} \mathrm{C}$ to nominal fluences of 1.1 ,

$5.5,10.6$, and $29.3 \times 10^{24} \mathrm{n} / \mathrm{m}^{2}$ previously reported [4] compared with TEM following postirradiation isochronal annealing to $399^{\circ} \mathrm{C} / 5$-hours and $510^{\circ} \mathrm{C} / 5$-hours, and one specimen from capsule SCl-5 that was post-irradiated isothermal annealed at $427^{\circ} \mathrm{C}$ for 500 hours. Each line is the average for each specimen.

\begin{tabular}{|c|c|c|c|c|c|c|c|}
\hline \multirow[b]{2}{*}{ Capsule } & \multirow{2}{*}{\begin{tabular}{|c} 
Neutron \\
Fluence \\
{$\left[X 10^{24} \mathrm{n} / \mathrm{m}^{2}\right.$} \\
$(\mathrm{E}>1 \mathrm{MeV})]$
\end{tabular}} & \multicolumn{3}{|c|}{$<$ a $>$ loops } & \multicolumn{3}{|c|}{$<\mathrm{c}>$ loops } \\
\hline & & $\begin{array}{c}\text { Average } \\
\text { diameter } \pm \text { St. } \\
\text { deviation }[\mathrm{nm}]\end{array}$ & $\begin{array}{c}\text { Max-Min } \\
\text { diameter } \\
{[\mathrm{nm}]}\end{array}$ & $\begin{array}{c}\text { Average Loop } \\
\text { number } \\
\text { density } \pm \text { St. } \\
\text { deviation / } \\
\text { Max - Min } \\
{\left[\# / \mathrm{cm}^{3}\right]}\end{array}$ & $\begin{array}{c}\text { Average } \\
\text { diameter } \pm \\
\text { St. deviation } \\
{[\mathrm{nm}]}\end{array}$ & $\begin{array}{c}\text { Max - Min } \\
\text { diameter } \\
\text { [nm] }\end{array}$ & $\begin{array}{c}\text { Loop number } \\
\text { density } \\
{\left[\# / \mathrm{cm}^{3}\right]}\end{array}$ \\
\hline SCl-2 & 1.1 & $6.08 \pm 2.43$ & $\begin{array}{c}19.19- \\
0.84\end{array}$ & $\begin{array}{c}10.50 \times 10^{15} \\
\pm 2.31 \times 10^{15} / \\
13.9-8.89 \\
\times 10^{15}\end{array}$ & $\mathrm{~N} / \mathrm{A}$ & $N / A$ & N/A \\
\hline SCl-3 & 5.5 & $14.60 \pm 7.35$ & $\begin{array}{c}54.00- \\
4.26\end{array}$ & $\begin{array}{c}1.11 \times 10^{15} \\
\pm 0.24 \times 10^{15} \\
1.39-0.75 \\
\times 10^{15} \\
\end{array}$ & $48.4 \pm 27.0$ & $\begin{array}{c}54.00- \\
4.26\end{array}$ & $<2.02 \times 10^{12}$ \\
\hline SCl-4 & 10.6 & $10.47 \pm 4.75$ & $\begin{array}{c}29.62- \\
2.42\end{array}$ & $\begin{array}{c}2.89 \times 10^{15} \\
\pm 0.95 \times 10^{15} \\
3.95-1.75 \\
\times 10^{15}\end{array}$ & $171.2 \pm 76.6$ & $\begin{array}{c}309.6- \\
49.8\end{array}$ & $\begin{array}{c}6.60 \times 10^{12} \\
\pm 7.64 \times 10^{12} \\
/ \\
12.0-1.19 \\
\times 10^{12} \\
\end{array}$ \\
\hline SCl-5 & 29.3 & $10.09 \pm 4.75$ & $\begin{array}{c}33.51- \\
3.45\end{array}$ & $\begin{array}{c}2.14 \times 10^{15} \\
\pm 0.54 \times 10^{15} \\
2.76-1.47 \\
\times 10^{15}\end{array}$ & $159.2 \pm 89.7$ & $\begin{array}{c}337.7- \\
69.4\end{array}$ & $\begin{array}{c}8.04 \times 10^{12} \\
\pm 1.11 \times 10^{13} \\
/ \\
2.09-0.11 \\
\times 10^{13} \\
\end{array}$ \\
\hline SCl-5 & 29.3 & $8.02 \pm 3.28$ & $\begin{array}{c}24.85- \\
2.53\end{array}$ & $\begin{array}{c}4.67 \times 10^{15} \\
\pm 1.50 \times 10^{15} \\
6.35-3.16 \\
\times 10^{15}\end{array}$ & $\mathrm{~N} / \mathrm{A}^{[3]}$ & $N / A$ & $\mathrm{~N} / \mathrm{A}$ \\
\hline \multicolumn{8}{|c|}{ This Specimen Was Post-irradiated Isochronal Annealed at $399^{\circ} \mathrm{C} / 5$-hours } \\
\hline SCl-6 & 29.6 & $4.53 \pm 2.14$ & $\begin{array}{c}15.12- \\
1.58\end{array}$ & \begin{tabular}{|c|}
$5.24 \times 10^{15}$ \\
$\pm 0.42 \times 10^{15}$ \\
$5.54-4.94$ \\
$\times 10^{15}$ \\
\end{tabular} & $\mathrm{~N} / \mathrm{A}$ & $\mathrm{N} / \mathrm{A}$ & $\mathrm{N} / \mathrm{A}$ \\
\hline \multicolumn{8}{|c|}{ This Specimen Was Post-irradiated Isochronal Annealed to $510^{\circ} \mathrm{C} / 5$-hours } \\
\hline SCl-7 & 29.6 & $20.79 \pm 12.89$ & $\begin{array}{c}79.63- \\
5.62\end{array}$ & $\begin{array}{c}3.26 \times 10^{14} \\
\pm 0.98 \times 10^{14} \\
4.46-2.63 \\
\times 10^{14} \\
\end{array}$ & $\mid 155.1 \pm 78.1$ & $\begin{array}{c}301.3- \\
45.6\end{array}$ & $6.54 \times 10^{12}$ \\
\hline
\end{tabular}

Note: 1. "--" means the data were not measured.

2. N/A means the respective $<a>$ or $<c>$ loops were not observed. 
Table 7. Summary of TEM characterization results from Alpha-annealed Zircaloy-2 postirradiated tensile specimens following irradiation testing at nominally $358^{\circ} \mathrm{C}$ to nominal fluences of $1.1,5.5,10.6$, and $29.3 \times 10^{24} \mathrm{n} / \mathrm{m}^{2}$ previously reported [4] compared with TEM following post-irradiation isochronal annealing to $399^{\circ} \mathrm{C} / 5$-hours and $510^{\circ} \mathrm{C} / 5$-hours, and one specimen from capsule SCl-5 that was post-irradiated isothermal annealed at $427^{\circ} \mathrm{C}$ for 500 hours. Each line is the average for each specimen.

\begin{tabular}{|c|c|c|c|c|c|c|c|}
\hline \multirow[b]{2}{*}{ Capsule } & \multirow{2}{*}{$\begin{array}{c}\text { Neutron } \\
\text { Fluence } \\
{\left[X 10^{24} \mathrm{n} / \mathrm{m}^{2}\right.} \\
(\mathrm{E}>1 \mathrm{MeV})]\end{array}$} & \multicolumn{3}{|c|}{$<$ a $>$ loops } & \multicolumn{3}{|c|}{$<\mathrm{c}>$ loops } \\
\hline & & \begin{tabular}{|c|} 
Average \\
diameter \pm St. \\
deviation $[\mathrm{nm}]$
\end{tabular} & $\begin{array}{c}\text { Max - Min } \\
\text { diameter } \\
{[\mathrm{nm}]}\end{array}$ & $\begin{array}{c}\text { Average Loop } \\
\text { number } \\
\text { density } \pm \text { St. } \\
\text { deviation / } \\
\text { Max - Min } \\
{\left[\# / \mathrm{cm}^{3}\right]}\end{array}$ & $\begin{array}{c}\text { Average } \\
\text { diameter } \pm \\
\text { St. deviation } \\
{[\mathrm{nm}]}\end{array}$ & $\begin{array}{c}\text { Max - Min } \\
\text { diameter } \\
{[\mathrm{nm}]}\end{array}$ & $\begin{array}{c}\text { Loop number } \\
\text { density } \\
{\left[\# / \mathrm{cm}^{3}\right]}\end{array}$ \\
\hline $\mathrm{SCl}-2$ & 1.1 & $7.00 \pm 3.07$ & $\begin{array}{c}22.92- \\
0.95\end{array}$ & $\begin{array}{c}2.61 \times 10^{15} \\
\pm 0.67 \times 10^{15} \\
3.35-2.05 \\
\times 10^{15}\end{array}$ & $\mathrm{~N} / \mathrm{A}$ & N/A & [3] \\
\hline $\mathrm{SCl}-3$ & 5.5 & $7.17 \pm 2.99$ & $\begin{array}{c}20.21- \\
1.99\end{array}$ & $\begin{array}{c}8.25 \times 10^{15} \\
\pm 2.16 \times 10^{15} / \\
10.1-4.86 \\
\times 10^{15}\end{array}$ & N/A & N/A & $\mathrm{N} / \mathrm{A}$ \\
\hline $\mathrm{SCl}-4$ & 10.6 & $7.46 \pm 2.53$ & $\begin{array}{c}14.56- \\
2.53\end{array}$ & $\begin{array}{c}3.60 \times 10^{15} \\
\pm 0.44 \times 10^{15} / \\
4.00-3.13 \\
\times 10^{15}\end{array}$ & $\begin{array}{c}169.3 \pm \\
42.69\end{array}$ & $\begin{array}{c}268.2- \\
111.6\end{array}$ & $\begin{array}{c}2.93 \times 10^{12} \\
\pm 2.43 \times 10^{12} \\
5.34-0.48 \\
\times 10^{12} \\
\end{array}$ \\
\hline $\mathrm{SCl}-5$ & 29.3 & $\mid 21.53 \pm 15.99$ & $\begin{array}{c}82.69- \\
4.39\end{array}$ & $\begin{array}{c}3.81 \times 10^{14} \\
\pm 1.02 \times 10^{14} / \\
4.79-2.62 \\
\times 10^{14}\end{array}$ & $\begin{array}{c}175.6 \pm \\
105.5\end{array}$ & $\begin{array}{c}432.0- \\
59.6\end{array}$ & $\begin{array}{c}2.21 \times 10^{12} \\
\pm 1.81 \times 10^{12} \\
4.85-1.02 \\
\times 10^{12}\end{array}$ \\
\hline \multicolumn{8}{|c|}{ This Specimen Was Post-irradiated Isochronal Annealed at $399^{\circ} \mathrm{C} / 5$-hours } \\
\hline SCl-7 & 29.6 & $10.23 \pm 5.43$ & $\begin{array}{c}34.53- \\
2.80\end{array}$ & $\begin{array}{c}1.85 \times 10^{15} \\
\pm 0.39 \times 10^{15} / \\
2.35-1.21 \\
\times 10^{15}\end{array}$ & $131.2 \pm 73.8$ & $\begin{array}{c}300.7- \\
55.7\end{array}$ & $\begin{array}{c}4.46 \times 10^{12} \\
\pm 6.06 \times 10^{12} \\
8.74-0.167 \\
\times 10^{12} \\
\end{array}$ \\
\hline \multicolumn{8}{|c|}{ This Specimen Was Post-irradiated Isochronal Annealed to $510^{\circ} \mathrm{C} / 5$-hours } \\
\hline SCl-6 & 29.6 & $20.68 \pm 12.20$ & $\begin{array}{c}75.85- \\
4.24\end{array}$ & $\begin{array}{c}3.31 \times 10^{14} \\
\pm 1.03 \times 10^{14} \\
4.69-2.18 \\
\times 10^{14} \\
\end{array}$ & $\begin{array}{c}208.9 \pm \\
102.8\end{array}$ & $\begin{array}{c}500.6- \\
88.4\end{array}$ & $\begin{array}{c}2.27 \times 10^{12} \\
\pm 1.84 \times 10^{12} \\
4.37-0.984 \\
\times 10^{12} \\
\end{array}$ \\
\hline \multicolumn{8}{|c|}{ This Specimen Was Post-irradiated Isothermal Annealed at $427^{\circ} \mathrm{C} / 500$-hours } \\
\hline $\mathrm{SCl}-5$ & 29.3 & $13.84 \pm 7.26$ & $\begin{array}{c}57.27- \\
2.57\end{array}$ & $\begin{array}{c}1.34 \times 10^{15} \\
\pm 0.53 \times 10^{15} / \\
1.74-0.76 \\
\times 10^{15}\end{array}$ & $\begin{array}{c}254.7 \pm \\
99.37\end{array}$ & $\begin{array}{c}424.2- \\
121.1\end{array}$ & $\begin{array}{c}0.957 \times 10^{12} \\
\pm .061 \times 10^{12} \\
1.00-0.914 \\
\times 10^{12} \\
\end{array}$ \\
\hline
\end{tabular}

Note: 1. "--" means the data were not measured.

2. N/A means the respective $<\mathrm{a}>$ or $<\mathrm{c}>$ loops were not observed.

3. The observation of $<c>$ loops was possible, but the evidence was inconclusive. 
Table 8. Summary of TEM characterization results from Beta-treated Zircaloy-2 post-irradiated tensile specimens following irradiation testing at nominally $358^{\circ} \mathrm{C}$ to nominal fluences of 1.1 ,

$5.5,10.6$, and $29.3 \times 10^{24} \mathrm{n} / \mathrm{m}^{2}$ previously reported [4] compared with TEM following postirradiation isochronal annealing to $399^{\circ} \mathrm{C} / 5$-hours and $510^{\circ} \mathrm{C} / 5$-hours, and one specimen from capsule $\mathrm{SCl}-5$ that was post-irradiated isothermal annealed at $427^{\circ} \mathrm{C}$ for 500 hours. Each line is the average for each specimen.

\begin{tabular}{|c|c|c|c|c|c|c|c|}
\hline \multirow[b]{2}{*}{ Capsule } & \multirow{2}{*}{\begin{tabular}{|c} 
Neutron \\
Fluence \\
{$\left[X 10^{24} \mathrm{n} / \mathrm{m}^{2}\right.$} \\
$(\mathrm{E}>1 \mathrm{MeV})]$
\end{tabular}} & \multicolumn{3}{|c|}{$<$ a $>$ loops } & \multicolumn{3}{|c|}{$<\mathrm{c}>$ loops } \\
\hline & & $\begin{array}{c}\text { Average } \\
\text { diameter } \pm \text { St. } \\
\text { deviation }[\mathrm{nm}]\end{array}$ & $\begin{array}{c}\text { Max-Min } \\
\text { diameter } \\
{[\mathrm{nm}]}\end{array}$ & $\begin{array}{c}\text { Average Loop } \\
\text { number } \\
\text { density } \pm \text { St. } \\
\text { deviation / } \\
\text { Max - Min } \\
{\left[\# / \mathrm{cm}^{3}\right]}\end{array}$ & $\begin{array}{c}\text { Average } \\
\text { diameter } \pm \\
\text { St. deviation } \\
{[\mathrm{nm}]}\end{array}$ & $\begin{array}{c}\text { Max-Min } \\
\text { diameter } \\
\text { [nm] }\end{array}$ & $\begin{array}{c}\text { Loop number } \\
\text { density } \\
{\left[\# / \mathrm{cm}^{3}\right]}\end{array}$ \\
\hline SCl-2 & 1.1 & $9.24 \pm 3.74$ & $\begin{array}{c}31.15- \\
3.05\end{array}$ & $\begin{array}{c}1.29 \times 10^{15} \\
\pm 0.43 \times 10^{15} / \\
1.86-0.94 \\
\times 10^{15}\end{array}$ & $\mathrm{~N} / \mathrm{A}$ & $\mathrm{N} / \mathrm{A}$ & $\mathrm{N} / \mathrm{A}$ \\
\hline $\mathrm{SCl}-3$ & 5.5 & $9.30 \pm 3.29$ & $\begin{array}{c}18.77- \\
3.01\end{array}$ & $\begin{array}{c}5.45 \times 10^{15} \\
\pm 0.74 \times 10^{15} \\
6.06-4.51 \\
\times 10^{15}\end{array}$ & [3] & $\mathrm{N} / \mathrm{A}$ & [3] \\
\hline $\mathrm{SCl}-4$ & 10.6 & $7.92 \pm 3.22$ & $\begin{array}{c}22.73- \\
2.28\end{array}$ & $\begin{array}{c}3.66 \times 10^{15} \\
\pm 0.68 \times 10^{15} \\
4.27-2.50 \\
\times 10^{15}\end{array}$ & $\mathrm{~N} / \mathrm{A}$ & $\mathrm{N} / \mathrm{A}$ & $\mathrm{N} / \mathrm{A}$ \\
\hline SCl-5 & 29.3 & $18.18 \pm 8.41$ & $\begin{array}{c}65.09- \\
6.36\end{array}$ & $\begin{array}{c}5.31 \times 10^{14} \\
\pm 3.75 \times 10^{14} \\
10.9-3.03 \\
\times 10^{14} \\
\end{array}$ & $220.5 \pm 84.7$ & $\begin{array}{c}378.0- \\
146.0\end{array}$ & $\begin{array}{c}7.76 \times 10^{12} \\
\pm 3.90 \times 10^{12} / \\
10.5-4.98 \\
\times 10^{12} \\
\end{array}$ \\
\hline \multicolumn{8}{|c|}{ This Specimen Was Post-irradiated Isochronal Annealed at $399^{\circ} \mathrm{C} / 5$-hours } \\
\hline SCl-7 & 29.6 & $26.98 \pm 18.99$ & $\begin{array}{c}118.9- \\
5.00\end{array}$ & \begin{tabular}{|c}
$2.31 \times 10^{14}$ \\
$\pm 0.39 \times 10^{14}$ \\
$2.77-1.88$ \\
$\times 10^{14}$
\end{tabular} & $200.0 \pm 96.6$ & $\begin{array}{c}513.0- \\
70.8\end{array}$ & $\begin{array}{c}3.80 \times 10^{12} \\
\pm 2.45 \times 10^{12} / \\
6.05-0.167 \\
\times 10^{12}\end{array}$ \\
\hline \multicolumn{8}{|c|}{ This Specimen Was Post-irradiated Isochronal Annealed to $510^{\circ} \mathrm{C} / 5$-hours } \\
\hline SCl-7 & 29.6 & $18.96 \pm 12.93$ & $\begin{array}{c}102.7- \\
4.41\end{array}$ & \begin{tabular}{|c|}
$3.55 \times 10^{14}$ \\
$\pm 1.54 \times 10^{14}$ \\
$5.53-2.12$ \\
$\times 10^{14}$ \\
\end{tabular} & $175.7 \pm 99.2$ & $\begin{array}{c}472.5- \\
39.8\end{array}$ & $\begin{array}{c}7.45 \times 10^{12} \\
\pm 12.4 \times 10^{12} / \\
26.1-0.88 \\
\times 10^{12} \\
\end{array}$ \\
\hline \multicolumn{8}{|c|}{ This Specimen Was Post-irradiated Isothermal Annealed at $427^{\circ} \mathrm{C} / 500$-hours } \\
\hline SCl-5 & 29.3 & $21.50 \pm 10.77$ & $\begin{array}{c}74.00- \\
4.47\end{array}$ & $\begin{array}{c}4.25 \times 10^{14} \\
\pm 0.821 \times 10^{14} \\
/ / \\
5.41-3.45 \\
\times 10^{14}\end{array}$ & $\begin{array}{c}195.1 \pm \\
105.2\end{array}$ & $\begin{array}{c}446.8- \\
50.2\end{array}$ & $\begin{array}{c}4.34 \times 10^{12} \\
\pm 2.32 \times 10^{12} / \\
7.00-2.68 \\
\times 10^{12}\end{array}$ \\
\hline
\end{tabular}

Note: 1. "--" means the data were not measured.

2. N/A means the respective $<$ a $>$ or $<c>$ loops were not observed.

3. Conclusive evidence of $\langle\mathrm{c}>$ loops were observed, but quantitative measurements were not performed. 


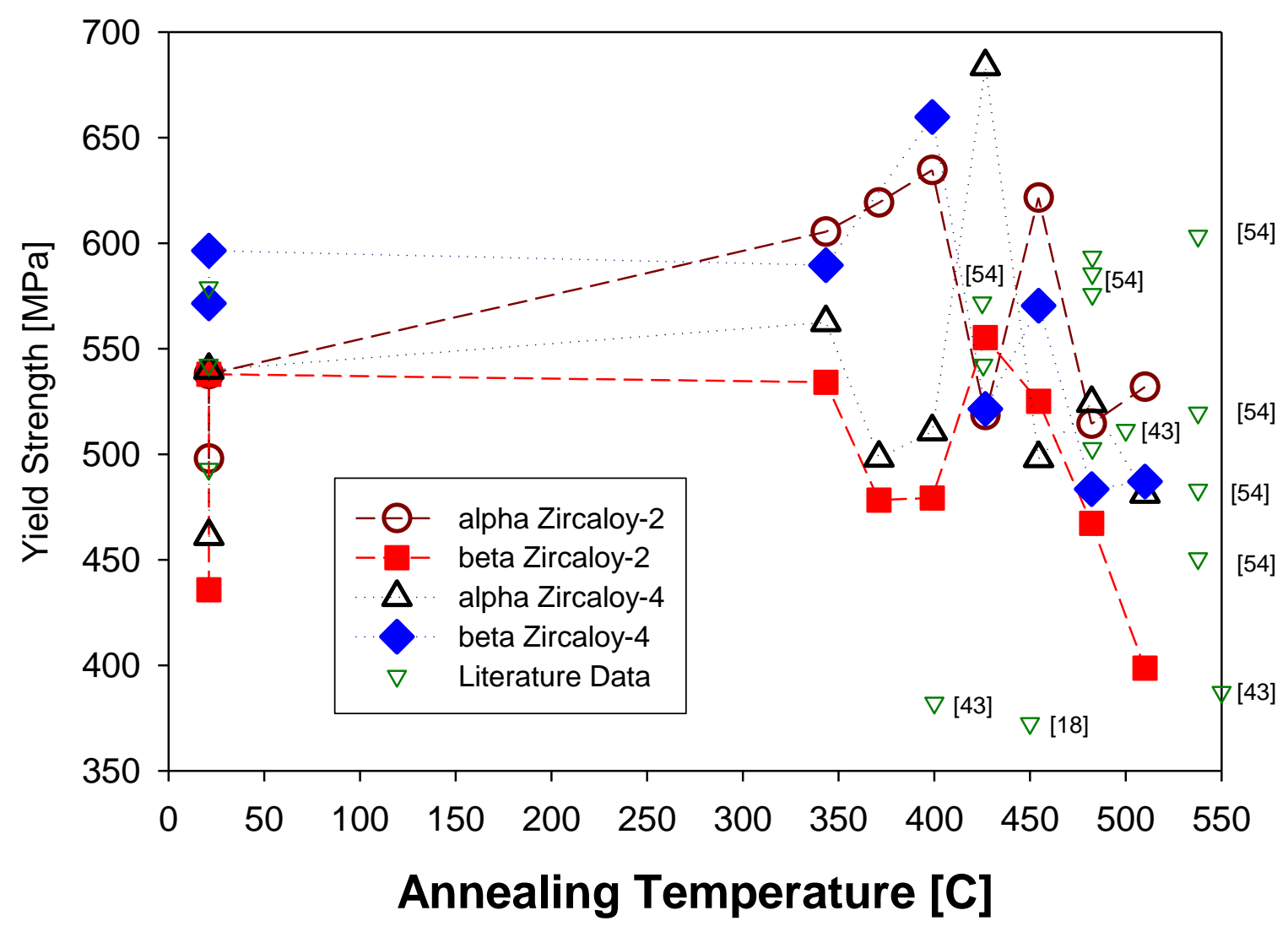

(a)

Figure 1. Comparison of tensile data for the post-irradiated isochronal annealing series for Zircaloy irradiated at nominally $312^{\circ} \mathrm{C}$ : (a) $0.2 \%$ yield strength compared with literature data for annealing times of 1 -hour or less $[18,45,56]$ for annealing times of 1 -hour or less with the label for the literature data given, (b) irradiation hardening data $\left(\Delta \sigma_{Y S}=\sigma_{Y S}(\right.$ irad $)-\sigma_{Y S}($ non-irad $\left.)\right)$ compared with literature data [58], (c) total elongation [56], and (d) uniform elongation [56]. The results at the annealing temperature of nominally $21^{\circ} \mathrm{C}$ are for previously report data for as-irradiated material [4]. 


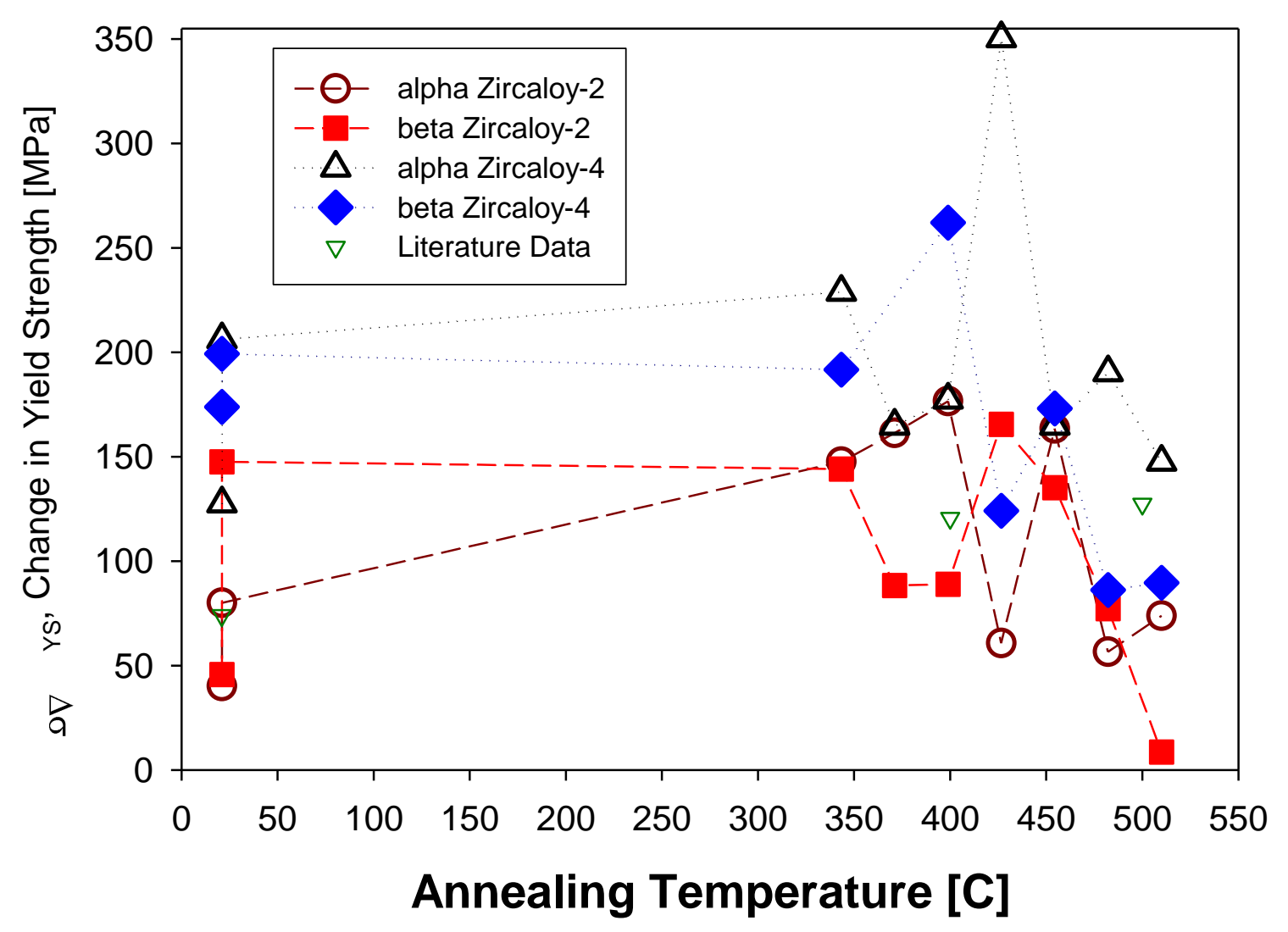

(b)

Figure 1. (continued) Comparison of tensile data for the post-irradiated isochronal annealing series for Zircaloy irradiated at nominally $312^{\circ} \mathrm{C}$ : (a) $0.2 \%$ yield strength compared with literature data for annealing times of 1 -hour or less [18,45,56] for annealing times of 1 -hour or less with the label for the literature data given, (b) irradiation hardening data $\left(\Delta \sigma_{\mathrm{YS}}=\sigma_{\mathrm{YS}}(\right.$ irad $)-\sigma_{\mathrm{YS}}($ non-irad) $)$ compared with literature data [58], (c) total elongation [56], and (d) uniform elongation [56]. The results at the annealing temperature of nominally $21^{\circ} \mathrm{C}$ are for previously report data for as-irradiated material [4]. 


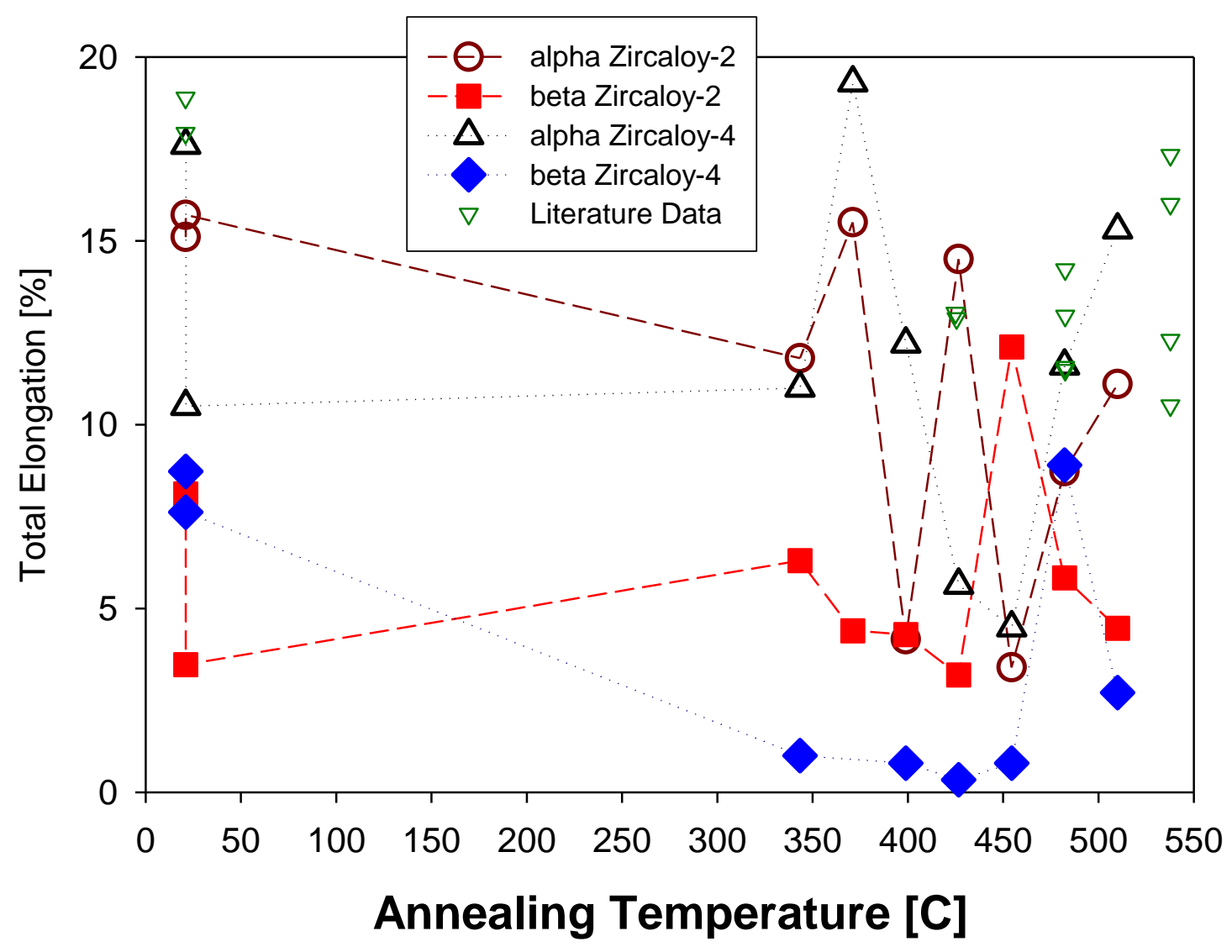

(c)

Figure 1. (continued) Comparison of tensile data for the post-irradiated isochronal annealing series for Zircaloy irradiated at nominally $312^{\circ} \mathrm{C}$ : (a) $0.2 \%$ yield strength compared with literature data for annealing times of 1 -hour or less [18,45,56] for annealing times of 1 -hour or less with the label for the literature data given, (b) irradiation hardening data $\left(\Delta \sigma_{Y S}=\sigma_{Y S}(\right.$ irad $)-\sigma_{Y S}($ non-irad $\left.)\right)$ compared with literature data [58], (c) total elongation [56], and (d) uniform elongation [56]. The results at the annealing temperature of nominally $21^{\circ} \mathrm{C}$ are for previously report data for as-irradiated material [4]. 


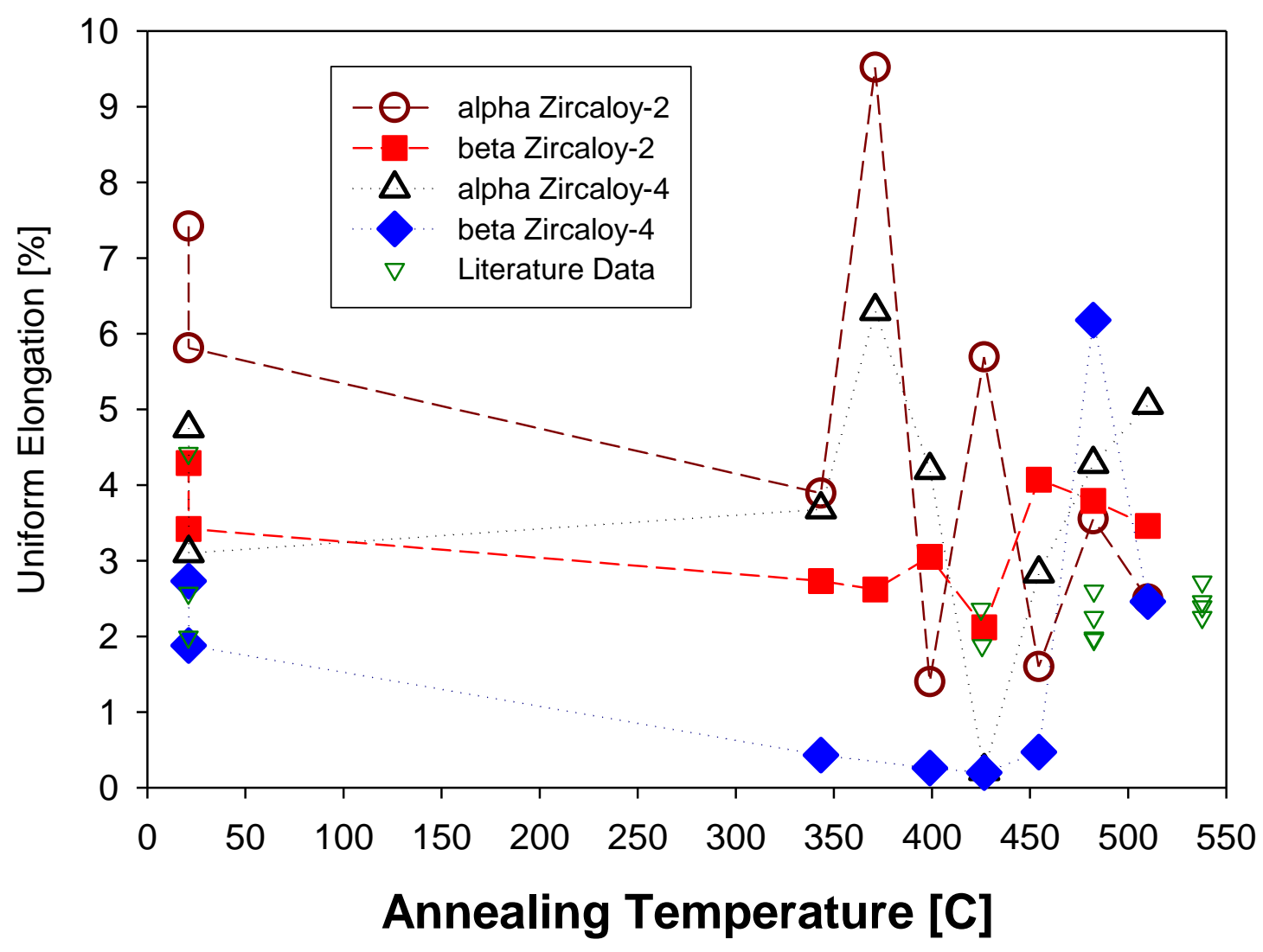

(d)

Figure 1. (continued) Comparison of tensile data for the post-irradiated isochronal annealing series for Zircaloy irradiated at nominally $312^{\circ} \mathrm{C}$ : (a) $0.2 \%$ yield strength compared with literature data for annealing times of 1 -hour or less [18,45,56] for annealing times of 1 -hour or less with the label for the literature data given, (b) irradiation hardening data $\left(\Delta \sigma_{Y S}=\sigma_{Y S}(\right.$ irad $)-\sigma_{Y S}($ non-irad) $)$ compared with literature data [58], (c) total elongation [56], and (d) uniform elongation [56]. The results at the annealing temperature of nominally $21^{\circ} \mathrm{C}$ are for previously report data for as-irradiated material [4]. 


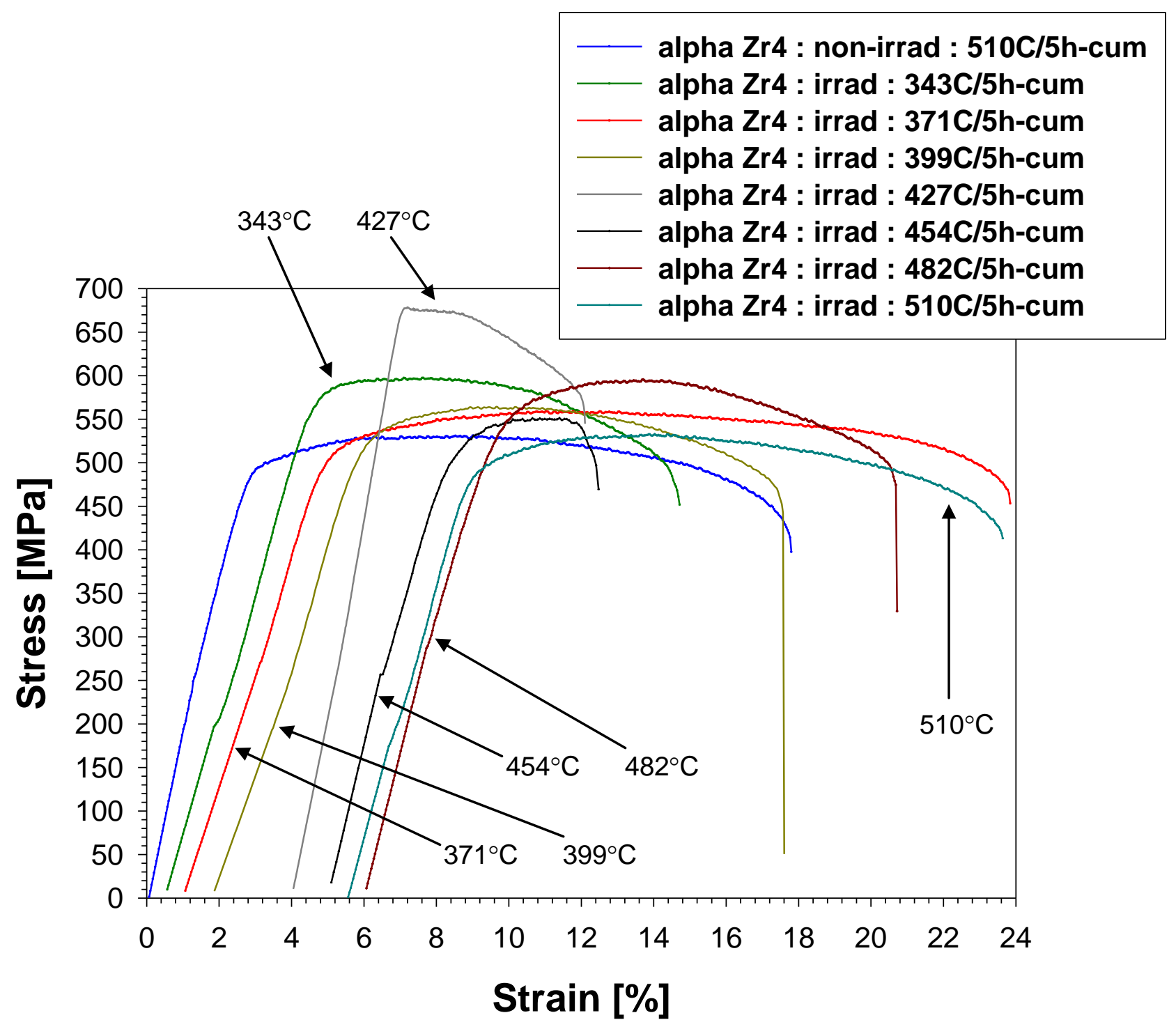

(a)

Figure 2. Summary plot of engineering stress-strain curves for the non-irradiated and postirradiated isochronal annealing series for Zircaloy irradiated at nominally $312^{\circ} \mathrm{C}$ for: (a) alphaannealed Zircaloy-4, (b) beta-treated Zircaloy-4 (no results are plotted for the $371^{\circ} \mathrm{C}$ isochronal anneal as this specimen was fractured during handling prior to testing), (c) alpha-annealed Zircaloy-2, and (d) beta-treated Zircaloy-2. The stress-strain curves were determined from the load versus actuator displacement with no correction made for compliance of the load frame. The curves were purposely off-set from the origin by strain with respect to increasing fluence. The isochronal anneal temperatures are identified. 


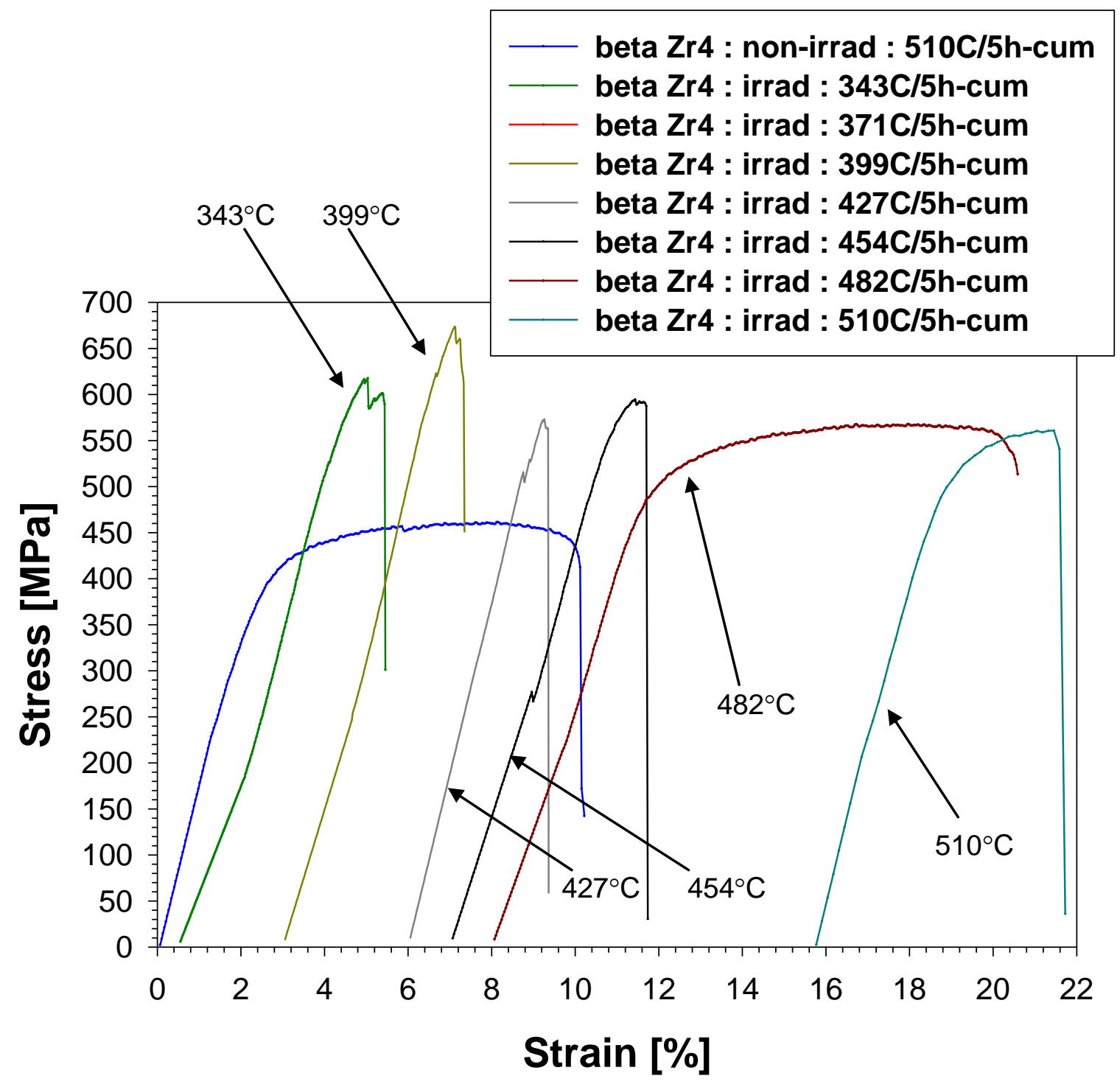

(b)

Figure 2. (continued) Summary plot of engineering stress-strain curves for the non-irradiated and post-irradiated isochronal annealing series for Zircaloy irradiated at nominally $312^{\circ} \mathrm{C}$ for: (a) alpha-annealed Zircaloy-4, (b) beta-treated Zircaloy-4 (no results are plotted for the $371^{\circ} \mathrm{C}$ isochronal anneal as this specimen was fractured during handling prior to testing), (c) alpha-annealed Zircaloy2, and (d) beta-treated Zircaloy-2. The stress-strain curves were determined from the load versus actuator displacement with no correction made for compliance of the load frame. The curves were purposely off-set from the origin by strain with respect to increasing fluence. The isochronal anneal temperatures are identified. 


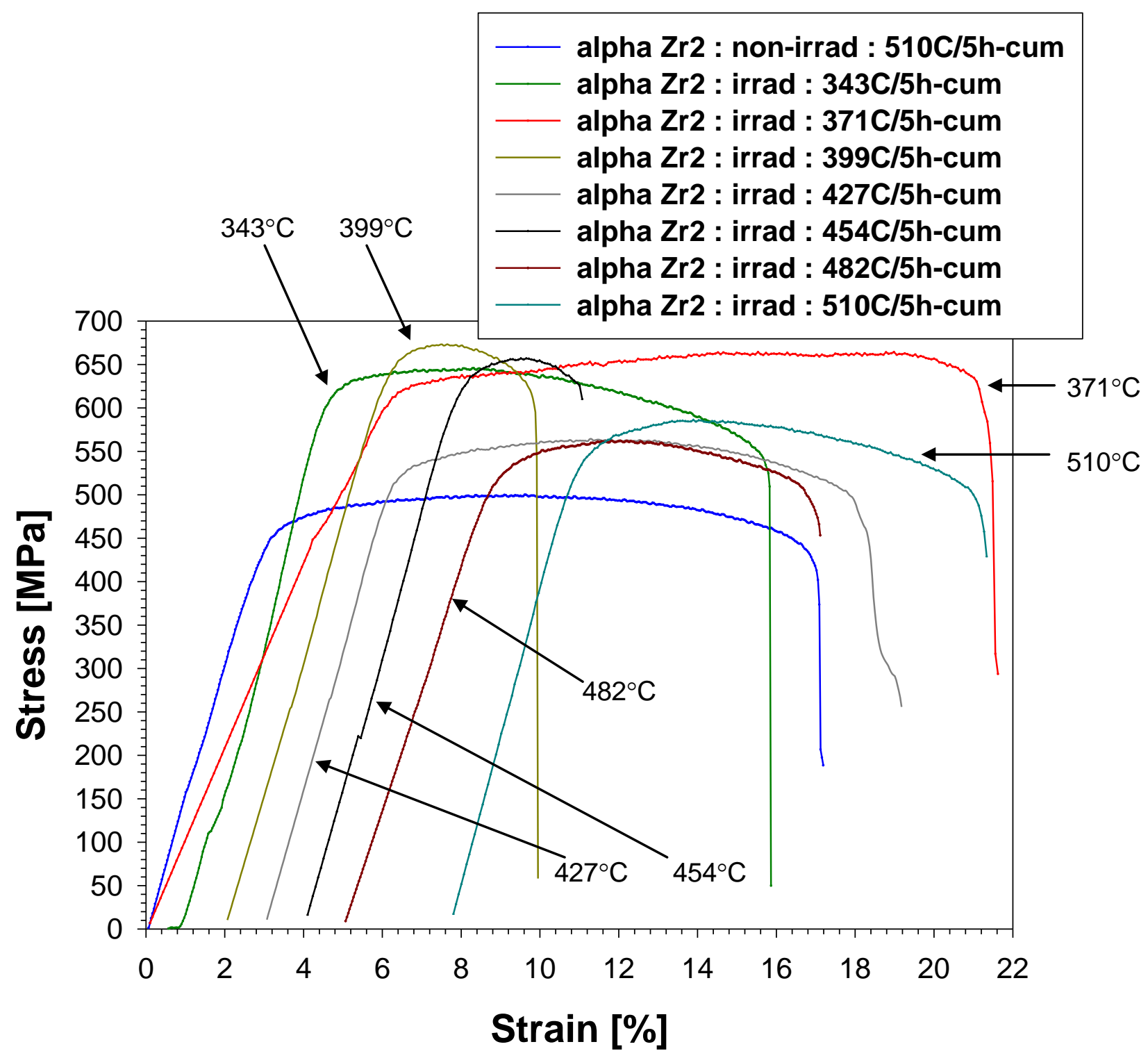

(c)

Figure 2. (continued) Summary plot of engineering stress-strain curves for the non-irradiated and post-irradiated isochronal annealing series for Zircaloy irradiated at nominally $312^{\circ} \mathrm{C}$ for: (a) alpha-annealed Zircaloy-4, (b) beta-treated Zircaloy-4 (no results are plotted for the $371^{\circ} \mathrm{C}$ isochronal anneal as this specimen was fractured during handling prior to testing), (c) alpha-annealed Zircaloy2, and (d) beta-treated Zircaloy-2. The stress-strain curves were determined from the load versus actuator displacement with no correction made for compliance of the load frame. The curves were purposely off-set from the origin by strain with respect to increasing fluence. The isochronal anneal temperatures are identified. 


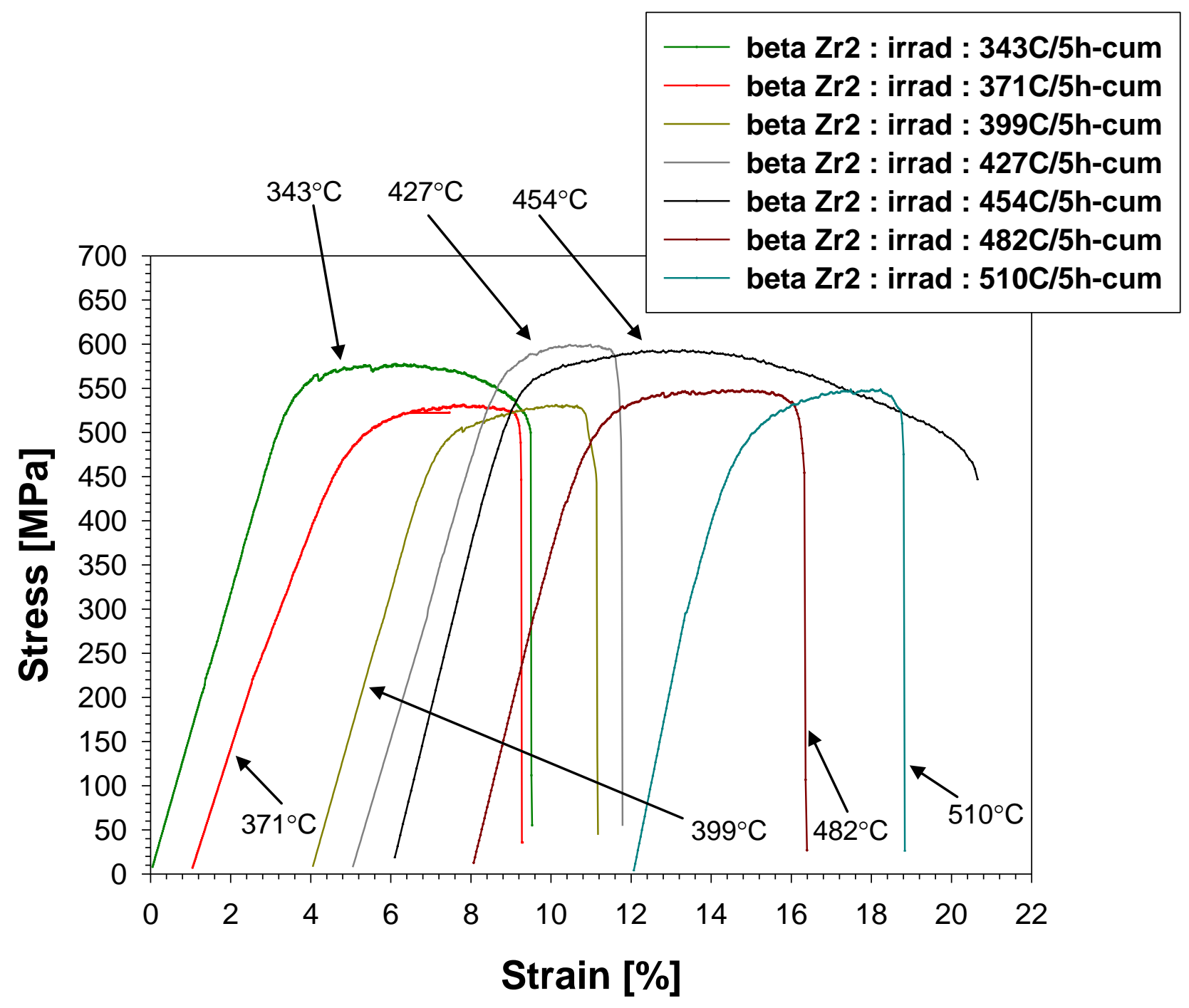

(d)

Figure 2. (continued) Summary plot of engineering stress-strain curves for the non-irradiated and post-irradiated isochronal annealing series for Zircaloy irradiated at nominally $312^{\circ} \mathrm{C}$ for: (a) alpha-annealed Zircaloy-4, (b) beta-treated Zircaloy-4 (no results are plotted for the $371^{\circ} \mathrm{C}$ isochronal anneal as this specimen was fractured during handling prior to testing), (c) alpha-annealed Zircaloy2 , and (d) beta-treated Zircaloy-2. The stress-strain curves were determined from the load versus actuator displacement with no correction made for compliance of the load frame. The curves were purposely off-set from the origin by strain with respect to increasing fluence. The isochronal anneal temperatures are identified. 


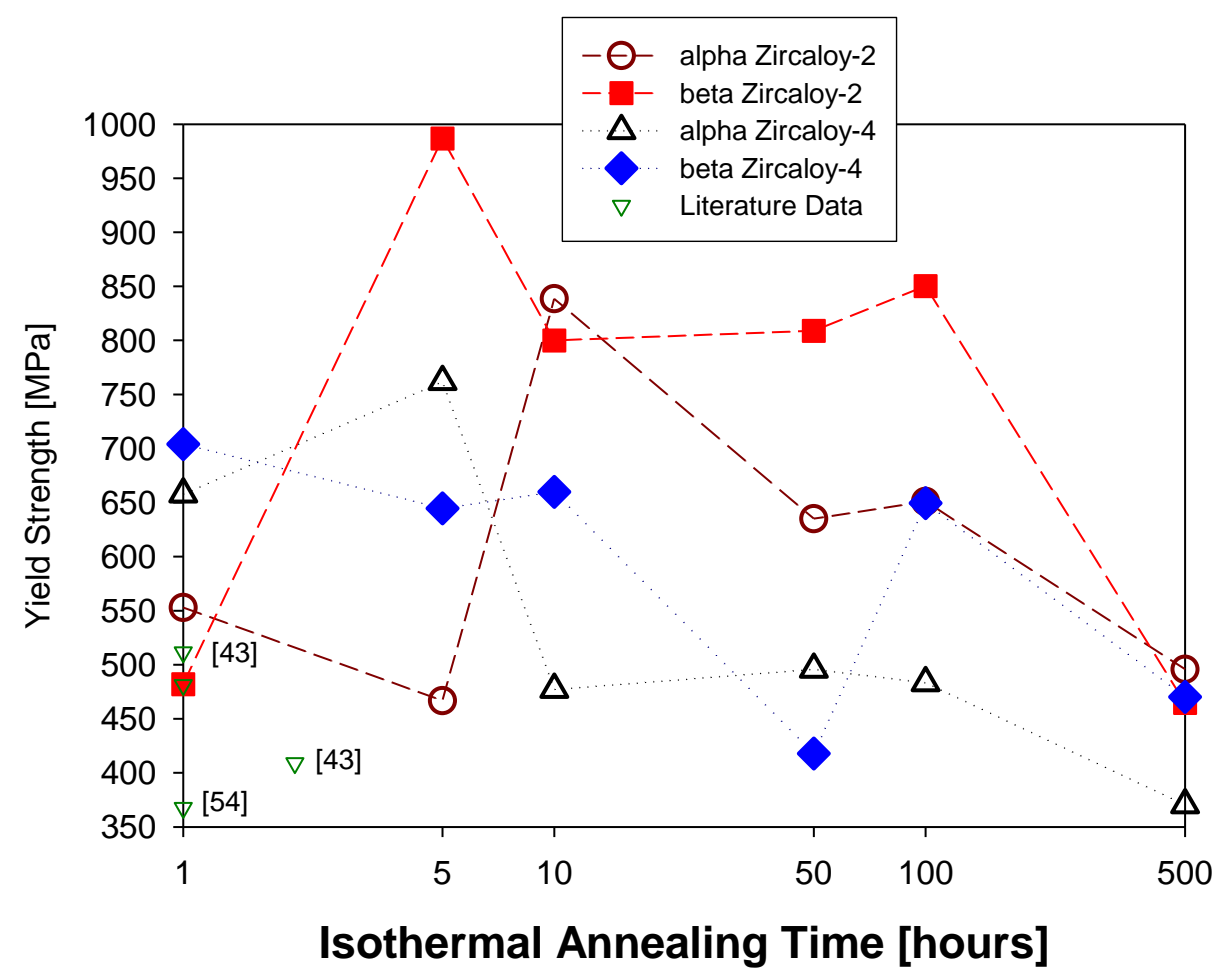

Page 45

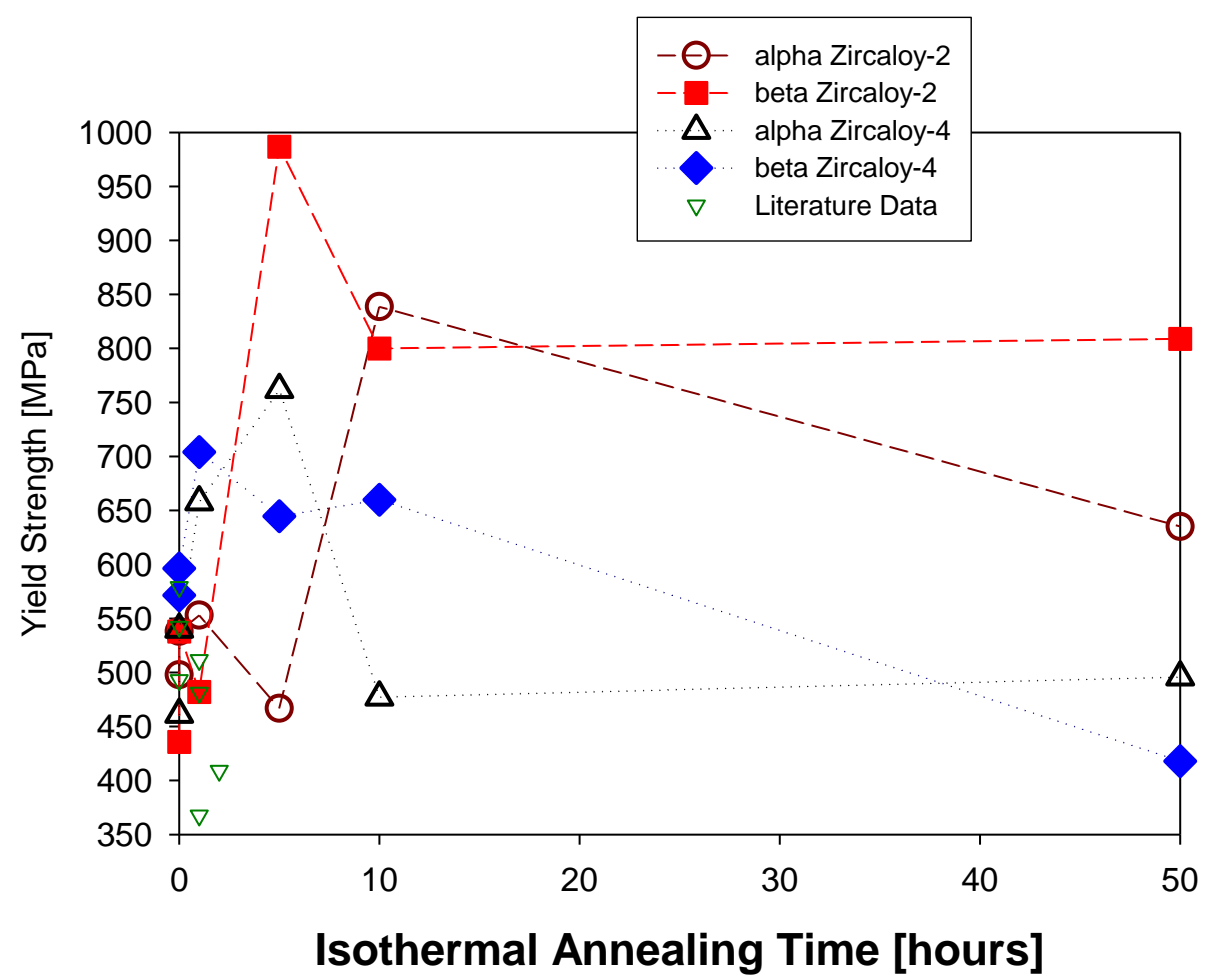

Figure 3. Comparison of tensile data for the post-irradiated isothermal annealing at $427^{\circ} \mathrm{C}$ for Zircaloy irradiated at nominally $312^{\circ} \mathrm{C}$ for compared with literature data for isothermal annealing at $427^{\circ} \mathrm{C}$ to $500^{\circ} \mathrm{C}[45,56]$ : (a) $0.2 \%$ yield strength with time shown on log scale and time from $0 \mathrm{~h}$ to $50 \mathrm{~h}$ with a label added for the literature data, (b) irradiation hardening data $\left(\Delta \sigma_{Y S}=\sigma_{Y S}(\right.$ irad $)-\sigma_{Y S}$ (nonirad)) where there is not literature data, (c) total elongation, and (d) uniform elongation. The results at the annealing temperature of nominally $21^{\circ} \mathrm{C}$ are for previously report data for as-irradiated material [4]. 


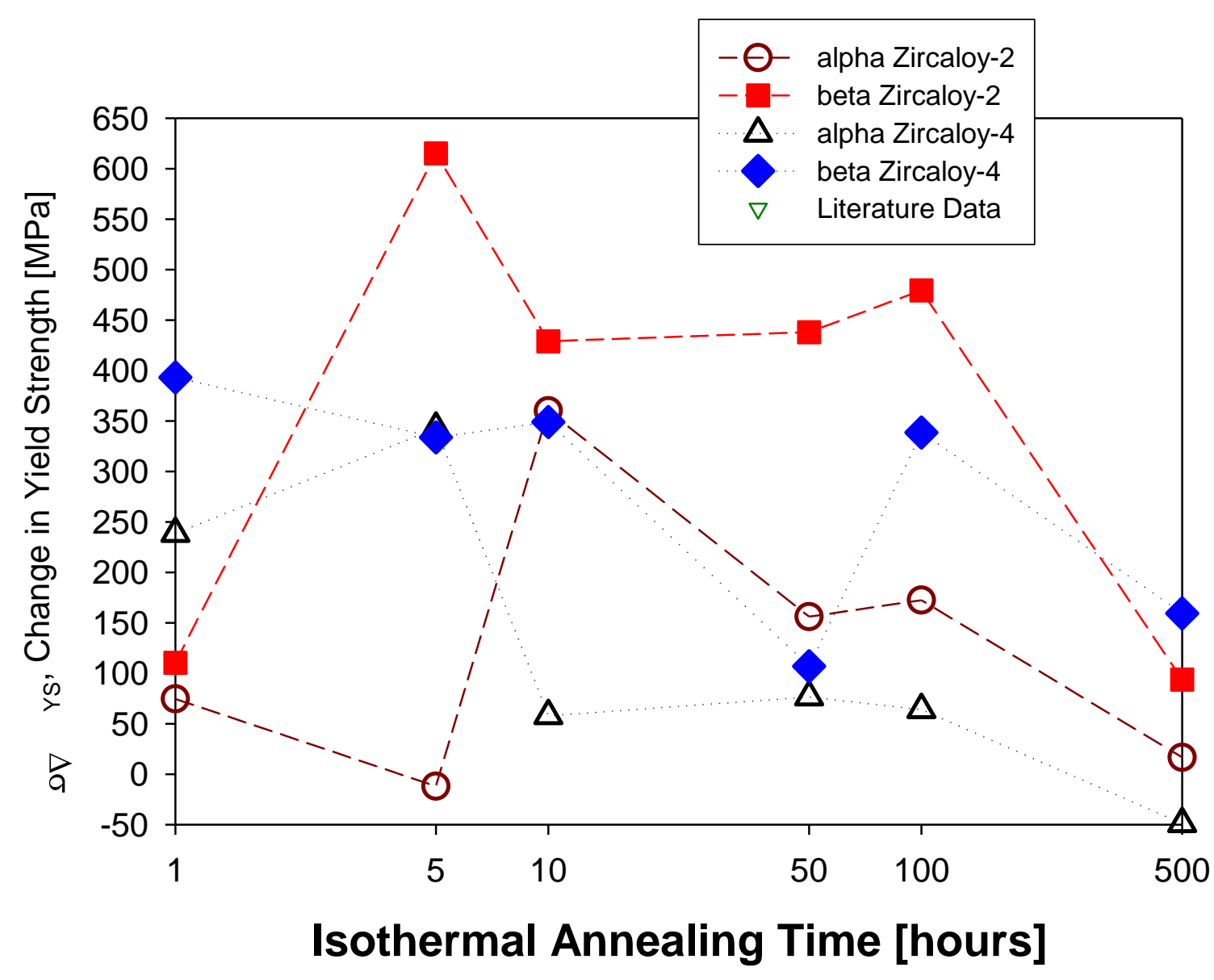

(b)

Figure 3. (continued) Comparison of tensile data for the post-irradiated isothermal annealing at $427^{\circ} \mathrm{C}$ for Zircaloy irradiated at nominally $312^{\circ} \mathrm{C}$ for compared with literature data for isothermal annealing at $427^{\circ} \mathrm{C}$ to $500^{\circ} \mathrm{C}[45,56]$ : (a) $0.2 \%$ yield strength with time shown on log scale and time from $0 \mathrm{~h}$ to $50 \mathrm{~h}$ with a label added for the literature data, $(\mathrm{b})$ irradiation hardening data $\left(\Delta \sigma_{\mathrm{YS}}=\right.$ $\sigma_{Y S}\left(\right.$ irad) $-\sigma_{Y S}($ non-irad)) where there is not literature data, (c) total elongation, and (d) uniform elongation. The results at the annealing temperature of nominally $21^{\circ} \mathrm{C}$ are for previously report data for as-irradiated material [4]. 


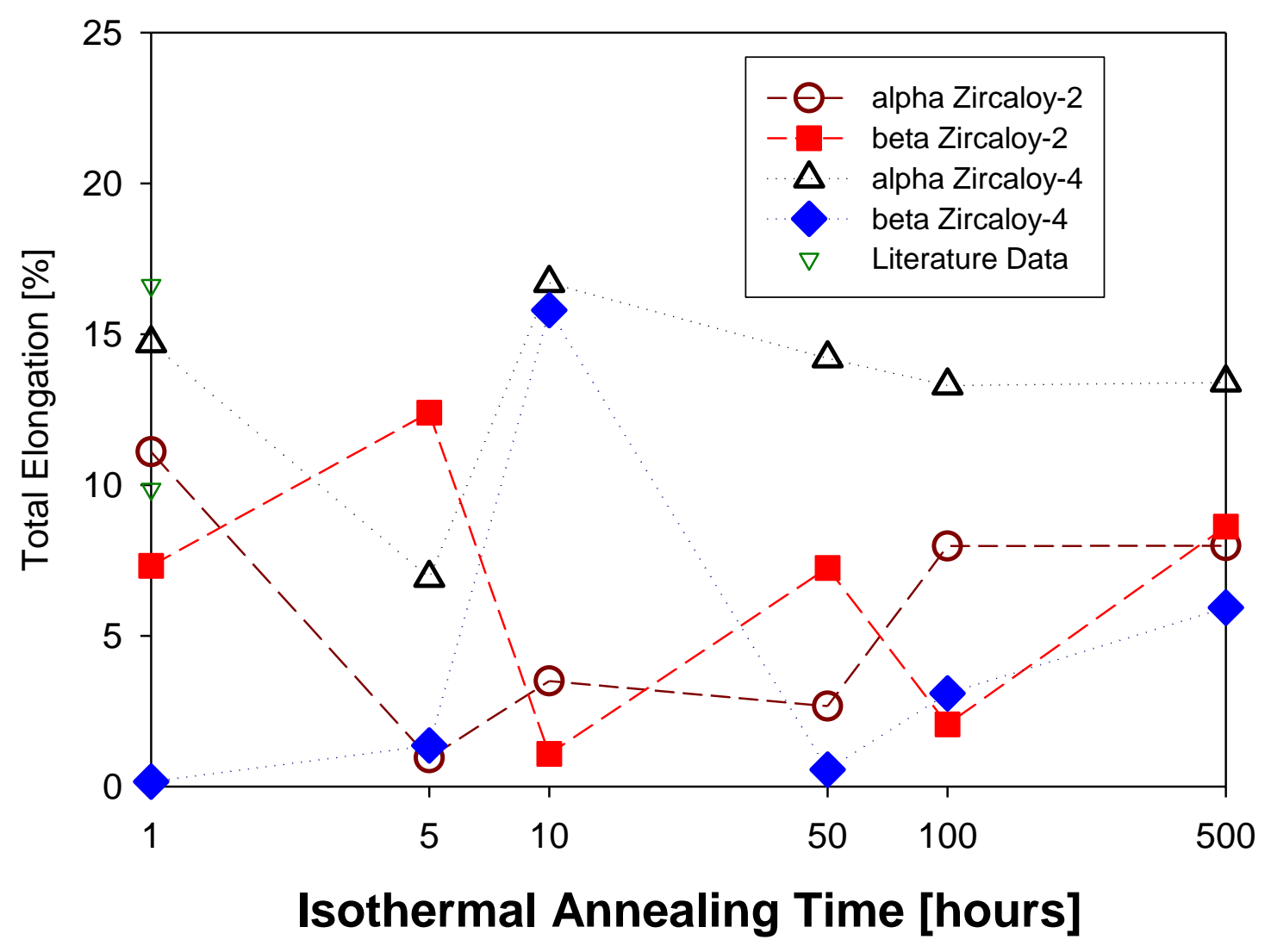

(c)

Figure 3. (continued) Comparison of tensile data for the post-irradiated isothermal annealing at $427^{\circ} \mathrm{C}$ for Zircaloy irradiated at nominally $312^{\circ} \mathrm{C}$ for compared with literature data for isothermal annealing at $427^{\circ} \mathrm{C}$ to $500^{\circ} \mathrm{C}[45,56]$ : (a) $0.2 \%$ yield strength with time shown on log scale and time from $0 \mathrm{~h}$ to $50 \mathrm{~h}$ with a label added for the literature data, $(\mathrm{b})$ irradiation hardening data $\left(\Delta \sigma_{\mathrm{YS}}=\right.$ $\sigma_{Y S}($ irad $)-\sigma_{Y S}($ non-irad)) where there is not literature data, (c) total elongation, and (d) uniform elongation. The results at the annealing temperature of nominally $21^{\circ} \mathrm{C}$ are for previously report data for as-irradiated material [4]. 


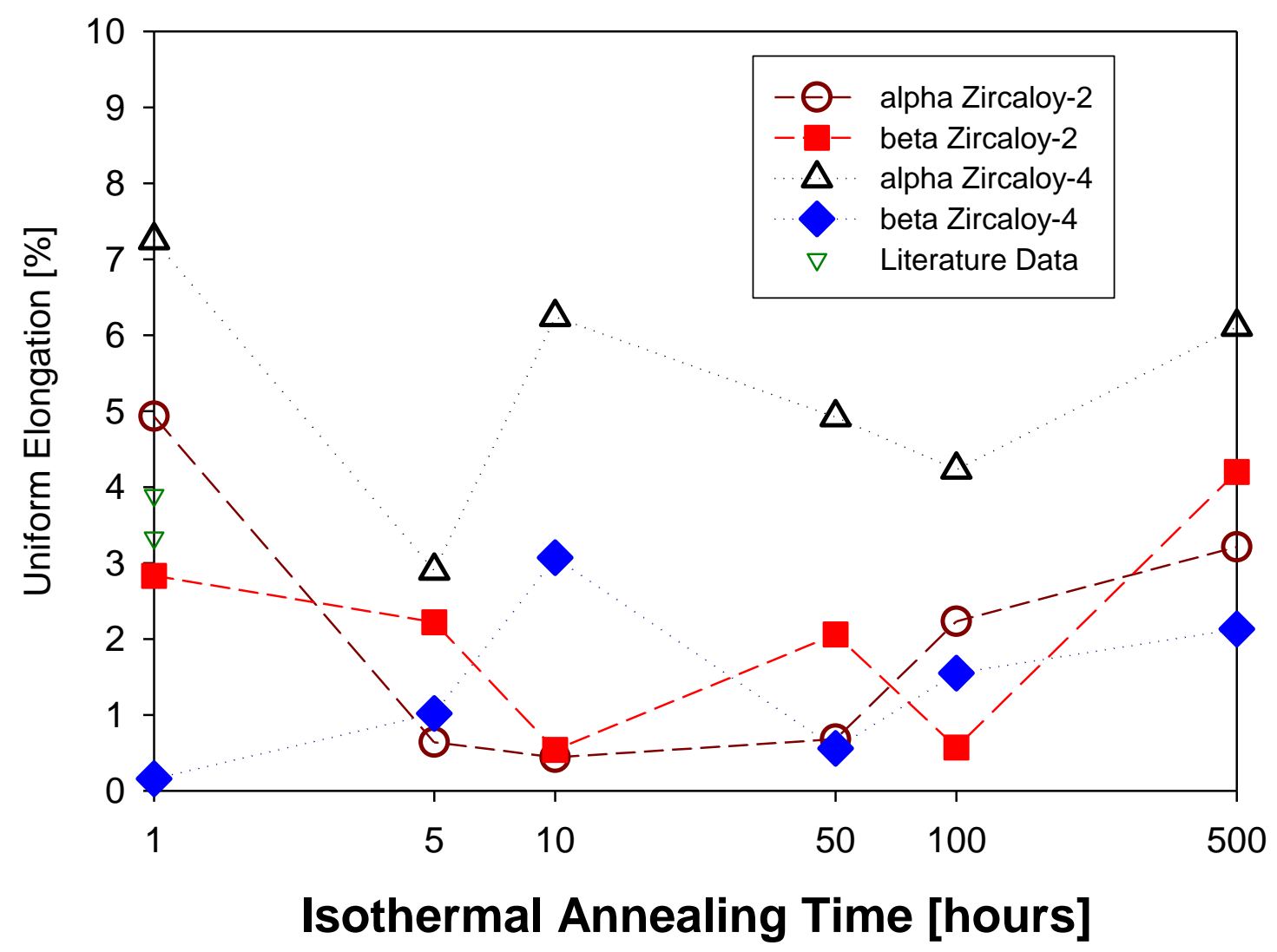

(d)

Figure 3. (continued) Comparison of tensile data for the post-irradiated isothermal annealing at $427^{\circ} \mathrm{C}$ for Zircaloy irradiated at nominally $312^{\circ} \mathrm{C}$ for compared with literature data for isothermal annealing at $427^{\circ} \mathrm{C}$ to $500^{\circ} \mathrm{C}[45,56]$ : (a) $0.2 \%$ yield strength with time shown on log scale and time from $0 \mathrm{~h}$ to $50 \mathrm{~h}$ with a label added for the literature data, $(\mathrm{b})$ irradiation hardening data $\left(\Delta \sigma_{\mathrm{YS}}=\right.$ $\sigma_{Y S}($ irad $)-\sigma_{Y S}($ non-irad)) where there is not literature data, (c) total elongation, and (d) uniform elongation. The results at the annealing temperature of nominally $21^{\circ} \mathrm{C}$ are for previously report data for as-irradiated material [4]. 


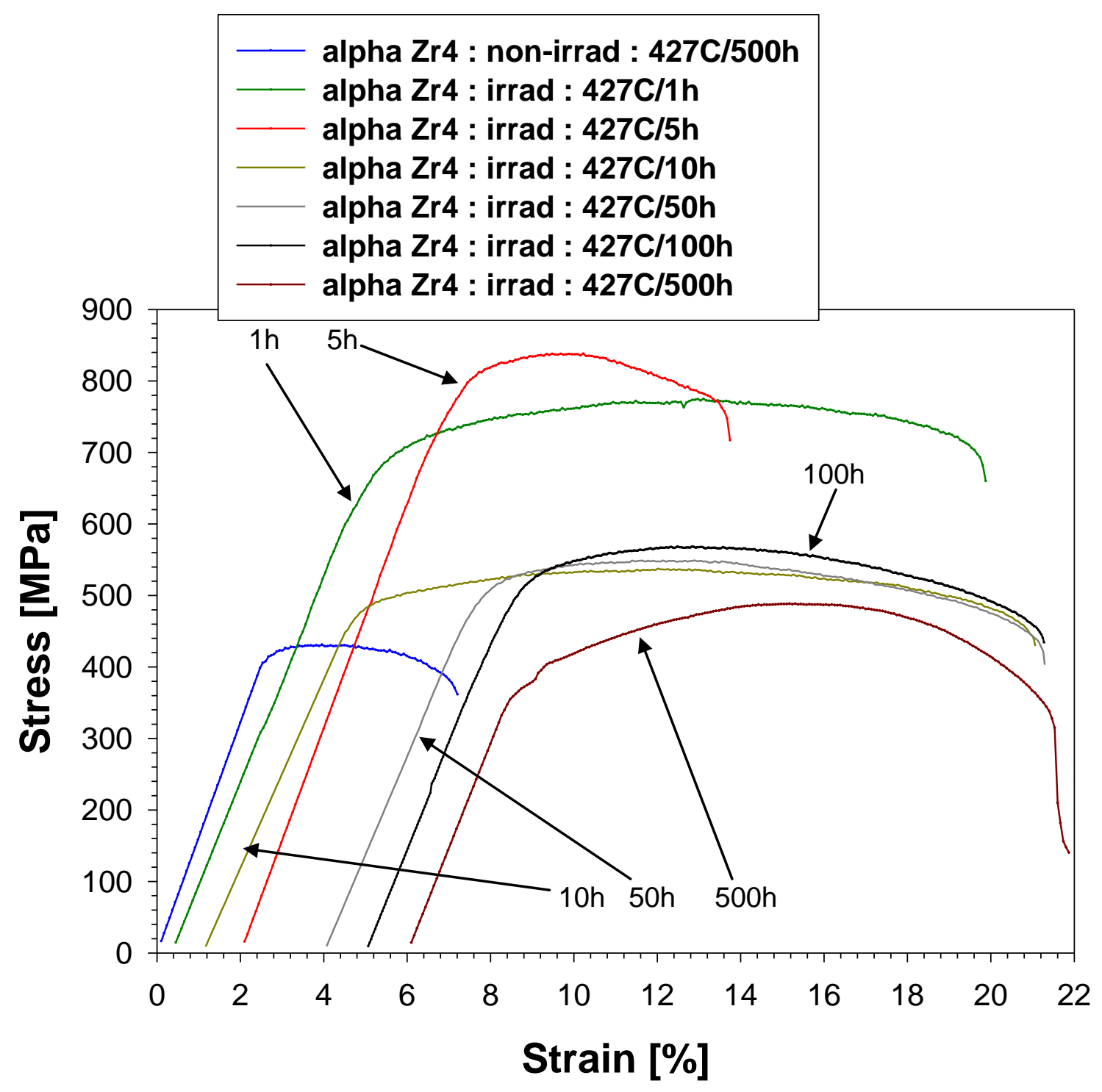

(a)

Figure 4. Summary plot of engineering stress-strain curves for the non-irradiated and postirradiated isothermal annealing at $427^{\circ} \mathrm{C}$ for Zircaloy irradiated at nominally $312^{\circ} \mathrm{C}$ for: (a) alphaannealed Zircaloy-2, (b) beta-treated Zircaloy-2, (c) alpha-annealed Zircaloy-4, and (d) beta-treated Zircaloy-4. The stress-strain curves were determined from the load versus actuator displacement with no correction made for compliance of the load frame. The curves were purposely off-set from the origin by strain with respect to increasing fluence. The annealing times are identified for each curve. 


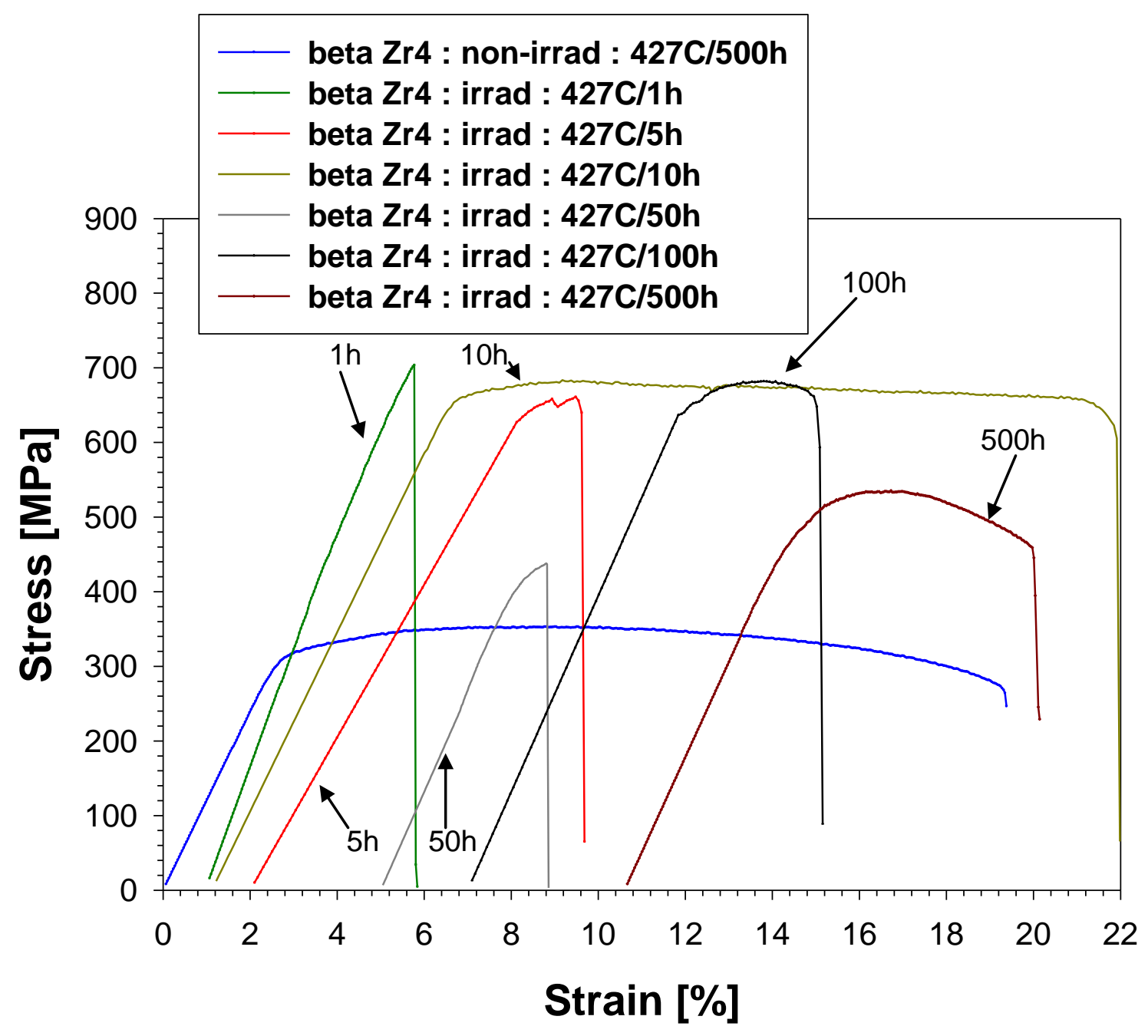

(b)

Figure 4. (continued) Summary plot of engineering stress-strain curves for the non-irradiated and post-irradiated isothermal annealing at $427^{\circ} \mathrm{C}$ for Zircaloy irradiated at nominally $312^{\circ} \mathrm{C}$ for: (a) alpha-annealed Zircaloy-2, (b) beta-treated Zircaloy-2, (c) alpha-annealed Zircaloy-4, and (d) betatreated Zircaloy-4. The stress-strain curves were determined from the load versus actuator displacement with no correction made for compliance of the load frame. The curves were purposely off-set from the origin by strain with respect to increasing fluence. The annealing times are identified for each curve. 


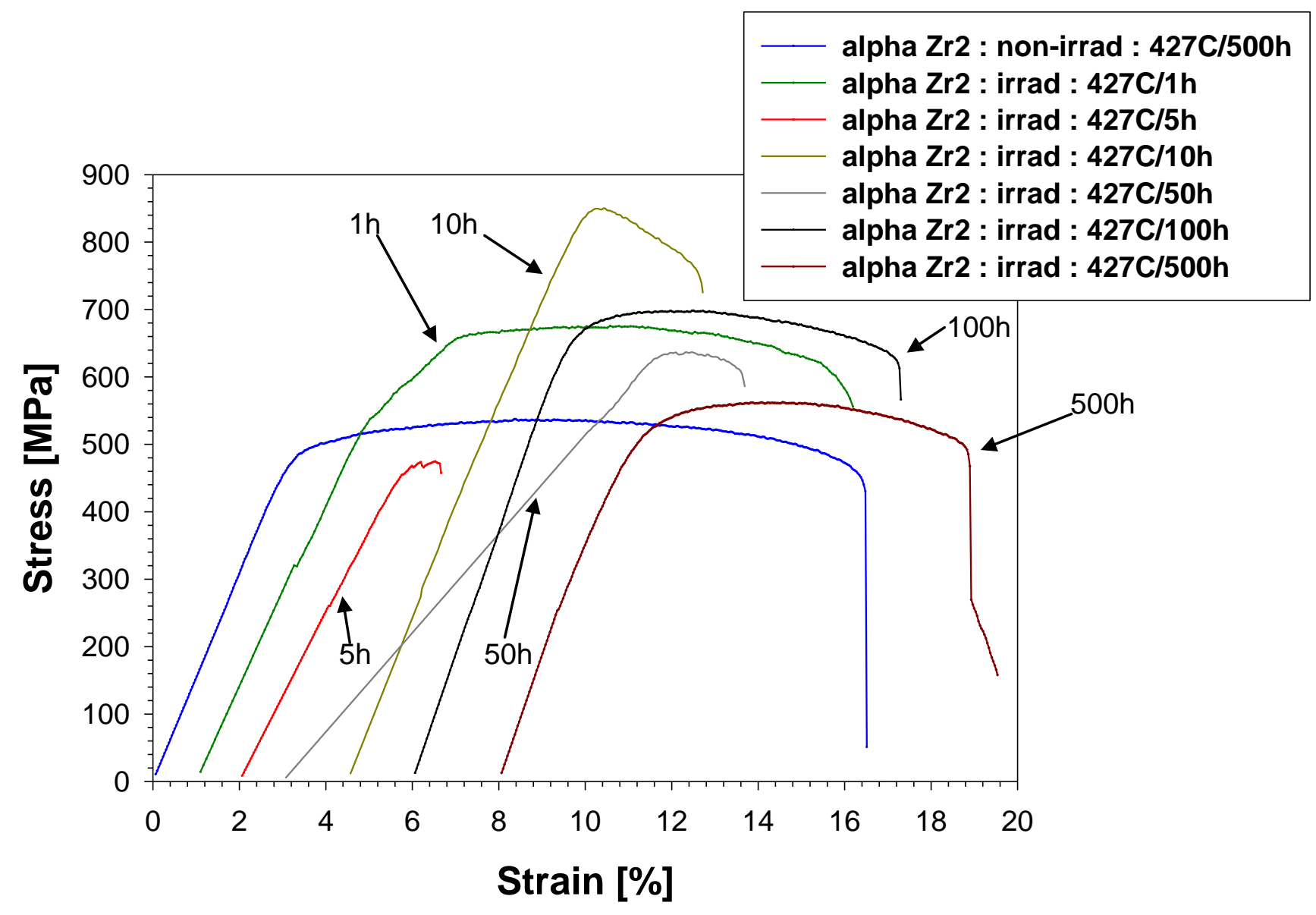

(c)

Figure 4. (continued) Summary plot of engineering stress-strain curves for the non-irradiated and post-irradiated isothermal annealing at $427^{\circ} \mathrm{C}$ for Zircaloy irradiated at nominally $312^{\circ} \mathrm{C}$ for: (a) alpha-annealed Zircaloy-2, (b) beta-treated Zircaloy-2, (c) alpha-annealed Zircaloy-4, and (d) betatreated Zircaloy-4. The stress-strain curves were determined from the load versus actuator displacement with no correction made for compliance of the load frame. The curves were purposely off-set from the origin by strain with respect to increasing fluence. The annealing times are identified for each curve. 


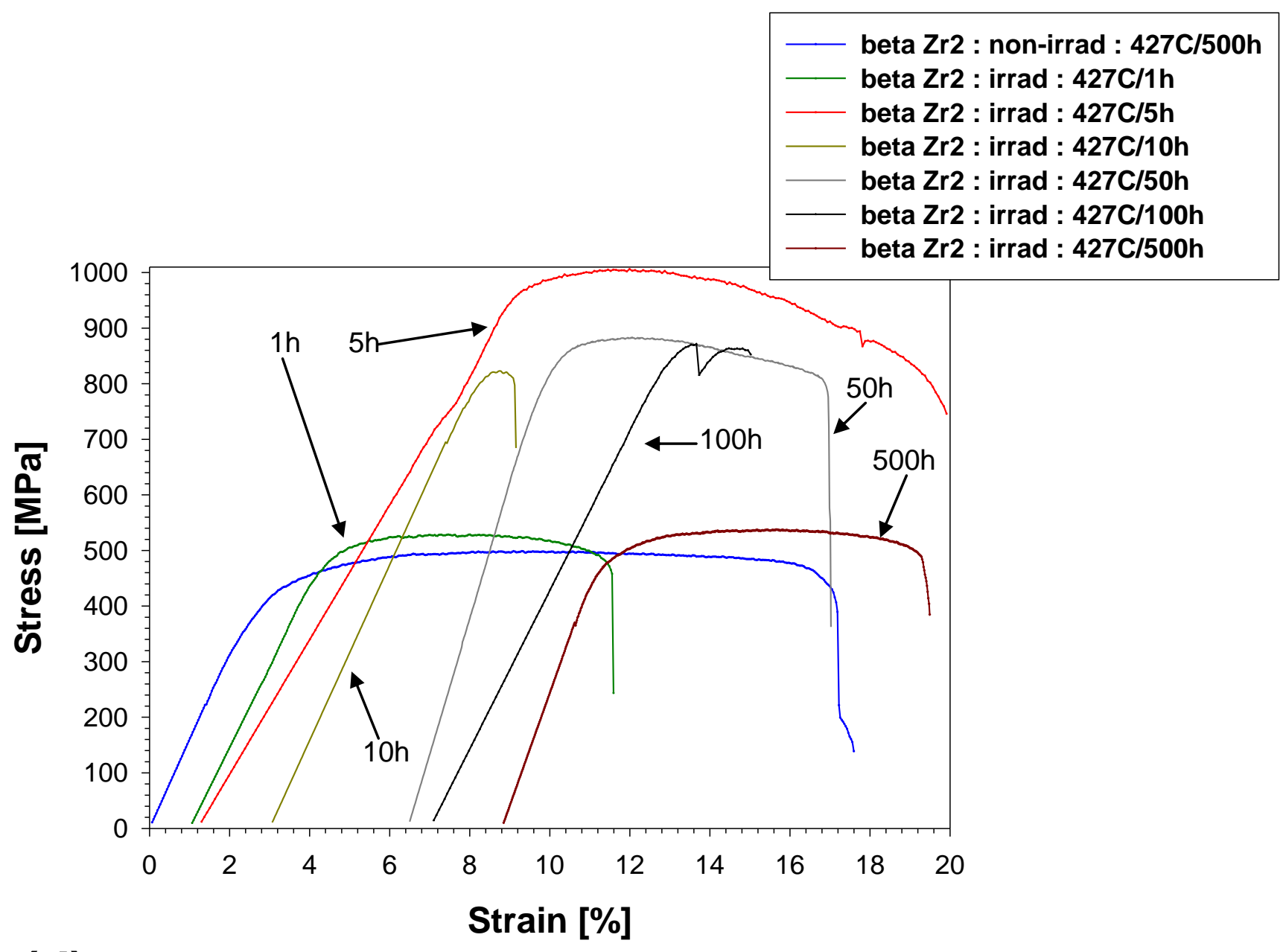

(d)

Figure 4. (continued) Summary plot of engineering stress-strain curves for the non-irradiated and post-irradiated isothermal annealing at $427^{\circ} \mathrm{C}$ for Zircaloy irradiated at nominally $312^{\circ} \mathrm{C}$ for: (a) alpha-annealed Zircaloy-2, (b) beta-treated Zircaloy-2, (c) alpha-annealed Zircaloy-4, and (d) beta-treated Zircaloy-4. The stress-strain curves were determined from the load versus actuator displacement with no correction made for compliance of the load frame. The curves were purposely off-set from the origin by strain with respect to increasing fluence. The annealing times are identified for each curve. 


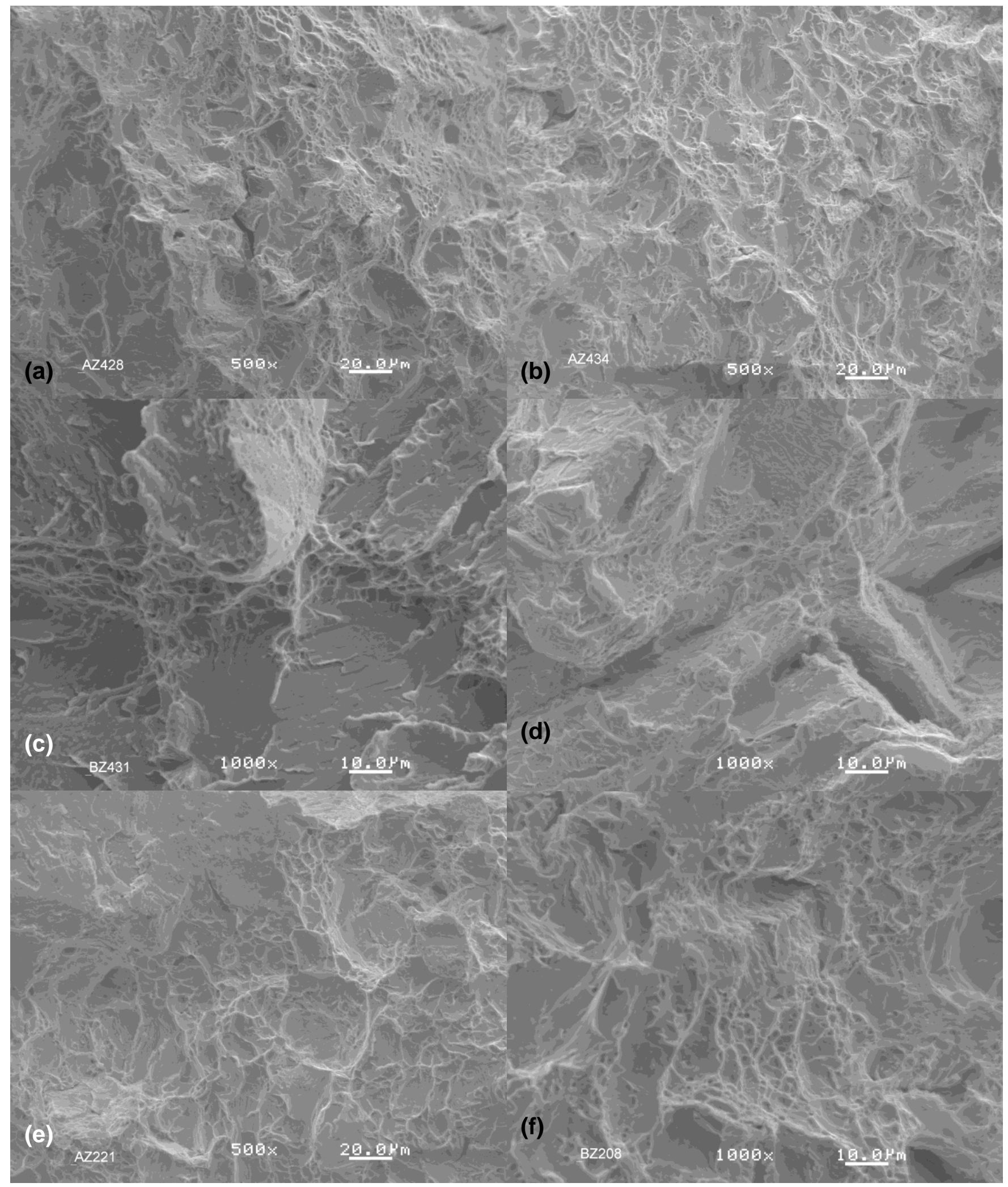

Figure 5. SEM fractography of irradiated tensile specimens $\left(2.96 \times 10^{25} \mathrm{n} / \mathrm{m}^{2}\right)$ following postirradiated isochronal annealing: (a) alpha-annealed Zircaloy-4 after isochronal anneal at $427^{\circ} \mathrm{C}$, (b) alpha-annealed Zircaloy-4 annealed at $510^{\circ} \mathrm{C}$, (c) beta-treated Zircaloy-4 after isochronal anneal at $427^{\circ} \mathrm{C}$, (d) beta-treated Zircaloy-4 annealed at $510^{\circ} \mathrm{C}$, (e) alpha-annealed Zircaloy-2 isocronal annealed at $427^{\circ} \mathrm{C}$, and (f) beta-treated Zircaloy-2 after isochronal anneal at $427^{\circ} \mathrm{C}$. 


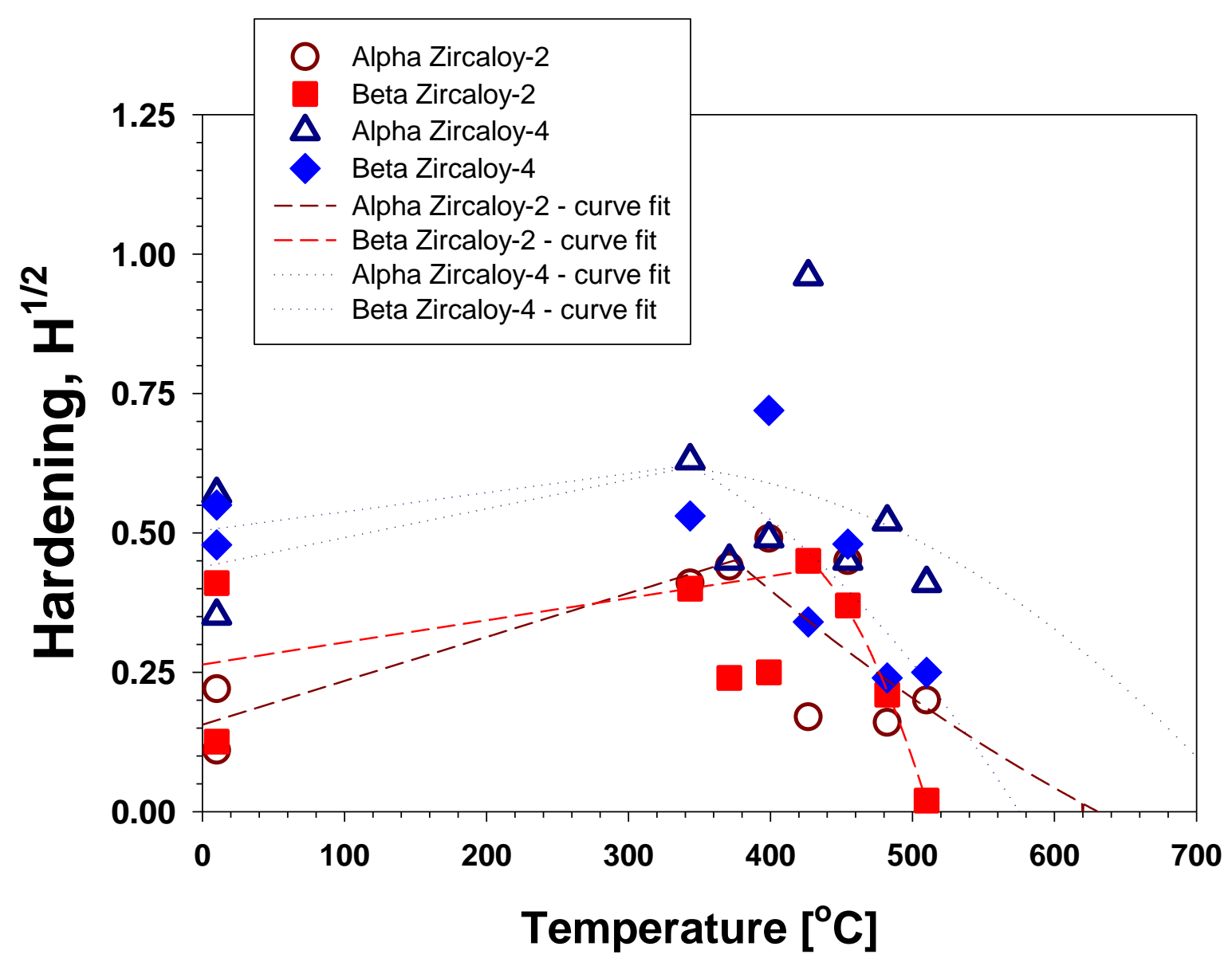

Figure 6. Plots of isochronal annealing results (5-hour anneals) for alpha-annealed and beta-treated Zircaloy-2 and Zircaloy-4 showing fractional irradiation hardening versus isochronal annealing temperature with the empirical fit to the recovery data used for the Meechan-Brinkman analysis. 


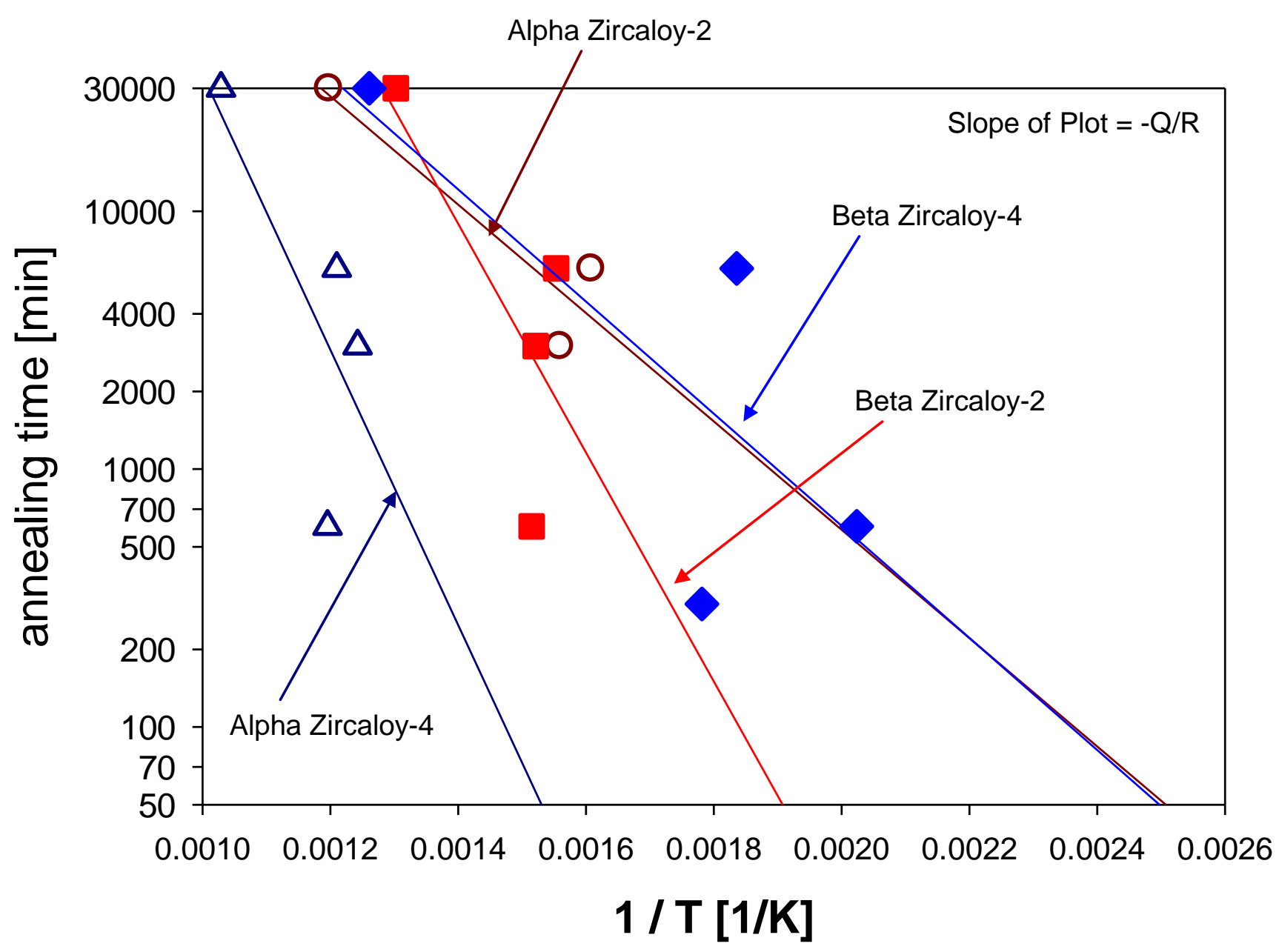

Figure 7. Semi-log plot of isothermal time interval versus inverse isochronal annealing temperature used to determine activation energy using the Meechan-Brinkman method for alphaannealed and beta-treated Zircaloy-2 and Zircaloy-4 with fits for individual material sets. 
$399^{\circ} \mathrm{C}$ Isochronal Anneal

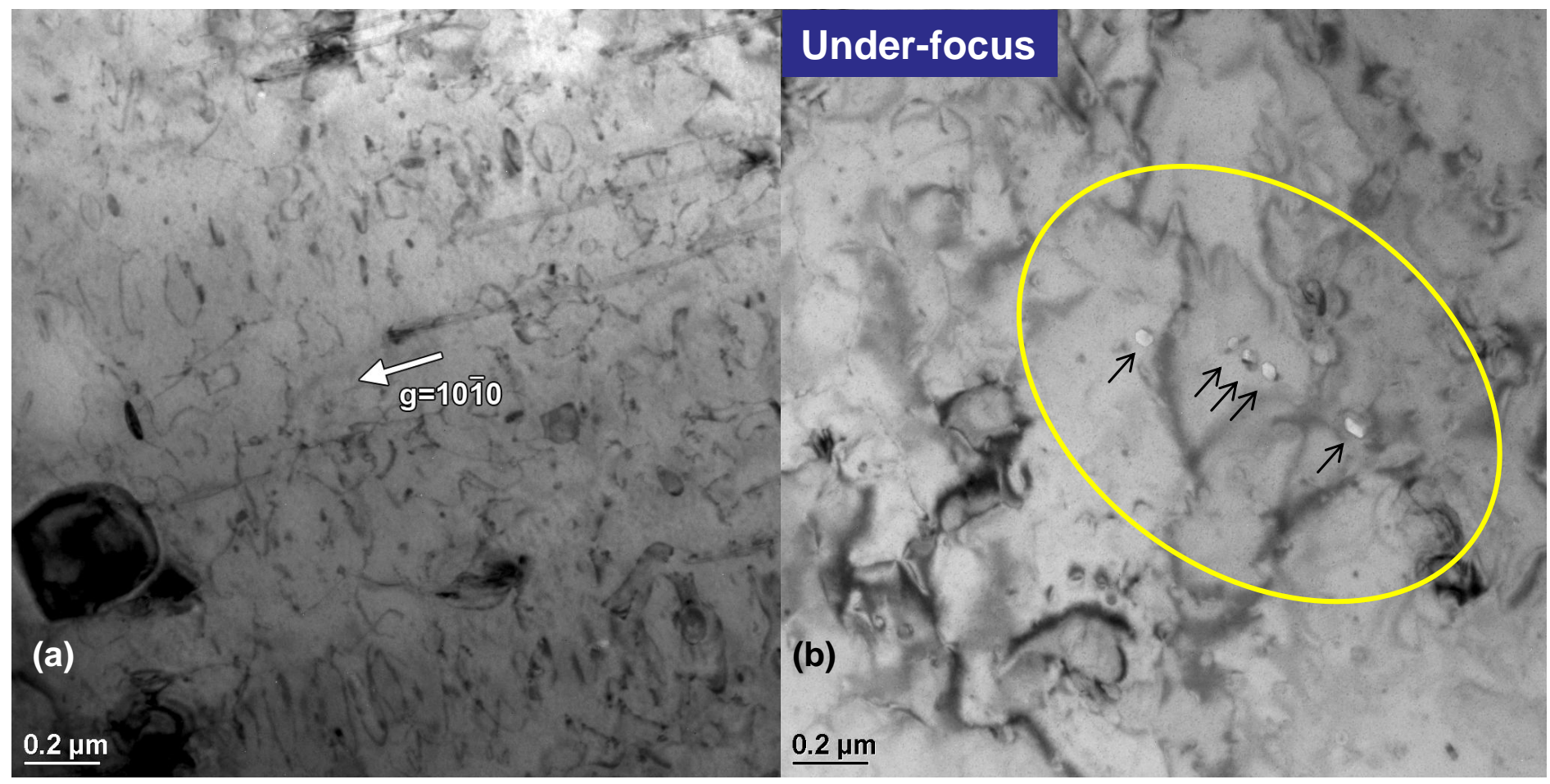

$399^{\circ} \mathrm{C}$ Isochronal Anneal

$510^{\circ} \mathrm{C}$ Isochronal Anneal

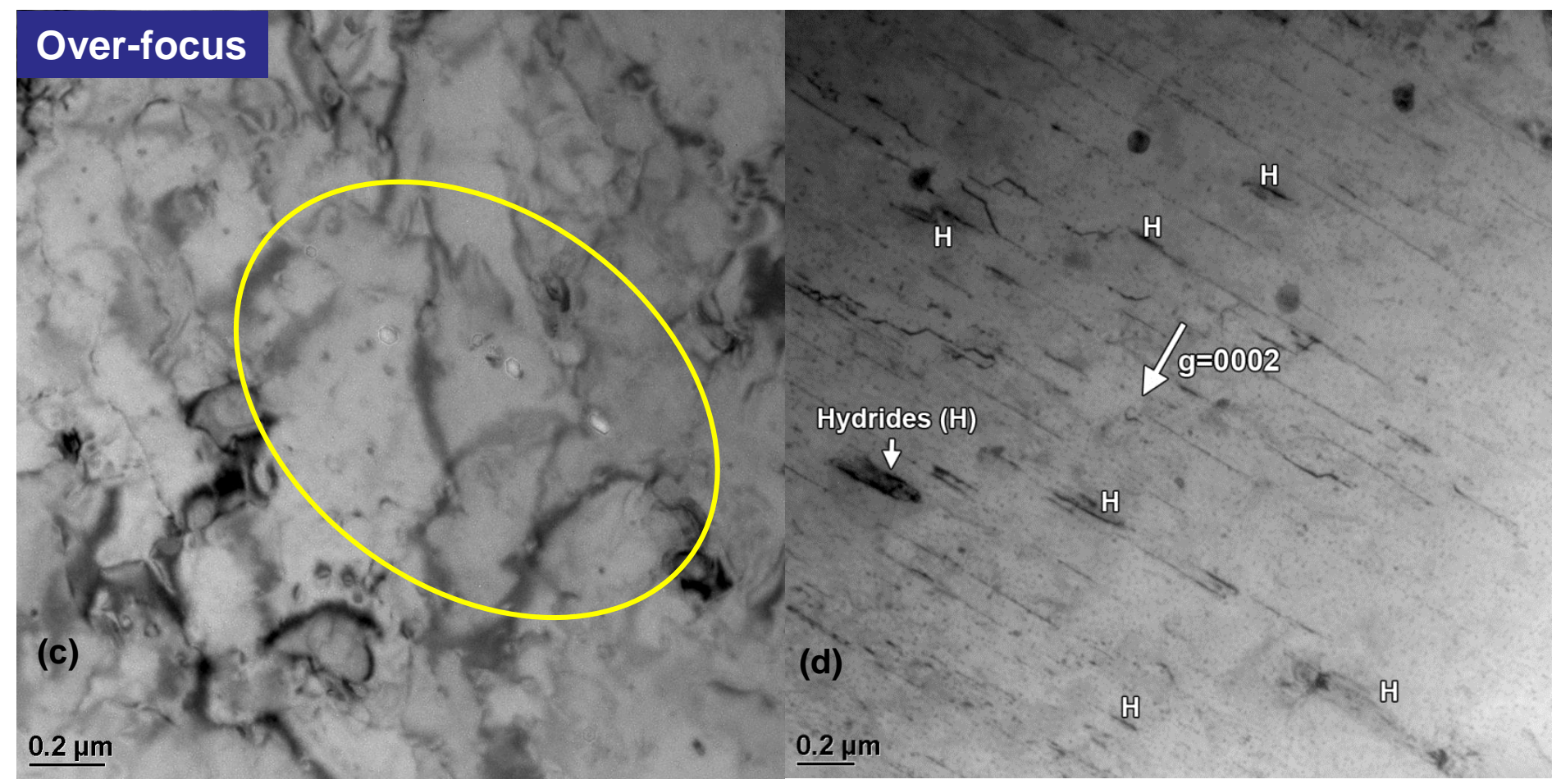

Fig. 8. Representative TEM images of loops and dislocations from alpha-annealed Zircaloy-4 following post-irradiation annealing: (a), (b) $+(\mathrm{c})$, and (d) $<$ a $>$ loops and dislocations, voids, and $<\mathrm{c}>$ loops and dislocations, respectively, following the $399^{\circ} \mathrm{C}$ isochronal anneal, (e) and (f) <a> loops and dislocations and stacking faults near <a> loops, respectively, following the $510^{\circ} \mathrm{C}$ isochronal anneal, and $(\mathrm{g})$ and $(\mathrm{h})<\mathrm{a}>$ and $<\mathrm{c}>$ loops and dislocations, respectively, following the $427^{\circ} \mathrm{C} / 500 \mathrm{~h}$ isothermal annealing. 


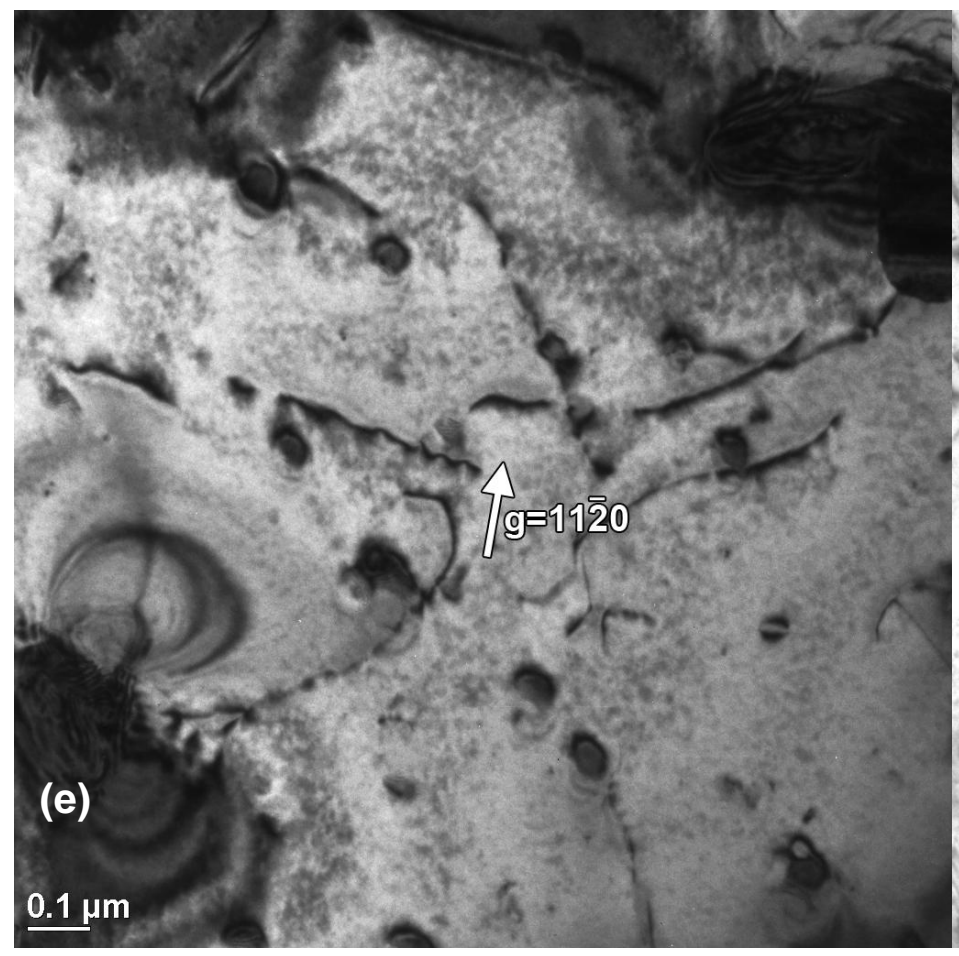

$427^{\circ} \mathrm{C} / 500 \mathrm{~h}$ Isothermal Anneal

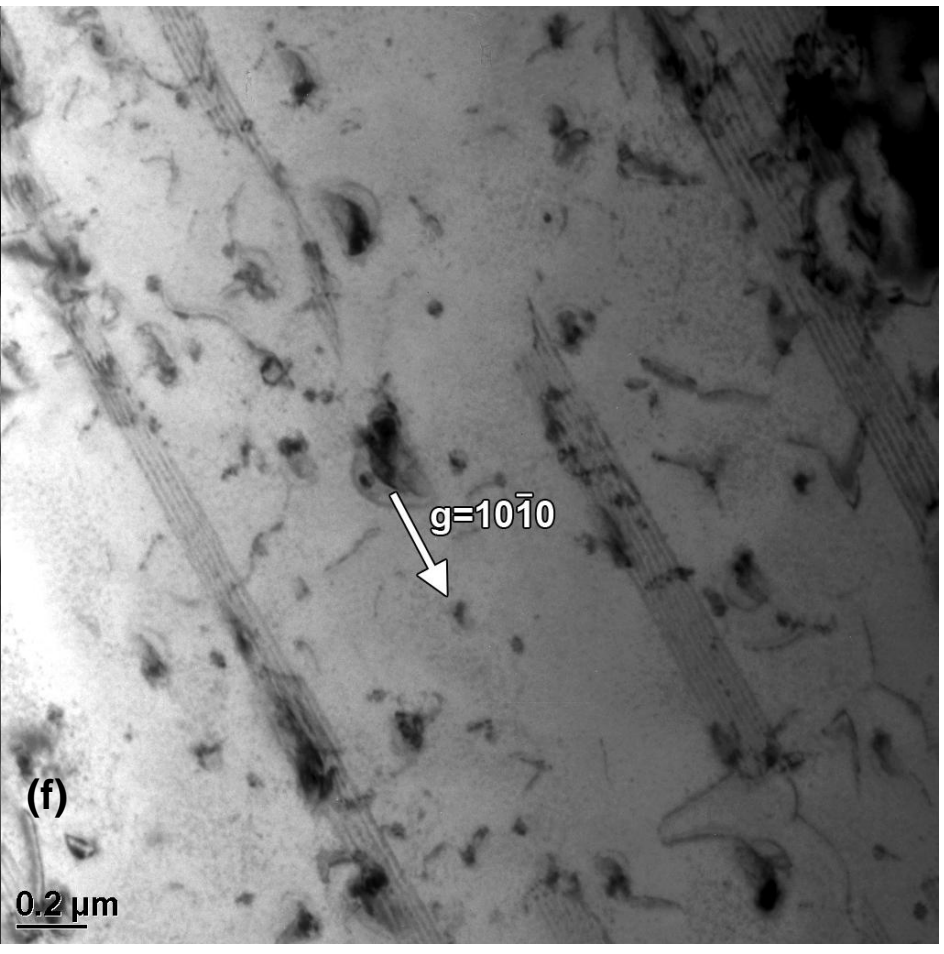

$427^{\circ} \mathrm{C} / 500 \mathrm{~h}$ Isothermal Anneal

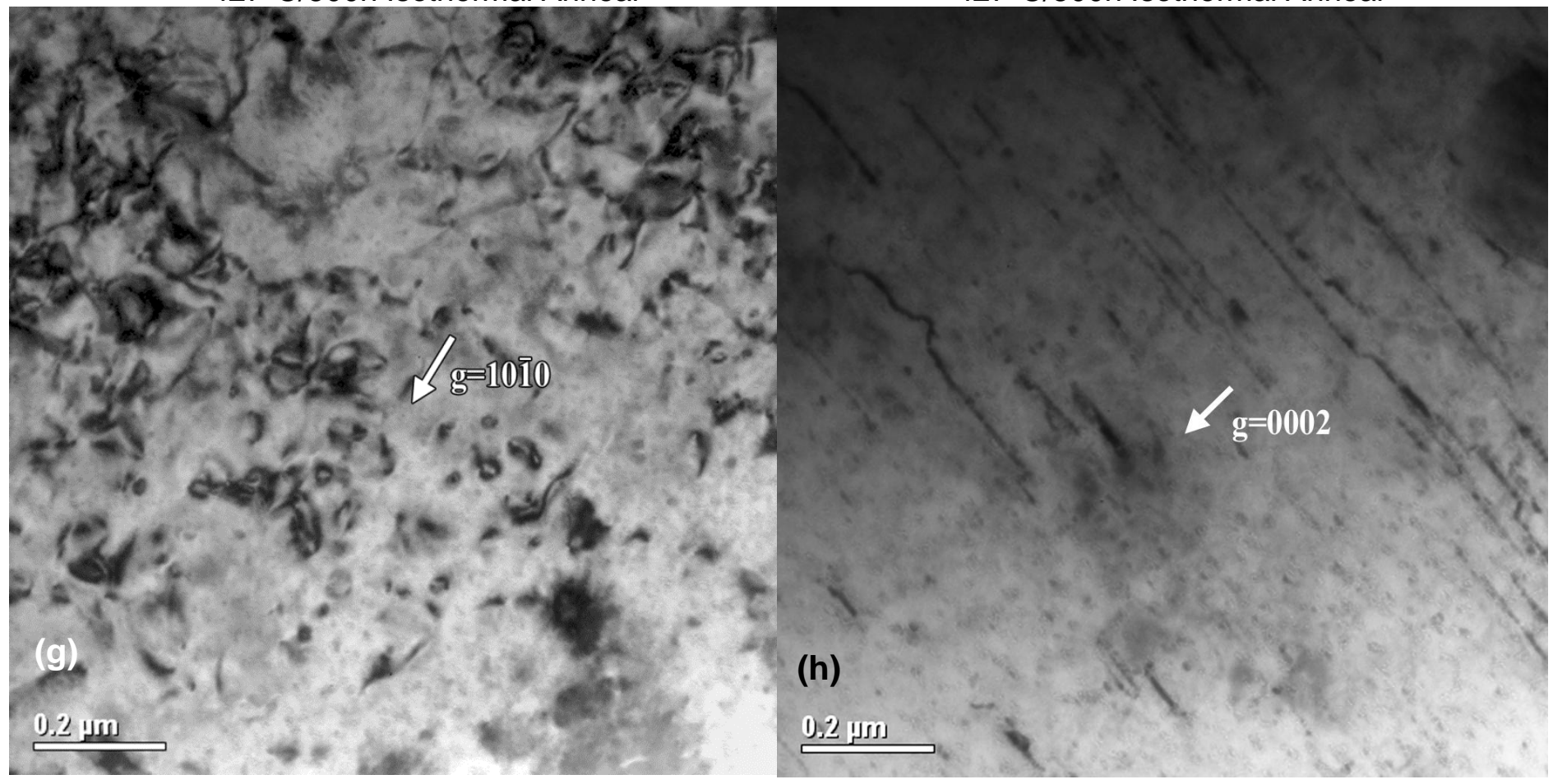

Fig. 8. (continued) Representative TEM images of loops and dislocations from alpha-annealed Zircaloy-4 following post-irradiation annealing: (a), (b)+(c), and (d) <a> loops and dislocations, voids, and $<\mathrm{C}>$ loops and dislocations, respectively, following the $399^{\circ} \mathrm{C}$ isochronal anneal, (e) and (f) $<a>$ loops and dislocations and stacking faults near $<a>$ loops, respectively, following the $510^{\circ} \mathrm{C}$ isochronal anneal, and $(\mathrm{g})$ and $(\mathrm{h})<\mathrm{a}>$ and $<\mathrm{c}>$ loops and dislocations, respectively, following the $427^{\circ} \mathrm{C} / 500 \mathrm{~h}$ isothermal annealing. 


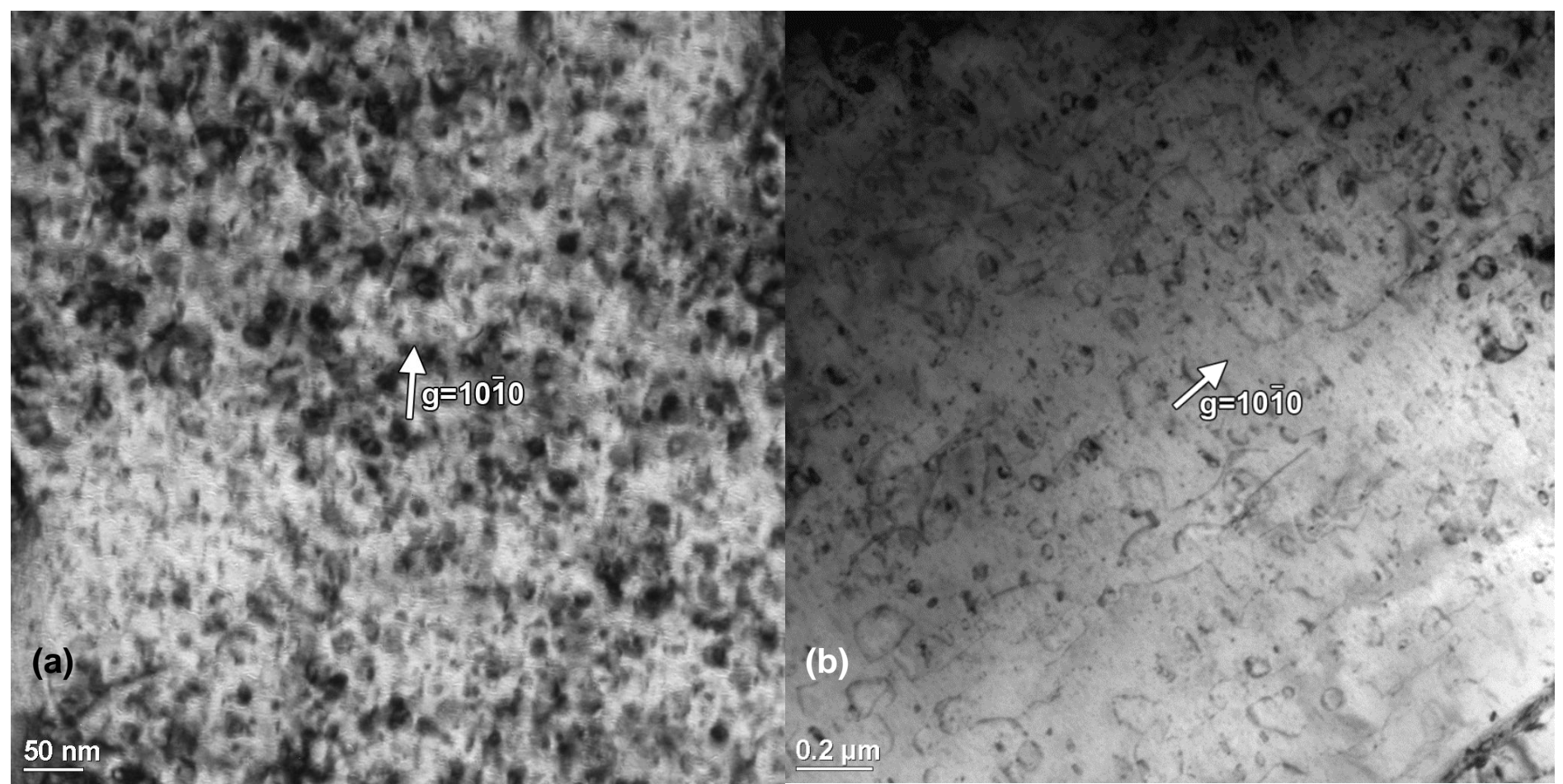

$510^{\circ} \mathrm{C}$ Isochronal Anneal

\section{$510^{\circ} \mathrm{C}$ Isochronal Anneal}

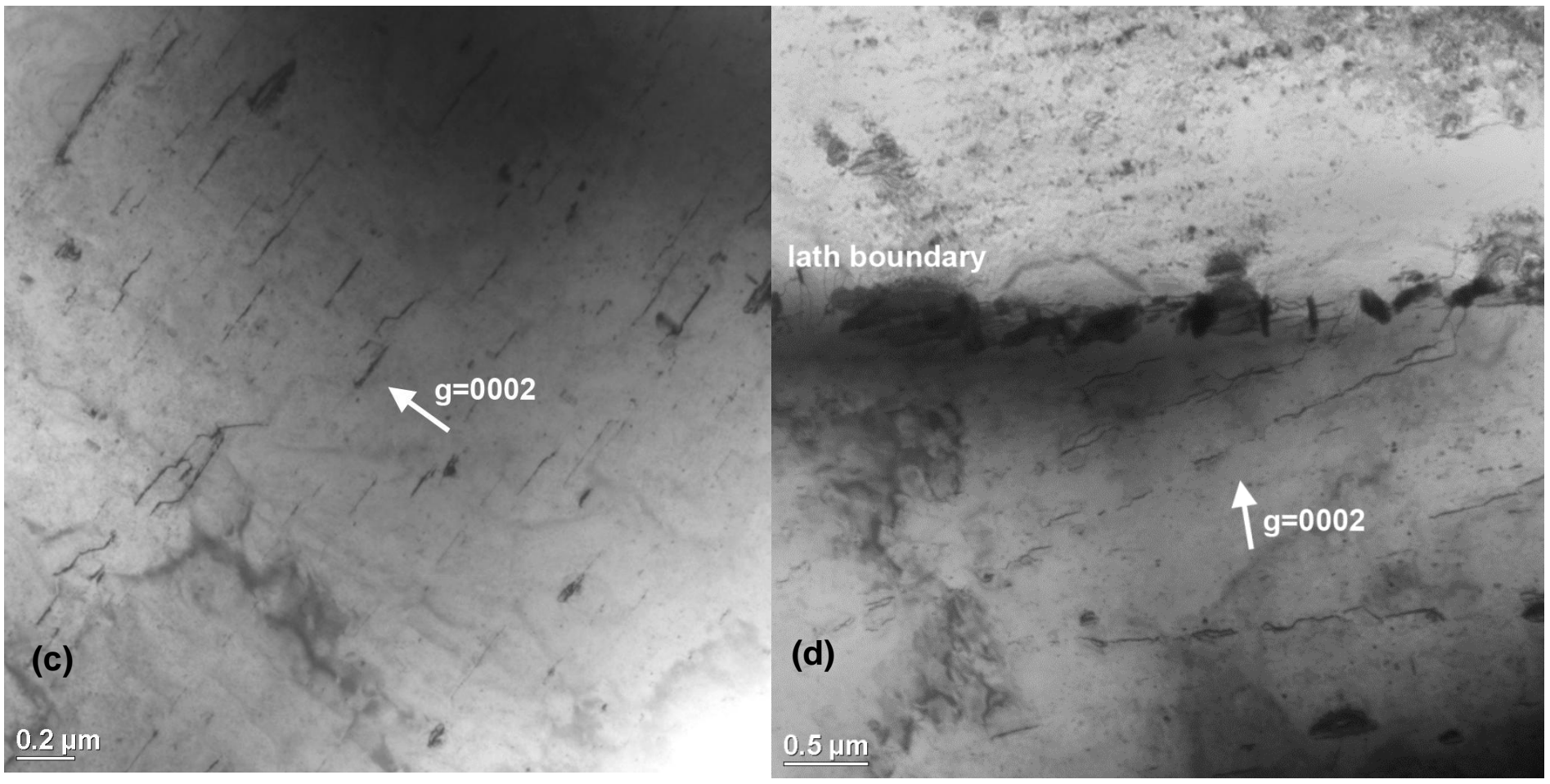

Fig. 9. Representative TEM images of loops, dislocations, and precipitates for beta-treated Zircaloy4 following post-irradiation annealing: (a), <a> loops following the $399^{\circ} \mathrm{C}$ isochronal anneal, and (b), (c), and (d) <a> loops and dislocations, $<\mathrm{c}>$ loops, and laves phase precipitates at lath boundary following the $510^{\circ} \mathrm{C}$ isochronal anneal. 


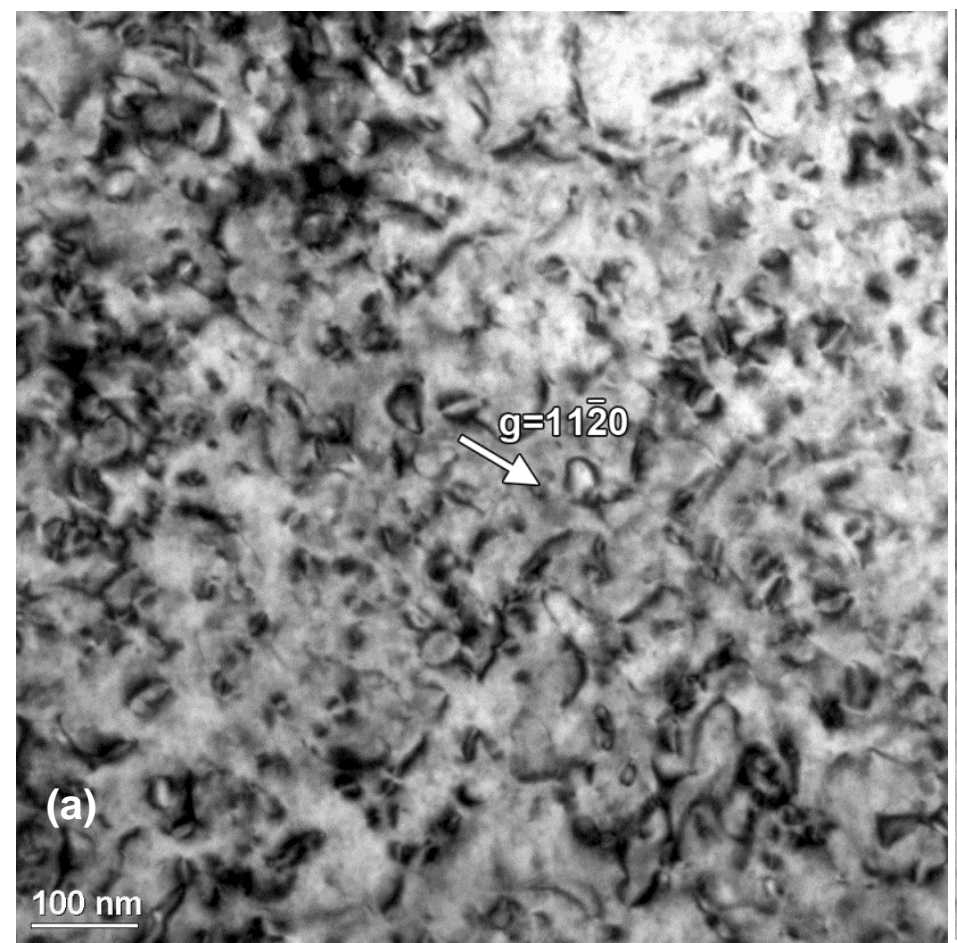

$510^{\circ} \mathrm{C}$ Isochronal Anneal

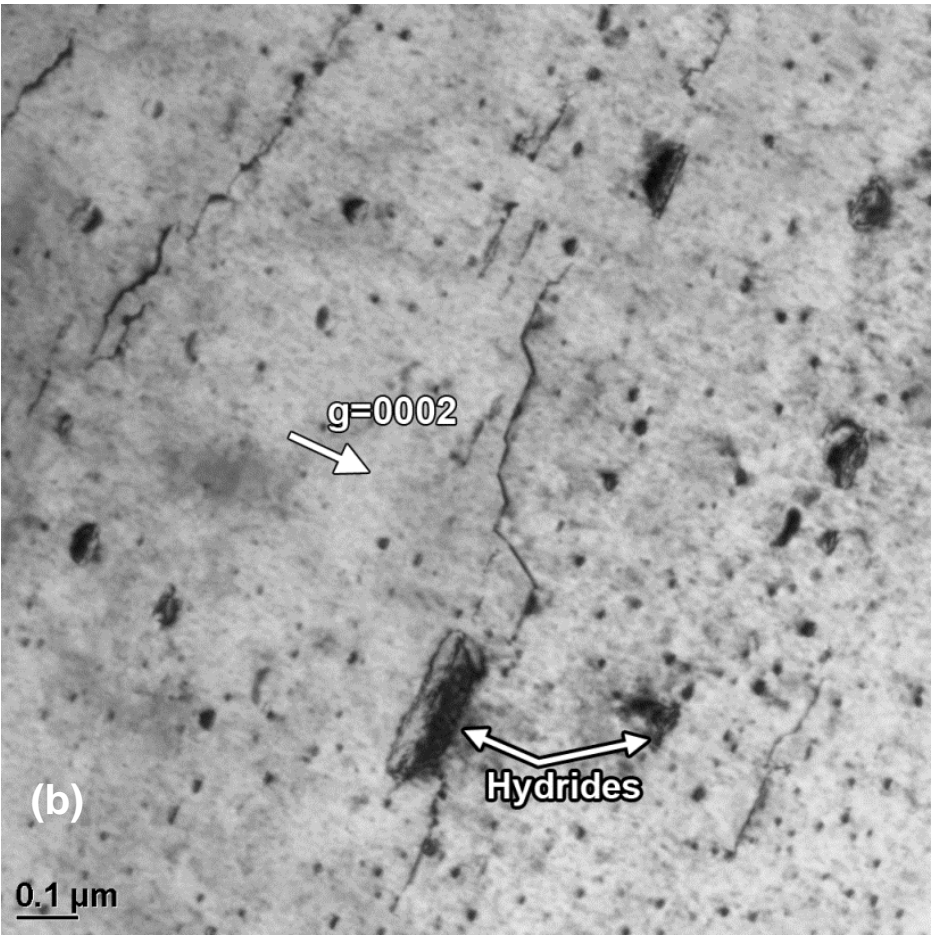

$510^{\circ} \mathrm{C}$ Isochronal Anneal

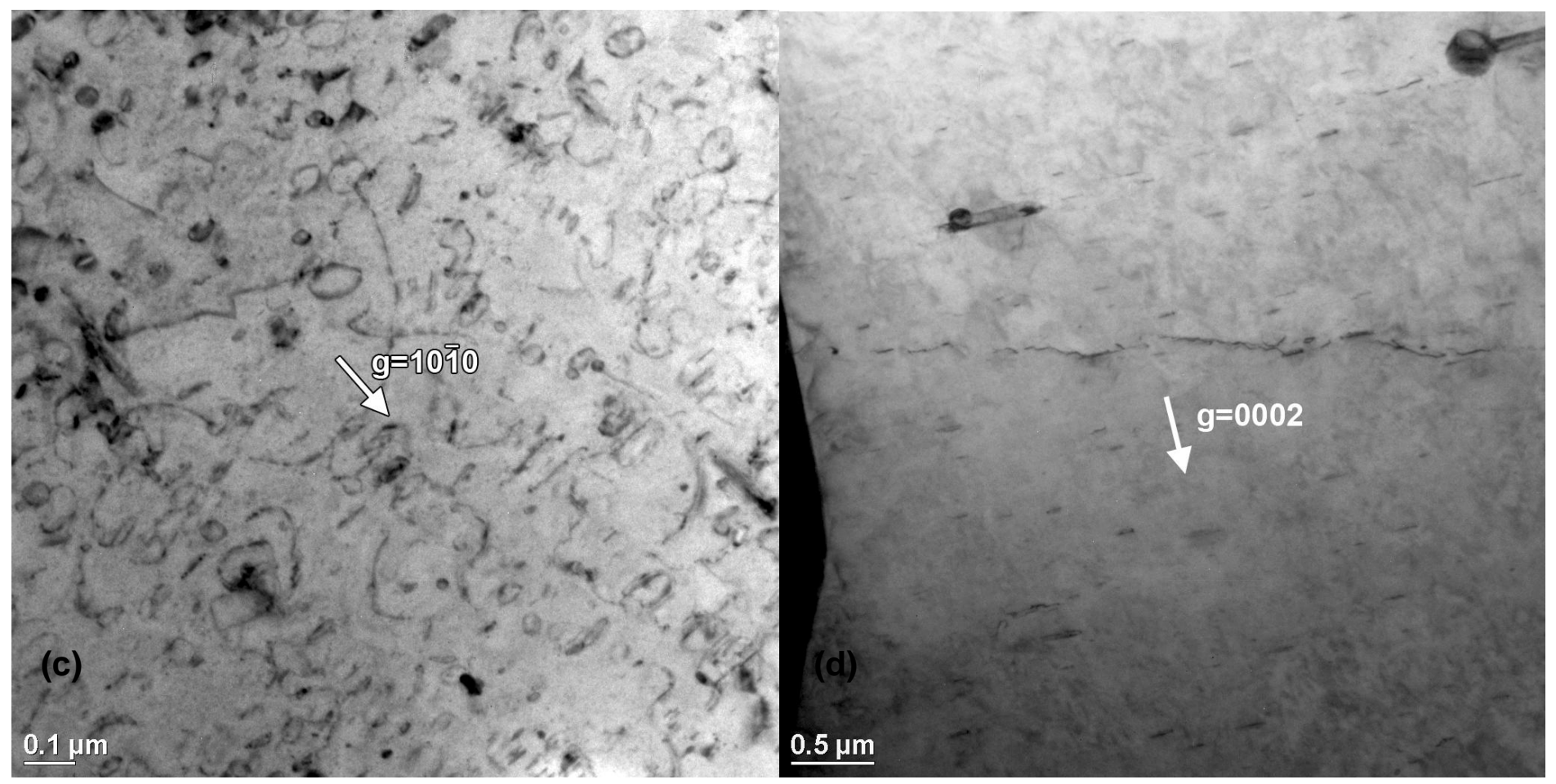

Fig. 10. Representative TEM images of loops, dislocations, and precipitates for alpha-annealed Zircaloy-2 following post-irradiation annealing: (a) and (b), $<a>$ loops and $<c>$ loops and dislocations following the $399^{\circ} \mathrm{C}$ isochronal anneal, (c), (d), and (e) <a> loops and dislocations, <c> loops, and laves phase precipitates following the $510^{\circ} \mathrm{C}$ isochronal anneal, and (f) and $(\mathrm{g})<\mathrm{a}>$ loops and dislocations and $<\mathrm{c}>$ loops, respectively, following the $427^{\circ} \mathrm{C} / 500 \mathrm{~h}$ isothermal annealing. 

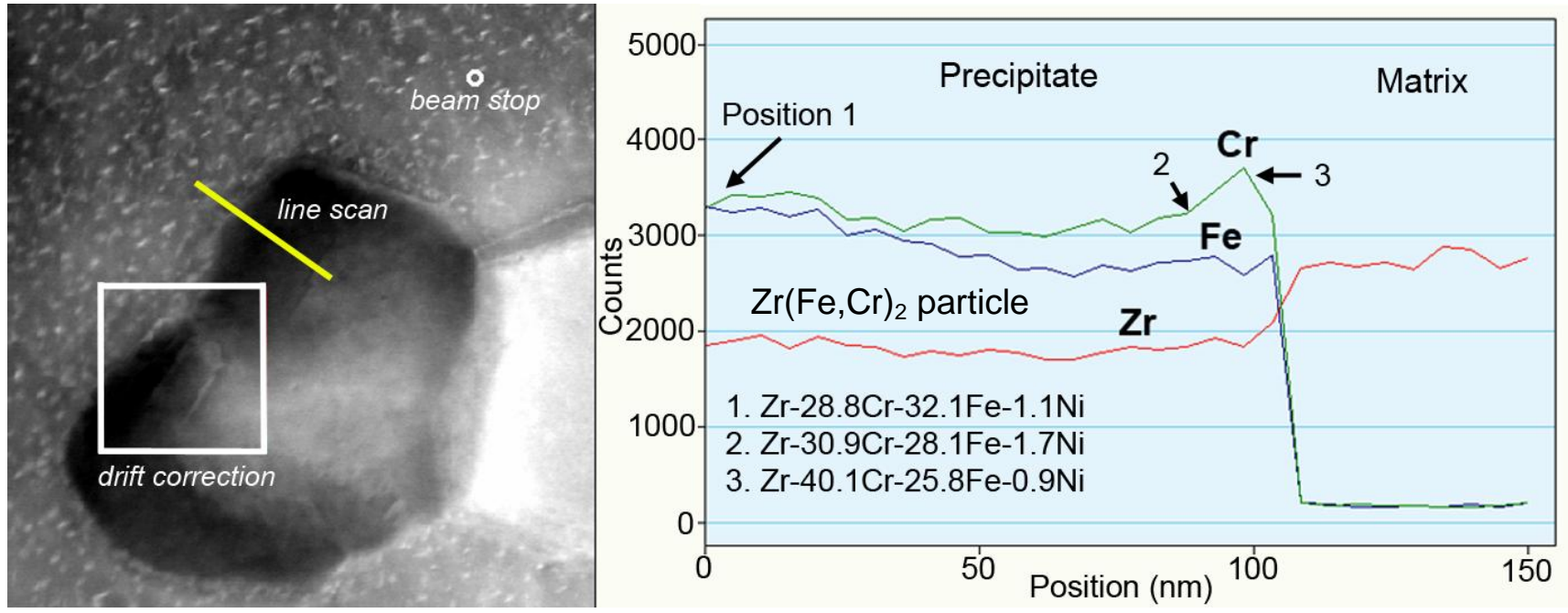

(e)

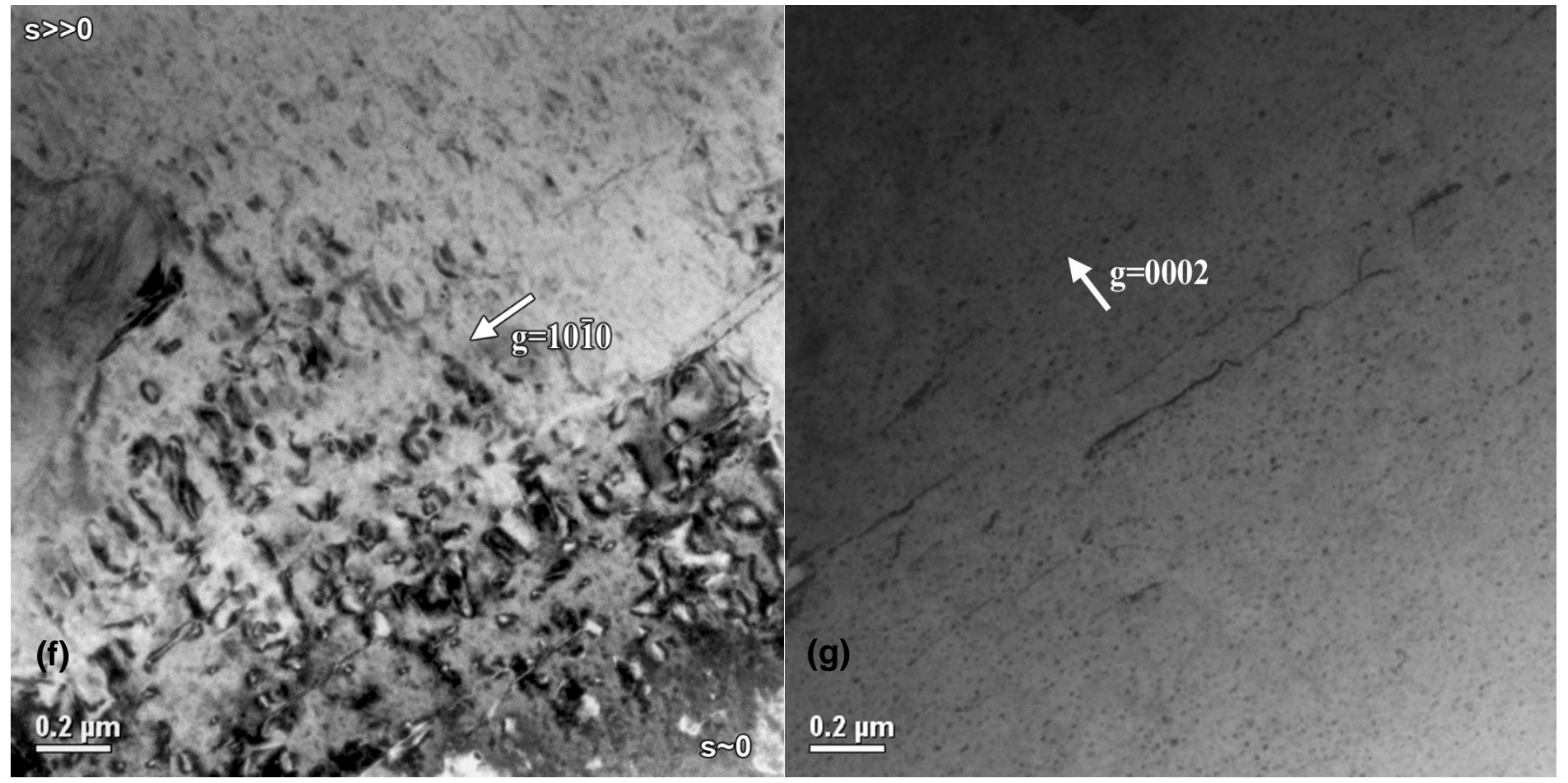

Fig. 10. (continued) Representative TEM images of loops, dislocations, and precipitates for alphaannealed Zircaloy-2 following post-irradiation annealing: (a) and (b), <a> loops and <c> loops and dislocations following the $399^{\circ} \mathrm{C}$ isochronal anneal, (c), (d), and (e) <a> loops and dislocations, <c> loops, and laves phase precipitates following the $510^{\circ} \mathrm{C}$ isochronal anneal, and (f) and $(\mathrm{g})<\mathrm{a}>$ loops and dislocations and $<\mathrm{C}>$ loops, respectively, following the $427^{\circ} \mathrm{C} / 500 \mathrm{~h}$ isothermal annealing. 


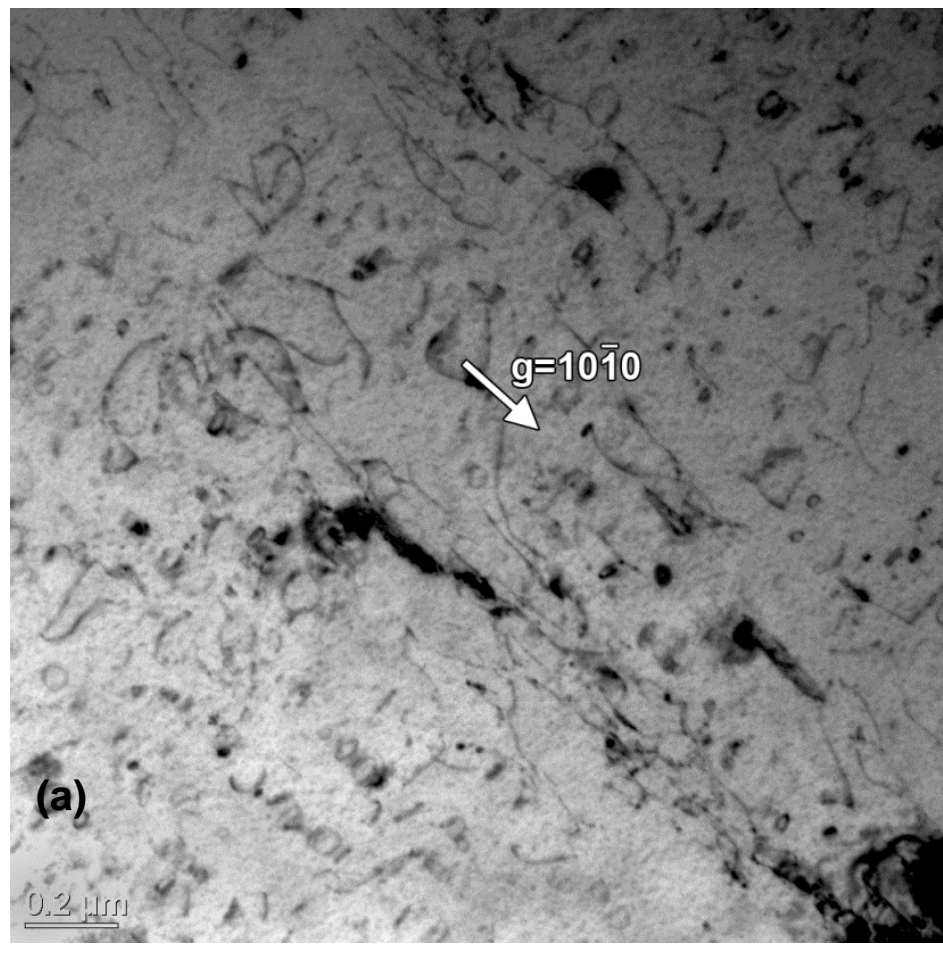

$510^{\circ} \mathrm{C}$ Isochronal Anneal

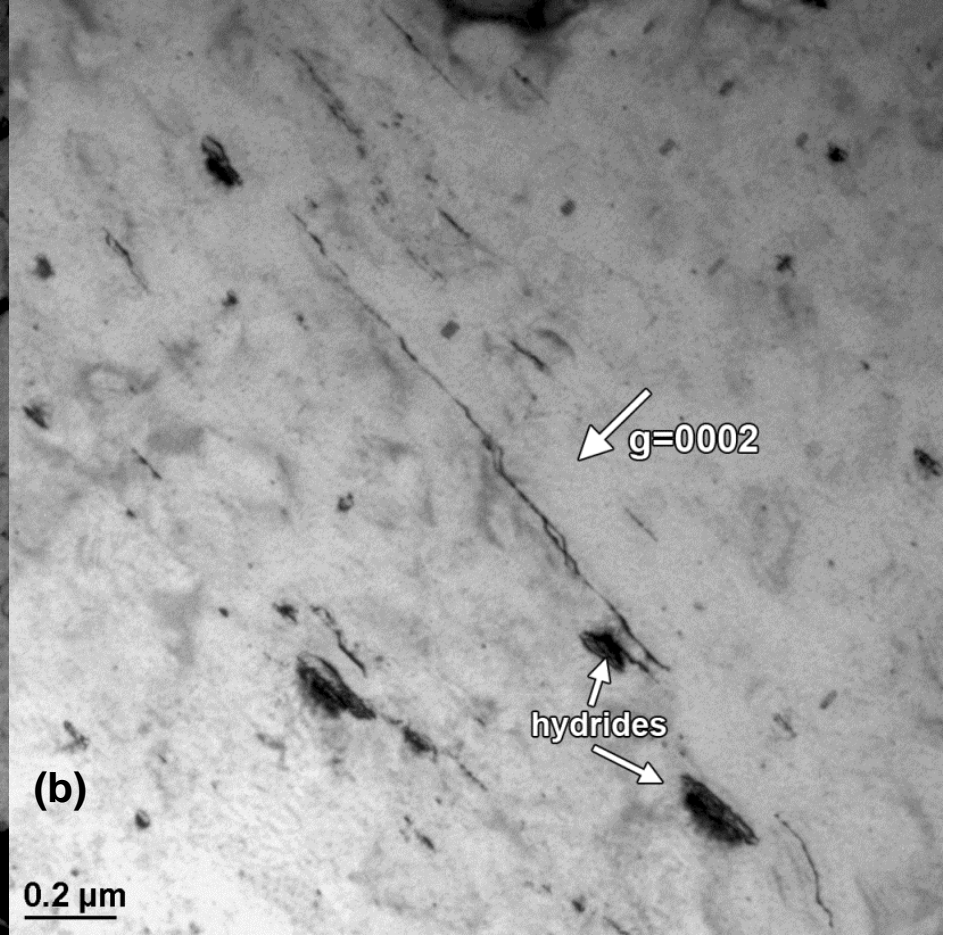

$510^{\circ} \mathrm{C}$ Isochronal Anneal

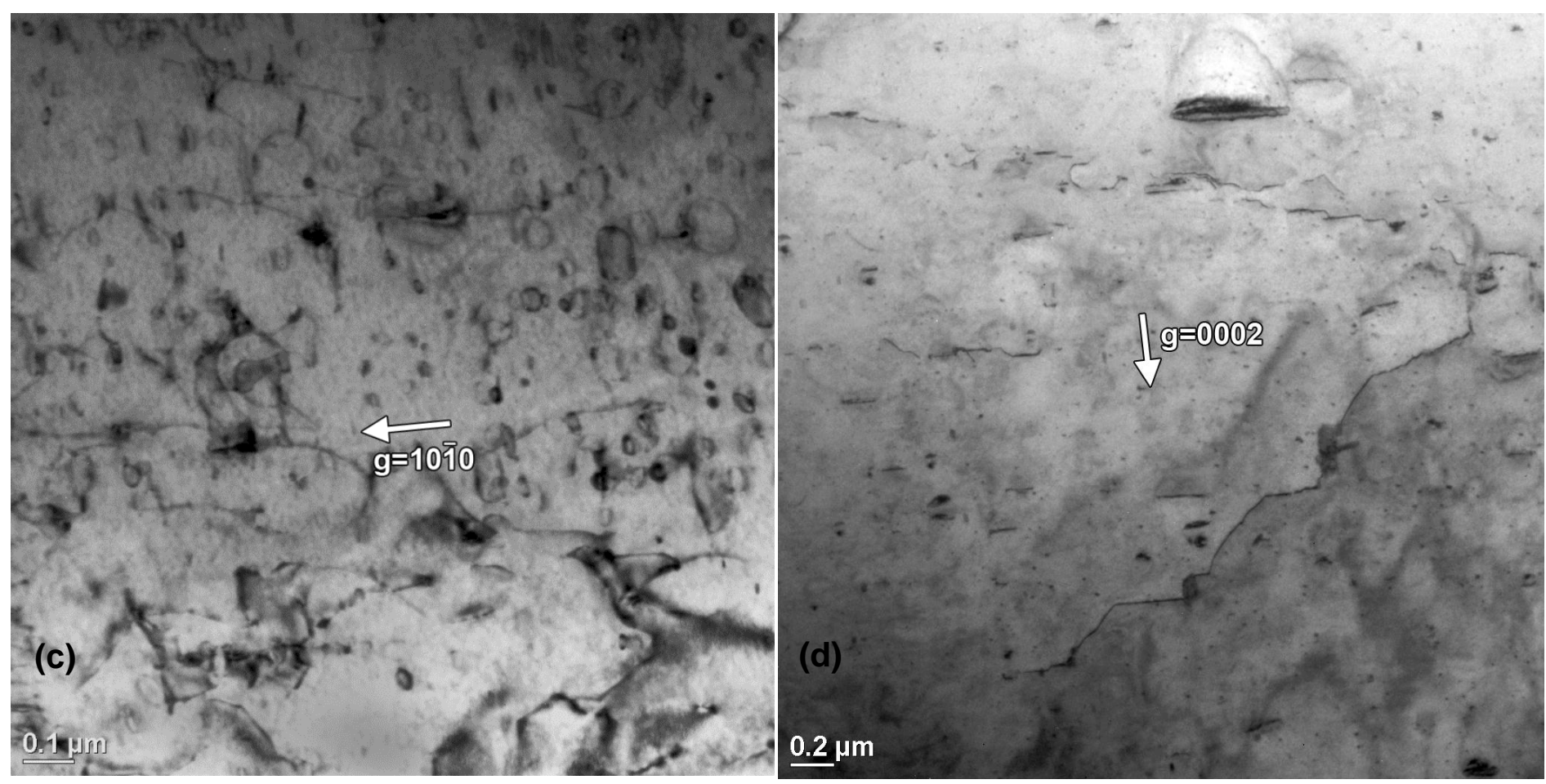

Fig. 11. Representative TEM images of loops and precipitates from beta-treated Zircaloy-2 following post-irradiation annealing: (a) and (b), <a $>$ loops and $<\mathrm{c}>$ loops and dislocations following the $399^{\circ} \mathrm{C}$ isochronal anneal, (c), and (d) $<$ a $>$ loops and dislocations and $<\mathrm{c}>$ loops following the $510^{\circ} \mathrm{C}$ isochronal anneal, and $(e)$ and $(f)<a>$ loops and dislocations and $<c>$ loops, respectively, following the $427^{\circ} \mathrm{C} / 500 \mathrm{~h}$ isothermal annealing. 
$427^{\circ} \mathrm{C} / 500 \mathrm{~h}$ Isothermal Anneal

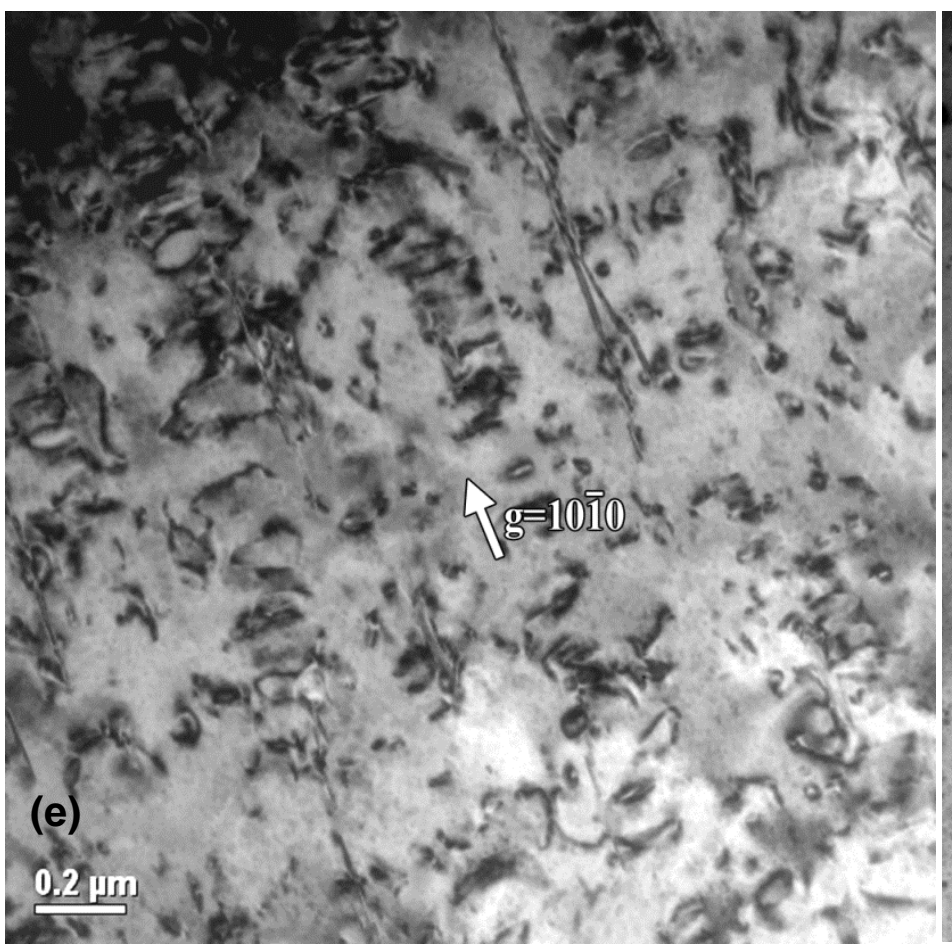

$427^{\circ} \mathrm{C} / 500 \mathrm{~h}$ Isothermal Anneal

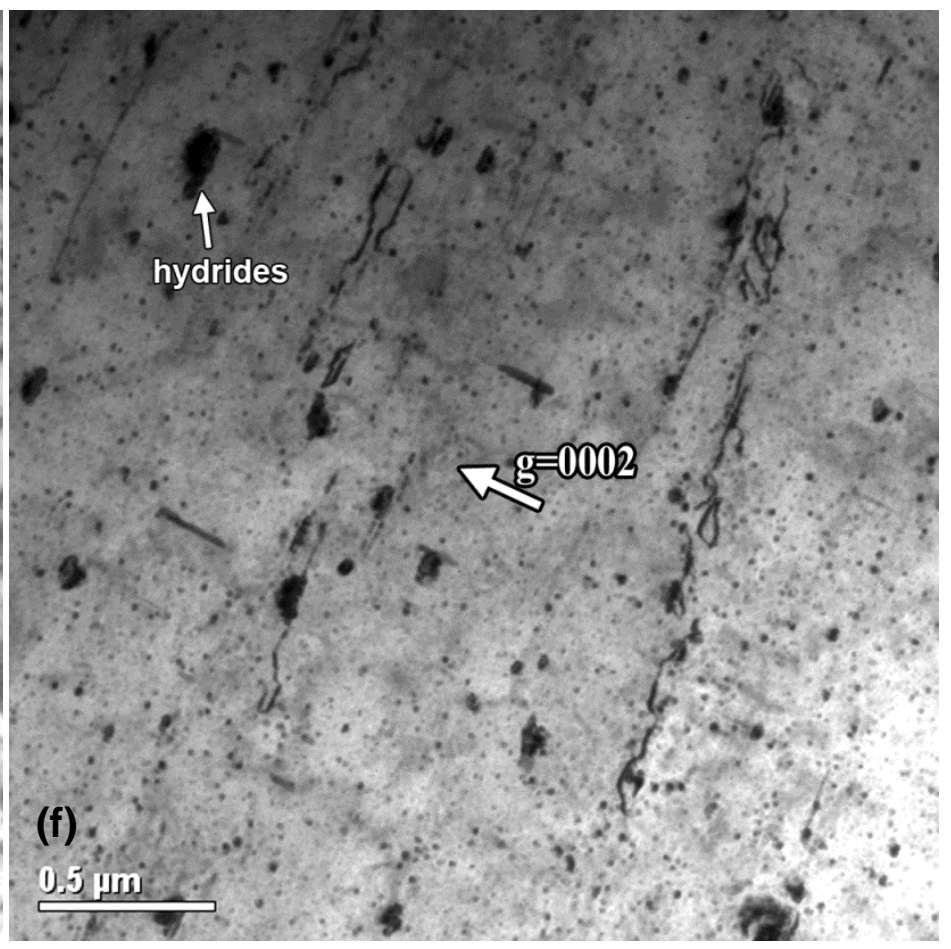

Fig. 11. (continued) Representative TEM images of loops and precipitates from beta-treated Zircaloy-2 following post-irradiation annealing: (a) and (b), <a> loops and $<\mathrm{c}>$ loops and dislocations following the $399^{\circ} \mathrm{C}$ isochronal anneal, (c), and (d) <a> loops and dislocations and $<\mathrm{c}>$ loops following the $510^{\circ} \mathrm{C}$ isochronal anneal, and $(e)$ and $(\mathrm{f})<\mathrm{a}>$ loops and dislocations and $<\mathrm{c}>$ loops, respectively, following the $427^{\circ} \mathrm{C} / 500 \mathrm{~h}$ isothermal annealing. 

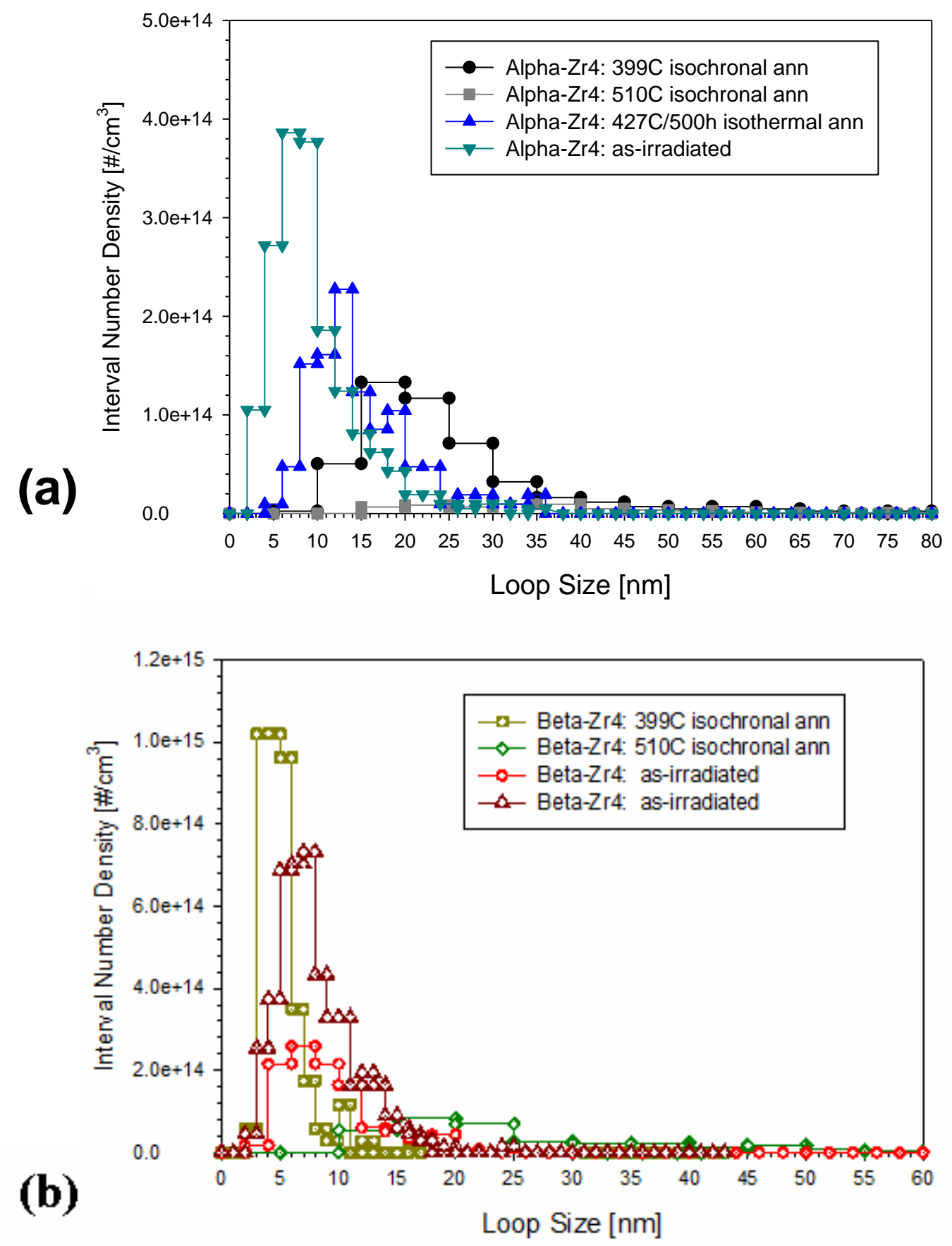

Figure 12. Measured <a> loop size distributions where the number of loops is defined in terms of a loop number density by dividing by interval <a> loop number by the total volume used for measurement. The results are determined from TEM characterization of as-irradiated at nominally $358^{\circ} \mathrm{C}$ to nominal fluence of $29.3 \times 10^{24} \mathrm{n} / \mathrm{m}^{2}(\mathrm{E}>1 \mathrm{MeV})$ and post-irradiated annealed $\left(399^{\circ} \mathrm{C}\right.$ and $510^{\circ} \mathrm{C}$ isochronal and $427^{\circ} \mathrm{C} / 500 \mathrm{~h}$ isothermal) for: (a) alpha-annealed Zircaloy-4, (b) beta-treated Zircaloy-4, (c) alpha-annealed Zircaloy-2, and (d) beta-treated Zircaloy-2. 

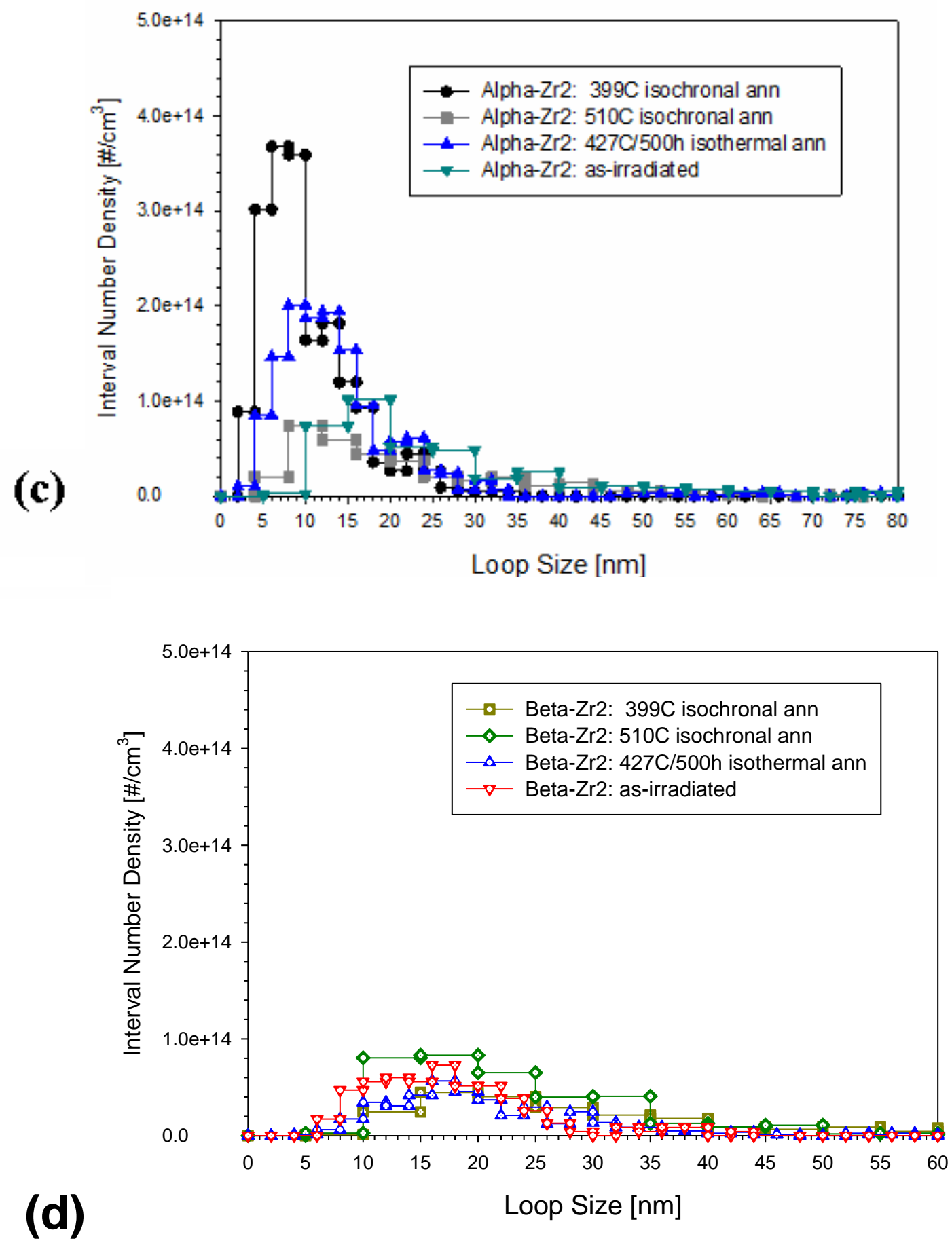

Figure 12. (continued) Measured <a> loop size distributions where the number of loops is defined in terms of a loop number density by dividing by interval $<a>$ loop number by the total volume used for measurement. The results are determined from TEM characterization of as-irradiated at nominally $358^{\circ} \mathrm{C}$ to nominal fluence of $29.3 \times 10^{24} \mathrm{n} / \mathrm{m}^{2}(\mathrm{E}>1 \mathrm{MeV})$ and post-irradiated annealed $\left(399^{\circ} \mathrm{C}\right.$ and $510^{\circ} \mathrm{C}$ isochronal and $427^{\circ} \mathrm{C} / 500 \mathrm{~h}$ isothermal) for: (a) alpha-annealed Zircaloy-4, (b) beta-treated Zircaloy-4, (c) alpha-annealed Zircaloy-2, and (d) beta-treated Zircaloy-2. 


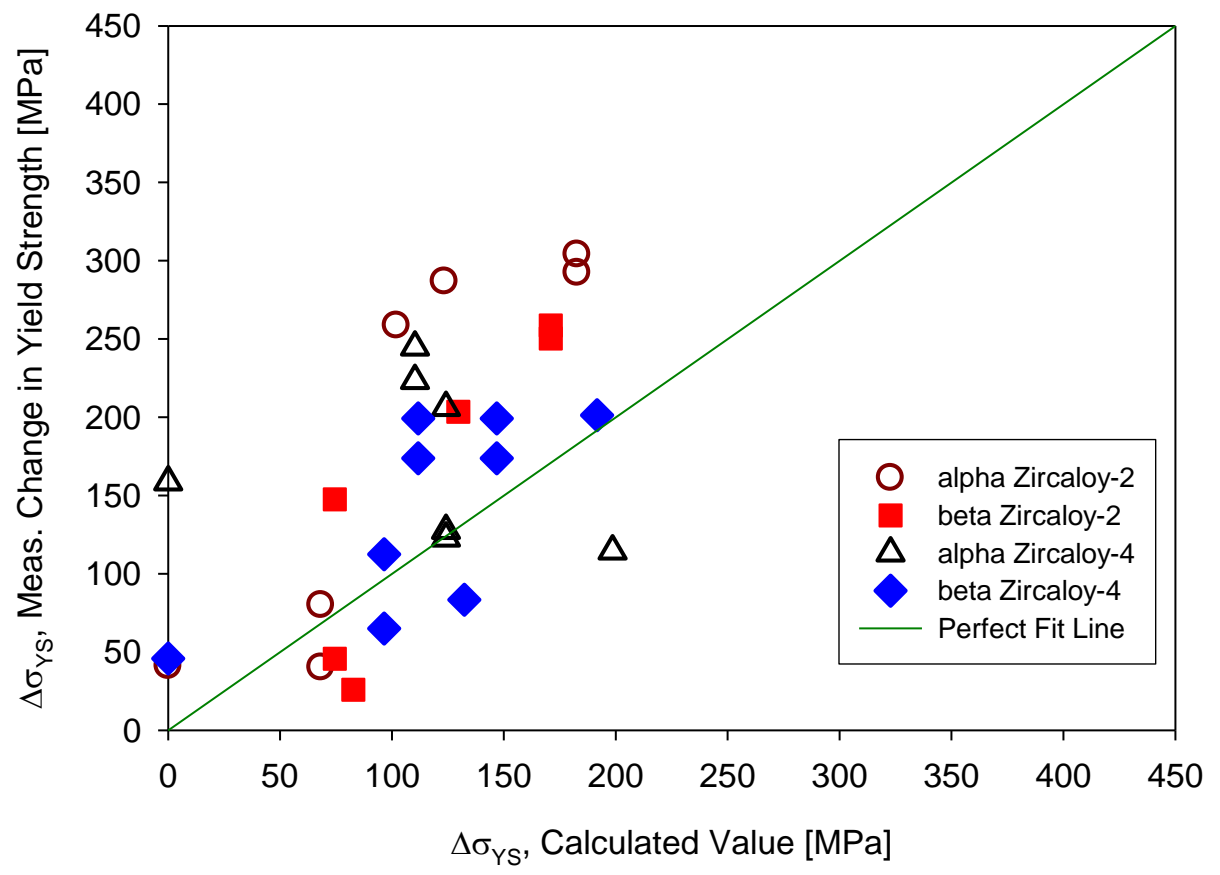

(a)

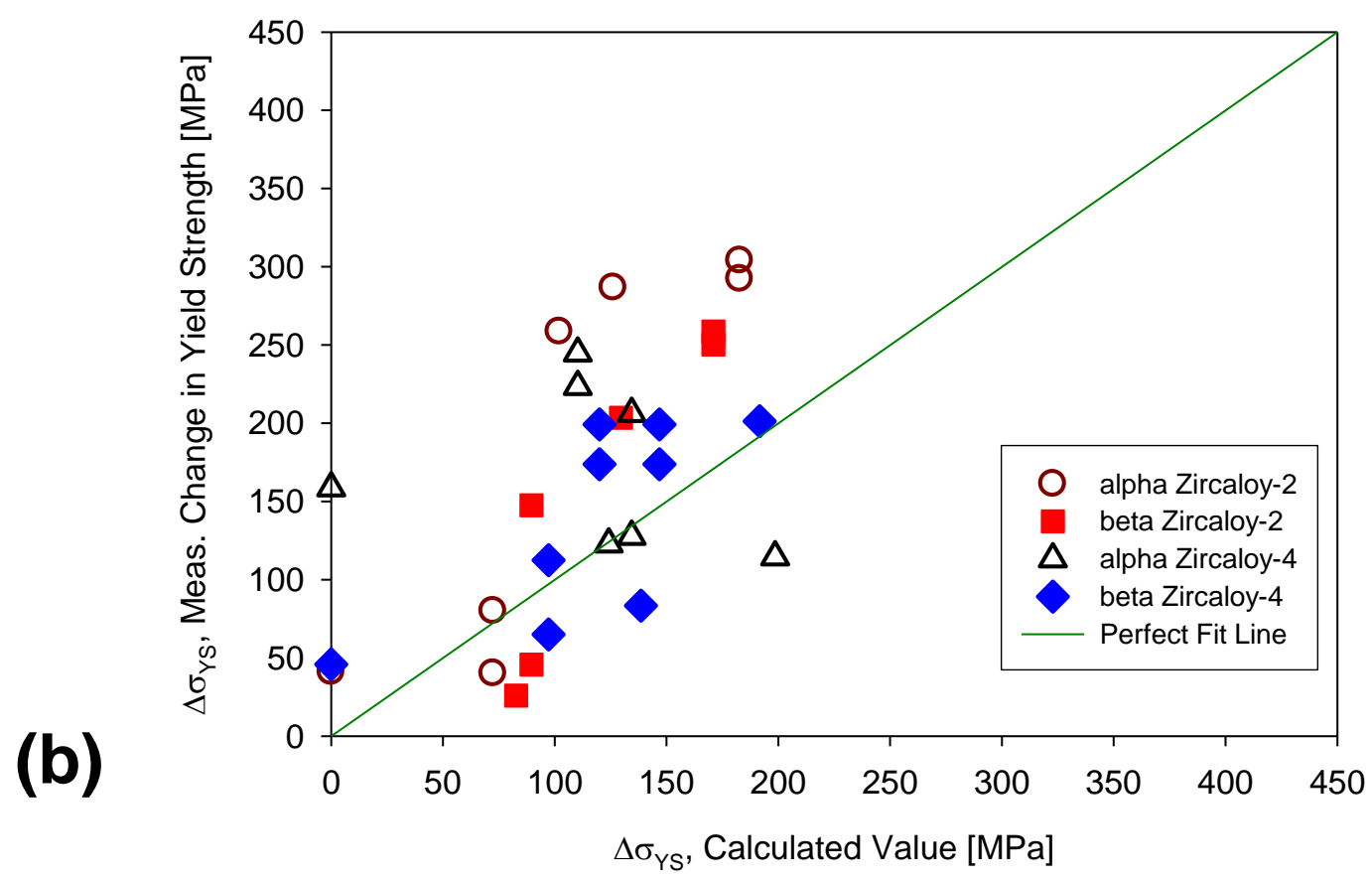

Figure 13. Comparison of calculated and measured irradiation hardening values determined for $<a>$ loops only and $\langle\mathrm{a}>+<\mathrm{C}>$ loops using the summation void hardening equation for alpha-annealed and beta-treated Zircaloy-2 and Zircaloy-4 irradiated at nominally $358^{\circ} \mathrm{C}$ for the as-irradiated condition [4] and post-irradiated annealing condition: (a) plot of measured versus calculated hardening using $<a>$ loops of the as-irradiated only, (b) plot of measured versus calculated hardening using $<a>+<\mathrm{C}\rangle$ loops for the as-irradiated only, (c) plot of measured versus calculated hardening using <a $>$ loops for only the post-irradiated annealed, and (d) plot of measured versus calculated hardening using $<a>+$ $<\mathrm{c}>$ loops for only the post-irradiated annealed. 


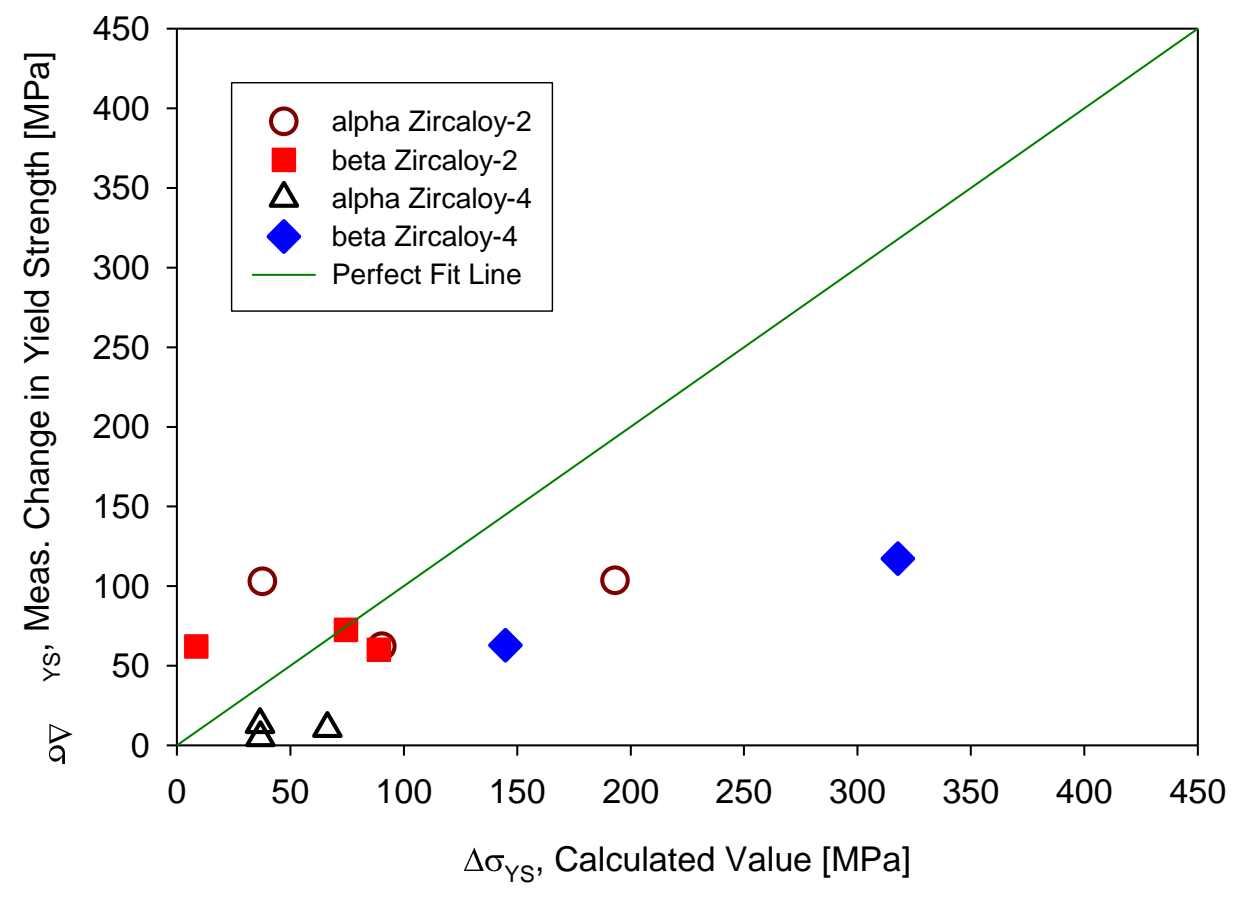

(c)

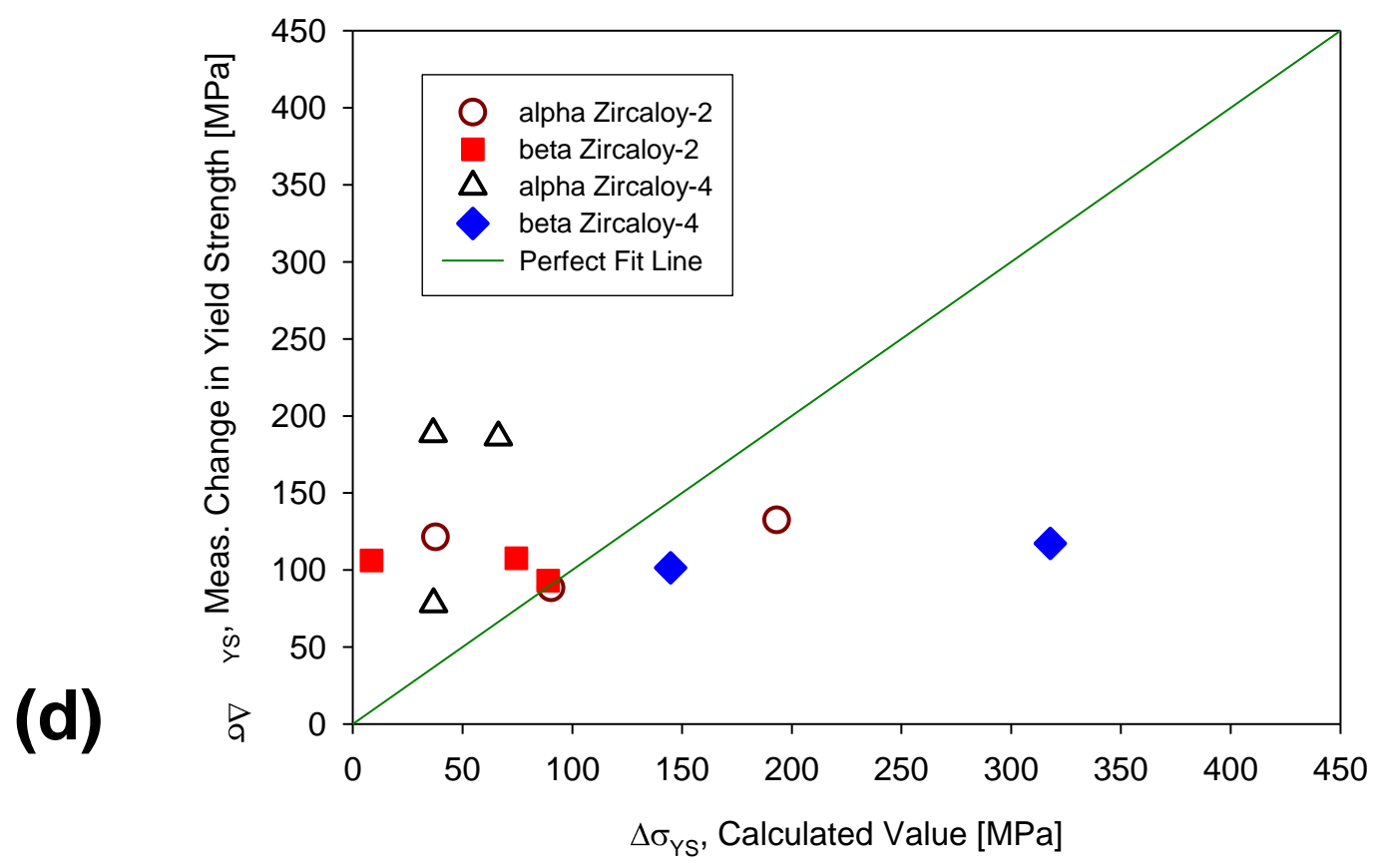

Figure 13. (continued) Comparison of calculated and measured irradiation hardening values determined for $<a>$ loops only and $<a>+<c>$ loops using the summation void hardening equation for alpha-annealed and beta-treated Zircaloy-2 and Zircaloy-4 irradiated at nominally $358^{\circ} \mathrm{C}$ for the asirradiated condition [4] and post-irradiated annealing condition: (a) plot of measured versus calculated hardening using <a> loops of the as-irradiated only, (b) plot of measured versus calculated hardening using $<a>+<c>$ loops for the as-irradiated only, (c) plot of measured versus calculated hardening using $<$ a $>$ loops for only the post-irradiated annealed, and (d) plot of measured versus calculated hardening using $<\mathrm{a}>+<\mathrm{c}>$ loops for only the post-irradiated annealed. 